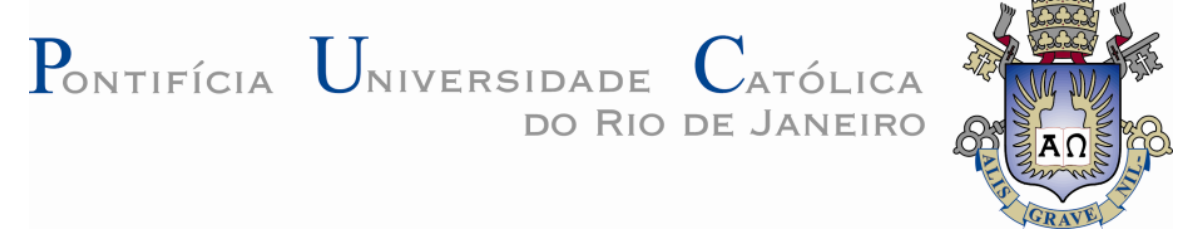

Guilherme Moreira Bessa

Estudo Experimental do Escoamento Laminar em Dutos de Óleos Pesados com Viscosidade Dependente da Temperatura

Dissertação apresentada ao Programa de Pósgraduação em Engenharia Mecânica da PUC-Rio como requisito parcial para obtenção do título de Mestre em Engenharia Mecânica.

Orientador: Prof. Luis Fernando Alzuguir Azevedo Coorientador: Igor Braga de Paula 


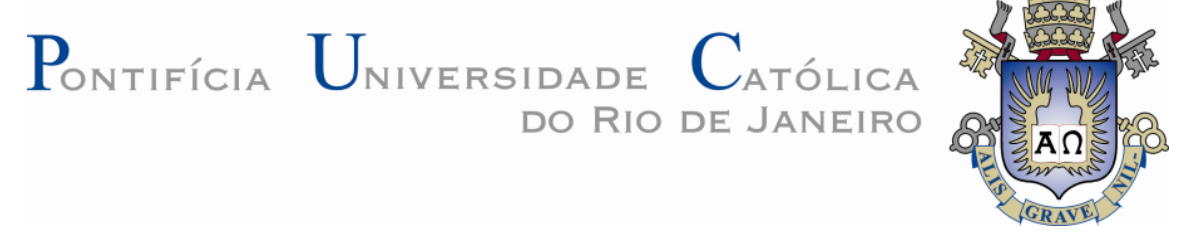

Guilherme Moreira Bessa

\section{Estudo Experimental do Escoamento Laminar em Dutos de Óleos Pesados com Viscosidade Dependente da Temperatura}

Dissertação de Mestrado apresentada como requisito parcial para obtenção do grau de Mestre pelo Programa de Pós-Graduação em Engenharia Mecânica do Departamento de Engenharia Mecânica do Centro Técnico Científico da PUC-Rio. Aprovada pela Comissão Examinadora abaixo assinada.

Prof. Luis Fernando Alzuguir Azevedo

Orientador

Departamento de Engenharia Mecânica - PUC-Rio

Dr. Igor Braga de Paula

Coorientador

Departamento de Engenharia Mecânica - PUC-Rio

Prof. Márcio da Silveira Carvalho

Departamento de Engenharia Mecânica - PUC-Rio

Prof. Angela Ourivio Nieckele

Departamento de Engenharia Mecânica - PUC-Rio

Dr. Márcia Cristina Khalil de Oliveira

CENPES - Petrobras

Prof. José Eugenio Leal Coordenador Setorial do Centro

Técnico Científico - PUC-Rio

Rio de Janeiro, 16 de Abril de 2013 
Todos os direitos reservados. É proibida a reprodução total ou parcial do trabalho sem autorização da universidade, do autor e do orientador.

\section{Guilherme Moreira Bessa}

Graduou-se em Engenharia Mecânica na Universidade Federal Fluminense em 2007.

Ficha Catalográfica

Bessa, Guilherme Moreira

Estudo experimental do escoamento laminar em dutos de óleos pesados com viscosidade dependente da temperatura / Guilherme Moreira Bessa ; orientador: Luis Fernando Azulguir Azevedo. - 2013.

107 f. : il.(color.) ; $30 \mathrm{~cm}$

Dissertação (Mestrado)-Pontifícia Universidade Católica do Rio de Janeiro, Departamento de Engenharia Mecânica, 2013.

Inclui bibliografia

1. Engenharia mecânica - Teses. 2. Óleos pesados. 3. Escoamento laminar em dutos. 4. Viscosidade variável. 5. Velocimetria laser-doppler. I. Azevedo, Luis Fernando Azulguir. II. Pontifícia Universidade Católica do Rio de Janeiro. Departamento de Engenharia Mecânica. III. Título. 
Para meus pais, Luiz Fernando e Dayse, pelo incentivo e dedicação. 


\section{Agradecimentos}

Gostaria de agradecer especialmente ao meu orientador Luis Fernando Azevedo, pelo apoio, paciência, orientação e entusiasmo a cada conquista neste projeto.

Gostaria de agradecer inúmeras vezes ao meu orientador Igor Braga de Paula, pela motivação diária, orientação, incentivo e profunda dedicação neste projeto.

À Petrobras pelo patrocínio e à PUC-Rio pelos auxílios concedidos, sem os quais este trabalho não poderia ter sido realizado.

À professora Angela Nieckele pela colaboração com as simulações tridimensionais.

Agradeço também aos professores membros da banca, pela participação, comentários e sugestões feitas ao trabalho apresentado.

Um obrigado muito especial ao aluno de iniciação científica, Pedro, e ao técnico do laboratório, Leo, por não pouparem esforços para sempre atender as demandas do projeto.

A todos os amigos do Laboratório de Termociências da PUC-Rio, que contribuíram de diferentes maneiras para o sucesso deste trabalho.

Aos professores e funcionários do departamento de Engenharia Mecânica da PUC-Rio que contribuíram para a realização deste trabalho.

Gostaria de agradecer meus pais, Dayse e Luiz Fernando, e meus irmãos Danielle e Wallace, que sempre me ensinaram a enfrentar as dificuldades e nesta caminhada foram indispensáveis para essa nova conquista.

Acima de tudo, agradeço a Deus por sua presença constante na minha vida, especialmente na realização deste projeto. 


\section{Resumo}

Bessa, Guilherme Moreira; Azevedo, Luis Fernando Alzuguir. Estudo Experimental do Escoamento Laminar em Dutos de Óleos Pesados com Viscosidade Dependente da Temperatura. Rio de Janeiro, 2013. 107p. Dissertação de Mestrado - Departamento de Engenharia Mecânica, Pontifícia Universidade Católica do Rio de Janeiro.

O presente trabalho é um estudo experimental sobre o escoamento laminar de óleos pesados através de dutos longos isolados termicamente e que apresentam forte dependência da viscosidade com a temperatura. O objetivo do estudo é identificar e interpretar o comportamento verificado em operações de campo onde a dependência da queda de pressão ao longo do duto com a vazão afasta-se significativamente da relação linear esperada para escoamentos hidrodinamicamente desenvolvidos. Para o estudo foi montado um experimento em escala de laboratório utilizando como fluido de trabalho uma solução de glicerina e água, que apresenta forte dependência da viscosidade com a temperatura. A solução quente de glicerina era bombeada por um tubo longo imerso em um meio refrigerado. A troca de calor do fluido com o ambiente frio produzia gradientes de temperatura radiais e axiais associados a fortes variações da viscosidade. Os experimentos conduzidos revelaram uma relação linear entre a vazão e a queda de pressão ao longo do duto para baixos e altos valores da vazão. No entanto, para valores intermediários da vazão, a relação entre vazão e queda de pressão afasta-se do comportamento linear, deixando de apresentar uma relação monotônica. Nesta região intermediária, os mesmos valores de queda de pressão foram observados para vazões de ordem de grandeza diferentes. Medidas de perfis radiais de temperatura e velocidade axial foram realizadas para duas diferentes posições axiais no duto. Sondas de termopar e a técnica de velocimetria laserDoppler foram utilizadas neste estudo. Os perfis de temperatura apresentaram forte assimetria como decorrência da presença de escoamentos secundários originados por convecção natural. Os perfis de velocidade axial foram pouco afetados pelos escoamentos secundários. Acredita-se que o impacto observado na tensão cisalhante na parede e, portanto, na queda de pressão, esteja associado à forte variação da viscosidade junto à parede fria, e não às variações do gradiente de velocidade na parede que não se mostraram significativas. Os resultados 
experimentais foram comparados com simulações numéricas tridimensionais e unidimensionais fornecidas por outros pesquisadores. A relação de queda de pressão com a vazão foi bem modelada por ambos os modelos. Os perfis radiais de velocidade foram bem previstos pelo modelo tridimensional, ao contrário dos perfis radiais de temperatura que se afastaram das medições.

\section{Palavras-chave}

Viscosidade dependente da temperatura; escoamento laminar; queda de pressão; perfis de velocidade; perfis de temperatura. 


\section{Abstract}

Bessa, Guilherme Moreira; Azevedo, Luis Fernando Alzuguir (Advisor). Experimental study of pipeline flow of heavy oil with temperaturedependent viscosity. Rio de Janeiro, 2013. 107p. MSc. Dissertation Departamento de Engenharia Mecânica, Pontifícia Universidade Católica do Rio de Janeiro.

The present work is an experimental study of laminar flows through long, thermally insulated pipes of heavy oils that present strong dependence of viscosity on temperature. The objective of the study was to reproduce and understand the behavior reported in field operations where the dependence of the pressure drop on the flow rate deviates significantly from the linear relationship expected for hydrodynamically fully developed flow. To this end, a laboratory-scale experiment was constructed employing as working fluid a glycerol-water solution displaying a strong dependence of viscosity on temperature. In the experiments, the heated glycerol solution was pumped through a long isolated pipe immersed in a cold environment. The heat exchange with the cold environment produced radial and axial thermal gradients in the fluid yielding strong viscosity variations. For the low and high ranges of the flow rate the experiments revealed a linear relationship between flow rate and pressure drop from the inlet to the exit of the test section. However, for intermediate values of the flow rate, the relationship between flow rate and pressure drop deviated from the linear behavior. Further, this relationship ceased to be monotonic. In this intermediate flow rate region, the same pressure drop values were measured for flow rates values differing in orders of magnitude. Radial profiles of temperature and axial velocity were measured at different axial positions along the pipe. Thermocouple probes and the laserDoppler velocimetry technique were employed in this study. Temperature profiles displayed strong asymmetry as a consequence of the presence of secondary flows induced by natural convection. The axial velocity profiles were little affected by the secondary flows. It is believed that the impact observed on the wall shear stress and, as a consequence, on the pressure drop, are associated with the strong viscosity variations close to the cold pipe wall, and not with the variations of the velocity gradient at the wall that were seen to be not too significant. The experimental results obtained were compared with one and tri-dimensional 
numerical solutions developed by other researchers. The relationship between pressure drop and flow rate was well predicted by both numerical models. The radial velocity profiles were well predicted by the tri-dimensional calculations, while the temperature profiles predictions were seen to deviate from the experiments.

\section{Keywords}

Temperature dependent viscosity; laminar flow; pressure drop; velocity profiles; temperature profiles. 


\section{Sumário}

1 Introdução 21

1.1. Organização do trabalho 23

1.2. Revisão bibliográfica 23

2 Fundamentação Teórica do Problema 26

3 Montagem Experimental 32

3.1. Fluido de trabalho 33

3.2. Seção de testes 35

3.3. Trocador de Calor 36

3.4. Circuito do Fluido de Trabalho 38

3.5. Circuito do Fluido Refrigerante 39

3.6. Sensores de Temperatura e Pressão 39

3.7. Medida de Vazão 40

3.8. Sistema de Aquisição de Dados $\quad 40$

3.9. Medição dos Perfis Radiais de Velocidade e Temperatura 40

4 Procedimento Experimental 46

4.1. Preparação dos Experimentos 46

4.2. Redução dos Dados Para o Experimento de Queda de Pressão 47

4.2.1. Dados Medidos 47

4.2.2. Amostra de Cálculo $\quad 51$

4.3. Procedimento Experimental Para Medição de Perfis de Velocidade $\quad 54$

4.4. Procedimento Experimental Para Medição de Perfis de Temperatura 57

5 Resultados $\quad 60$

5.1. Validação da Seção de Testes e Procedimento Experimental 60

5.2. Resultados de Queda de Pressão 61

5.3. Resultado de Temperatura de Saída da Solução de Glicerina 67

5.4. Resultados dos Perfis de Temperatura e Velocidade 68

5.5. Comparação com Solução Numérica Tridimensional 79 
6 Conclusões

7 Referências Bibliográficas

Apêndice $\quad 99$

A Estimativa das Incertezas nas Medições $\quad 99$

B Desenhos e Dimensões da Seção Experimental 104

B.1. Vista Geral da Seção 104

B.2. Janela de Visualização 105

B.3. Entrada da Seção Experimental 106

B.4. Flange com Tomadas de Pressão e Temperatura 107 


\section{Lista de figuras}

Figura 1.1 - Configuração simplificada da instalação de um oleoduto submarino. 21

Figura 2.1 - Representação esquemática do problema estudado. 27

Figura 3.1 - Descrição esquemática simplificada da seção

de testes projetada

Figura 3.2 - Variação da viscosidade com a temperatura da

solução de $95 \%$ de glicerina e 5\% de água utilizado nos experimentos. $\quad 34$

Figura 3.3 - Vista em perspectiva da seção experimental. 36

Figura 3.4 - Vista em corte de umas das extremidades do trocador de calor. 38

Figura 3.5 - Seção longitudinal da janela de visualização. 44

Figura 3.6 - Vista em corte do mecanismo utilizado para a

medição dos perfis de temperatura.

Figura 4.1 - Vista em corte da janela de visualização com

a presença dos feixes laser da sonda LDV.

Figura 4.2 - Refração ocorrida nos feixes laser da sonda LDV

até atingir a região de medição.

Figura 4.3 - Perfis radiais de temperatura da solução de glicerina para a coordenadas radias $0^{\circ}$ e $180^{\circ}$, para os mesmo valor da vazão.

Temperatura de entrada da glicerina: $70^{\circ} \mathrm{C}$. Temperatura da água de refrigeração: $5^{\circ} \mathrm{C}$.

Figura 5.1 - Coordenadas dos principais pontos de medição da seção de testes.

Figura 5.2 - Resultados experimentais para a queda de pressão em função da vazão para o escoamento da solução de glicerina. Temperatura de entrada da glicerina: $70^{\circ} \mathrm{C}$. Temperatura do fluido de refrigeração: $5^{\circ} \mathrm{C} . L / D_{i}=241$.

Figura 5.3 - Resultados adimensionais medidos de vazão versus queda de pressão para o escoamento de glicerina. Temperatura de entrada da glicerina igual a $70^{\circ} \mathrm{C}$. Temperatura da água de refrigeração igual a $5^{\circ} \mathrm{C} . L / D_{i}=241$.

Figura 5.4 - Temperatura de saída da solução de glicerina medida 
no centro do tubo em função da vazão. Temperatura de entrada

da glicerina: $70^{\circ} \mathrm{C}$. Temperatura da água de refrigeração: $5^{\circ} \mathrm{C} . L / D_{i}=241.67$

Figura 5.5 - Temperatura adimensional de saída da solução de glicerina medida no centro do tubo em função da vazão.Temperatura de entrada da glicerina: $70^{\circ} \mathrm{C}$. Temperatura da água de refrigeração: $5^{\circ} \mathrm{C} . L / D_{i}=241.68$ Figura 5.6 - Perfis radiais de temperatura da solução de glicerina para a coordenada axial $x=98 \mathrm{~mm}\left(x / D_{i}=8,3\right)$, para diferentes valores da vazão. Temperatura de entrada da glicerina: $70^{\circ} \mathrm{C}$. Temperatura da água de refrigeração: $5^{\circ} \mathrm{C}$.

Figura 5.7 - Perfis radiais de viscosidade da solução para a coordenada axial $x=98 \mathrm{~mm}\left(x / D_{i}=8,3\right)$, para diferentes valores da vazão.

Temperatura de entrada da glicerina: $70^{\circ} \mathrm{C}$. Temperatura da água de refrigeração: $5^{\circ} \mathrm{C}$.

Figura 5.8 - Desenho esquemático das correntes induzidas pela convecção natural devido ao resfriamento do fluido pelas paredes do tubo.

Figura 5.9 - Perfis radiais de temperatura da solução de glicerina para a coordenada axial $x=1420 \mathrm{~mm}\left(x / D_{i}=120,3\right)$ e para diferentes valores da vazão. Figura (a): Temperatura total medida. Figura (b): Variação em relação a máxima temperatura do perfil. Temperatura de entrada da glicerina: $70^{\circ} \mathrm{C}$. Temperatura da água de refrigeração: $5^{\circ} \mathrm{C}$.

Figura 5.10 - Perfis radiais de viscosidade da solução para a coordenada axial $x=1420 \mathrm{~mm}\left(x / D_{i}=120,3\right)$, para diferentes valores da vazão. Temperatura de entrada da glicerina: $70^{\circ} \mathrm{C}$. Temperatura da água de refrigeração: $5^{\circ} \mathrm{C}$.

Figura 5.11 - Perfis radiais de velocidade da solução de glicerina para a coordenada axial $x=98 \mathrm{~mm}\left(x / D_{i}=8,3\right)$, para diferentes valores da vazão.

(a) Componente axial da velocidade. Figura (b) Componente axial da velocidade normalizada. Linha contínua - perfil parabólico teórico Temperatura de entrada da glicerina: $70^{\circ} \mathrm{C}$. Temperatura da água de refrigeração: $5^{\circ} \mathrm{C}$.

Figura 5.12 - Perfis radiais de velocidade da solução de glicerina para a coordenada axial $x=1420 \mathrm{~mm}\left(x / D_{i}=120,3\right)$, para diferentes valores da vazão. Figura (a): Velocidade axial total. Figura (b): Linha contínua - 
perfil parabólico teórico; símbolos - perfil de velocidade normalizado. Temperatura de entrada da glicerina: $70^{\circ} \mathrm{C}$. Temperatura da água de refrigeração: $5^{\circ} \mathrm{C}$.

Figura 5.13 - - Variação de viscosidade ao longo do diâmetro para diferentes valores da vazão. Estimativa com base na correlação $4.1 \mathrm{e}$ no perfil de temperaturas medido experimentalmente. Valores normalizados em relação à média do perfil de viscosidades.

Figura 5.14 - Variação da razão $\mathrm{Gr} / \mathrm{Re}^{2}$ para diferentes vazões.

Comparação entre as regiões de medição.

Figura 5.15 - Comparação entre os resultados numéricos $3 D$ e experimentais para a queda de pressão em função da vazão para o escoamento da solução de glicerina. Temperatura de entrada da glicerina: $70^{\circ} \mathrm{C}$. Temperatura do fluido de refrigeração: $5^{\circ} \mathrm{C} . L / D_{i}=241$.

Figura 5.16 - Comparação entre os resultados numéricos $3 D$ e experimentais para os perfis radiais de velocidade da solução de glicerina em duas coordenadas axiais para vazão de $1000 \mathrm{ml} / \mathrm{min}$.

(a) $x / D_{i}=8,3$ (b). Temperatura de entrada da glicerina: $70^{\circ} \mathrm{C}$. Temperatura da água de refrigeração: $5^{\circ} \mathrm{C}$.

Figura 5.17 - Comparação entre os resultados numéricos $3 D$ e experimentais para os perfis radiais de velocidade da solução de glicerina em duas coordenadas axiais para vazão de $100 \mathrm{ml} / \mathrm{min}$. (a) . $x / D_{i}=8,3$. (b) Temperatura de entrada da glicerina: $70^{\circ} \mathrm{C}$. Temperatura da água de refrigeração: $5^{\circ} \mathrm{C}$.

Figura 5.18 - Comparação entre os resultados numéricos $3 D$ e experimentais para os perfis radiais de temperatura da solução de glicerina nas coordenadas axiais $x / D_{i}=8,3$ e $x / D_{i}=120,3$, para vazão de $1000 \mathrm{ml} / \mathrm{min}$. Temperatura de entrada da glicerina: $70^{\circ} \mathrm{C}$. Temperatura da água de refrigeração: $5^{\circ} \mathrm{C}$.

Figura 5.19 - Comparação entre os resultados numéricos $3 D$ e experimentais para os perfis radiais de temperatura da solução de glicerina nas coordenadas axiais $x / D_{i}=8,3$ e $x / D_{i}=120,3$, para vazão de $100 \mathrm{ml} / \mathrm{min}$. Temperatura de entrada da glicerina: $70^{\circ} \mathrm{C}$. Temperatura da água de refrigeração: $5^{\circ} \mathrm{C}$. 
Figura 5.20 - Resultados das simulações numéricas $3 D$ para os campos de velocidade da solução de glicerina na entrada e nas coordenadas axiais $x / D_{i}=4,5,8,3$ e 120,3 , para vazão de $50 \mathrm{ml} / \mathrm{min}$. Temperatura de entrada da glicerina: $70^{\circ} \mathrm{C}$. Temperatura da água de refrigeração: $5^{\circ} \mathrm{C}$.

Figura 5.21 - Resultados das simulações numéricas $3 D$ para os campos de temperatura da solução de glicerina nas coordenadas axiais $x / D_{i}=8,3,34,120,3$ e 237 , para vazão de $50 \mathrm{ml} / \mathrm{min}$. Temperatura de entrada da glicerina: $70^{\circ} \mathrm{C}$. Temperatura da água de refrigeração: $5^{\circ} \mathrm{C}$.

Figura 5.22 - Comparação entre os resultados adimensionais numéricos e experimentais de vazão versus queda de pressão para o escoamento de solução de glicerina. Temperatura de entrada da glicerina igual a $70^{\circ} \mathrm{C}$. Temperatura da água de refrigeração igual a $5^{\circ} \mathrm{C} . L / D_{i}=241$.

Figura 5.23 - Comparação entre os resultados numéricos e experimentais para a queda de pressão em função da vazão para o escoamento da solução de glicerina. Temperatura de entrada da glicerina: $70^{\circ} \mathrm{C}$. Temperatura do fluido de refrigeração: $5^{\circ} \mathrm{C} . L / D_{i}=241$.

Figura 5.24 - Comparação entre os resultados numéricos e experimentais de temperatura de saída da solução de glicerina medida no centro do tubo em função da vazão. Temperatura de entrada da glicerina: $70^{\circ} \mathrm{C}$. Temperatura da água de refrigeração: $5^{\circ} \mathrm{C} . L / D_{i}=241$.

Figura B.1 - Vista geral em corte da seção experimental com as principais dimensões longitudinais.

Figura B.2 - (a) Vistas lateral e em corte frontal da Janela de Visualização. (b) Vista detalhada do interior da Janela de Visualização. 105 Figura B.3 - Vista em corte da região de entrada da Seção.

Figura B.4 - Flange sedes para as tomadas de pressão e temperatura.

Duas unidades semelhantes foram instaladas na entrada e na saída da seção de testes. 


\section{Lista de tabelas}

Tabela 3.1 - Propriedades termofísicas do fluido de trabalho à $70^{\circ} \mathrm{C}$, temperatura de entrada e referência no trabalho. Solução 95\% glicerina e $5 \%$ água.

Tabela 4.1 - Relação dos dados medidos em cada experimento.

Tabela 4.2 - Relação dos dados medidos no experimento para um determinado caso típico.

Tabela 5.1 - Comparação entre os resultados teóricos e experimentais para queda de pressão.

Tabela 5.2 - Resultados experimentais para o escoamento da solução de $95 \%$ glicerina e $5 \%$ de água. Temperatura de entrada da solução:

$70^{\circ} \mathrm{C}$. Temperatura da água de refrigeração: $5^{\circ} \mathrm{C}$. Distância adimensional entre tomadas de pressão, $L / D_{i}=241$.

Tabela 5.3 - Exemplo de validação das medições dos perfis de velocidade com a vazão nominal do escoamento.

Tabela A.1 - Valores das incertezas em cada variável medida utilizados na estimativa das incertezas nas medições do experimento.

Tabela A.2 - Valores de incerteza na vazão, pressão, número de Reynolds e pressão adimensional em cada vazão medida no experimento associados a um nível de probabilidade de abrangência de $95,4 \%$. 


\section{Lista de Variáveis}

\section{Letras Latinas}

$L$ - Comprimento da região de troca térmica no tubo interno do trocador de calor (mm)

$D$ - Diâmetro interno do tubo por onde escoa o fluido de trabalho ( $\mathrm{mm}$ )

$D_{i}$ - Diâmetro interno do tubo por onde escoa o fluido de trabalho ( $\mathrm{mm}$ )

$D_{e}$ - Diâmetro externo do tubo por onde escoa o fluido de trabalho $(\mathrm{mm})$

$e$ - Espessura da parede do tubo por onde escoa o fluido de trabalho $(\mathrm{mm})$

$R$ - Raio interno do tubo por onde escoa o fluido de trabalho $(\mathrm{mm})$

$r_{e}$ - Raio externo do tubo por onde escoa o fluido de trabalho $(\mathrm{mm})$

$k_{s}$ - Condutividade térmica do tubo por onde escoa o fluido de trabalho

$(W / m \cdot K)$

$Q$ - Vazão do fluido de trabalho $(\mathrm{ml} / \mathrm{min})$

$T$ - Temperatura do fluido de trabalho $\left({ }^{\circ} \mathrm{C}\right)$

$T_{\text {ref }}$ - Temperatura de referência do fluido de trabalho $\left({ }^{\circ} \mathrm{C}\right)$

$T_{e}$ - Temperatura de entrada do fluido de trabalho $\left({ }^{\circ} \mathrm{C}\right)$

$T_{s}$ - Temperatura de saída do fluido de trabalho $\left({ }^{\circ} \mathrm{C}\right)$

$T_{\infty}$ - Temperatura média no espaço anular do trocador de calor $\left({ }^{\circ} \mathrm{C}\right)$

$T_{r e}$ - Temperatura de entrada do fluido refrigerante $\left({ }^{\circ} \mathrm{C}\right.$ )

$T_{r s}$ - Temperatura de saída do fluido refrigerante $\left({ }^{\circ} \mathrm{C}\right.$ )

$\vec{g}$ - aceleração da gravidade $\left(\mathrm{m} / \mathrm{s}^{2}\right)$

$c_{p}$ - Calor específico do fluido de trabalho $(\mathrm{J} / \mathrm{kg} . \mathrm{K})$

$c_{p_{\text {ref }}}$ - Calor específico de referência do fluido de trabalho $(\mathrm{J} / \mathrm{kg} . \mathrm{K})$

$k$ - Condutividade térmica do fluido de trabalho $(W / m . K)$

$k_{s}$ - Condutividade térmica do tubo por onde escoa o fluido de trabalho $(W / m . K)$

$h$ - Coeficiente convectivo de transferência de calor interno $\left(W / m^{2} . K\right)$ 
$h_{e}$ - Coeficiente convectivo de transferência de calor no espaço anular $\left(W / m^{2} \cdot K\right)$

$u$ - Velocidade característica do fluido de trabalho $(\mathrm{m} / \mathrm{s})$

$\bar{u}_{e}$ - Velocidade média de entrada do fluido de trabalho $(\mathrm{m} / \mathrm{s})$

$u^{*}$ - Velocidade adimensional do fluido de trabalho

$p$ - Pressão do fluido de trabalho $(P a)$

$p^{*}$ - Pressão adimensional do fluido de trabalho

$\Delta P$ - Diferencial de pressão do fluido de trabalho $(P a)$

$\overline{\bar{D}}$ - Tensor taxa de deformação

$\overline{\bar{D}}^{*}$ - Tensor taxa de deformação adimensional

$U_{e f}$ - Coeficiente global efetivo de troca de calor $\left(W / \mathrm{m}^{2} . K\right)$

$U_{e f}^{*}$ - Coeficiente global efetivo adimensional de troca de calor

$n$ - Direção normal a parede do tubo

$A_{i}$ - Área interna do tubo por onde escoa o fluido de trabalho $\left(\mathrm{m}^{2}\right)$

$A_{e}$ - Área externa do tubo por onde escoa o fluido de trabalho $\left(\mathrm{m}^{2}\right)$

$R_{\text {cond }}$ - Resistência condutiva da parede do tubo por onde escoa o fluido de trabalho $(K / W)$

$A$ - Constante da função viscosidade

$B$ - Constante da função viscosidade

$A^{*}$ - Constante adimensional da função viscosidade

$B^{*}$ - Constante adimensional da função viscosidade

Pr - Prandtl

$G r$ - Grashof

Re - Reynolds

Ec- Eckert

$N$ - Número de registros no processo de aquisição de dados

$\dot{m}$ - Vazão mássica de glicerina $(\mathrm{kg} / \mathrm{s})$

$m_{f}$ - Massa do recipiente mais fluido ( $k g$ )

$m_{0}$ - Massa do recipiente $(\mathrm{kg})$

$t$ - Tempo $(s)$ 
$n_{1}$ - Índice de refração do ar

$n_{2}$ - Índice de refração do acrílico

$n_{3}$ - Índice de refração da glicerina

$x$ - posição axial no tubo por onde escoa o fluido de trabalho $(m)$

$x^{*}$ - posição axial adimensional no tubo

\section{Letras gregas}

$\theta$ - Temperatura adimensional do fluido de trabalho

$\theta_{r e f}$ - Temperatura adimensional de referência do fluido de trabalho

$\rho$ - massa específica do fluido de trabalho $\left(\mathrm{kg} / \mathrm{m}^{3}\right)$

$\rho$ - massa específica de referência do fluido de trabalho $\left(\mathrm{kg} / \mathrm{m}^{3}\right)$

$\mu$ - Viscosidade dinâmica do fluido de trabalho ( Pa.s)

$\mu^{*}$ - Viscosidade dinâmica adimensional do fluido de trabalho

$\mu_{\text {ref }}$ - Viscosidade dinâmica de referência do fluido de trabalho ( $P a . s$ )

$v$ - Viscosidade cinemática do fluido de trabalho $\left(\mathrm{m}^{2} / \mathrm{s}\right)$

$v_{\text {ref }}$ - Viscosidade cinemática de referência do fluido de trabalho $\left(\mathrm{m}^{2} / \mathrm{s}\right)$

$\beta$ - Coeficiente de expansão térmica do fluido de trabalho $\left({ }^{\circ} \mathrm{C}^{-1}\right)$

$\beta_{r e f}$ - Coeficiente de expansão térmica de referência do fluido de trabalho

$\left({ }^{\circ} C^{-1}\right)$

$\Phi$ - função dissipação viscosa $\left(W / m^{3}\right)$

$\phi^{*}$ - dissipação viscosa adimensional

$\tau$ - Tensor das tensões

$\mu_{0}$ - Constante da função viscosidade

$\mu_{0}^{*}$ - Constante adimensional da função viscosidade

$\alpha_{1}$ - Ângulo de incidência do feixe laser

$\alpha_{2}$ - Ângulo de feixe laser no acrílico

$\alpha_{3}$ - Ângulo de feixe laser na glicerina

$\alpha$ - Ângulo de inclinação do tubo no desenho esquemático 


\section{Superescritos}

* - Adimensional

\section{Subscritos}

ref - Referência

$e$ - Entrada

$s$ - Saída

$r e$ - Fluido refrigerante na entrada

$r s$ - Fluido refrigerante na saída

$i$ - Interno

cond - Condutiva

\section{Siglas}

BCP - Bomba de Cavidade Progressiva

CPVC - Policloreto de Vinila Clorado

PVC - Policloreto de Vinila

LDV - Laser-Doppler Velocimetry 
1

\section{Introdução}

O petróleo extraído em alto-mar é frequentemente transportado em dutos submarinos que interligam plataformas a unidades flutuantes de armazenagem. O petróleo é bombeado entre estas instalações por dutos submarinos instalados no leito marinho, normalmente a grandes profundidades. A Figura 1.1 apresenta de forma esquemática um destes arranjos de transporte submarino.

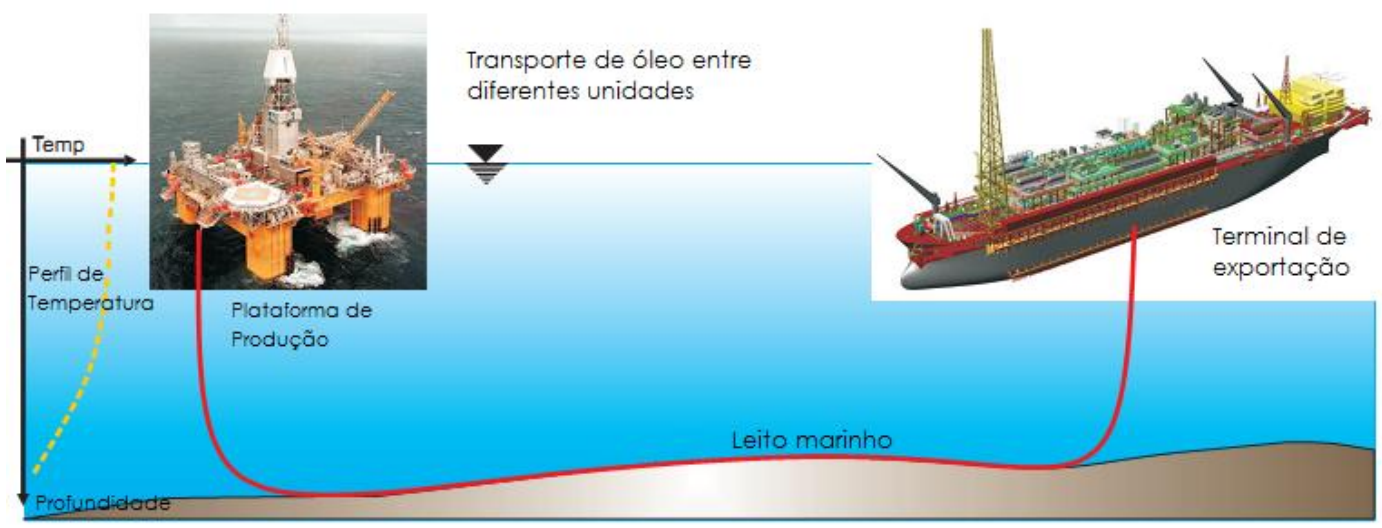

Figura 1.1 - Configuração simplificada da instalação de um oleoduto submarino.

Os petróleos pesados apresentam elevados valores de massa específica, e viscosidade, sendo a viscosidade, muitas vezes, fortemente dependente da temperatura. Estima-se que no Brasil $30 \%$ das reservas conhecidas sejam deste tipo de petróleo.

Devido aos baixos níveis de temperatura que prevalecem nos campos de águas profundas, a transferência de calor do petróleo escoando no interior dos dutos para o ambiente marinho pode levar ao seu resfriamento e consequente aumento de viscosidade. Aumento da viscosidade implica em aumentos na potência consumida para bombeamento do fluido. $O$ isolamento térmico destes dutos é utilizado com o intuito de diminuir as perdas de calor.

A dependência da viscosidade do petróleo com a temperatura cria condições de escoamento particulares, onde o perfil de velocidade pode afastarse significativamente do perfil parabólico característico de escoamentos laminares hidrodinamicamente desenvolvidos de fluidos Newtonianos. Como 
consequência, a relação entre vazão bombeada e queda de pressão na linha também se afasta do comportamento linear esperado para escoamento laminar desenvolvido em dutos longos escoando fluidos com propriedades independentes da temperatura.

Caso o isolamento térmico do duto fosse perfeito, não haveria troca de calor com o ambiente marinho e o petróleo escoaria com temperatura constante e, portanto, sem variação de viscosidade (neste raciocínio, estamos desprezando os efeitos de dissipação viscosa que poderiam levar ao aquecimento do fluido). Neste caso, teríamos a condição de escoamento laminar hidrodinamicamnte desenvolvido com a conhecida relação linear entre vazão e queda de pressão. Na hipótese oposta em que nenhum isolamento térmico fosse utilizado, a troca de calor com o ambiente externo se daria de forma intensa e o escoamento ocorreria com temperatura e viscosidade constantes ao longo do duto, levando, mais uma vez, à relação linear entre vazão e queda de pressão.

No caso real devido e perda de calor ao longo do duto, espera-se que a temperatura do petróleo em escoamento varie continuamente ao longo do comprimento do duto, assim como que existam gradientes radiais de temperatura no fluido em cada seção reta do duto. Esta variação de temperatura provoca uma variação na viscosidade, resultando em uma dependência da vazão com a queda de pressão que pode desviar-se significativamente da relação linear esperada para o escoamento hidrodinamicamente desenvolvido.

A presença de correntes de convecção natural pode alterar os perfis de velocidade e temperatura do escoamento impondo efeitos adicionais na queda de pressão do escoamento.

A capacidade de previsão do comportamento do escoamento de petróleo pesado através dutos instalados em águas frias é fundamental para o projeto de instalações de bombeio, assim como para a análise do desempenho hidrodinâmico dos dutos. Para isso, é necessário o conhecimento dos mecanismos físicos que controlam este escoamento, avaliando a importância relativa de cada um deles, de modo que modelos de simulação simples e confiáveis possam ser desenvolvidos e utilizados com segurança no projeto destas operações.

O presente trabalho descreve estudos experimentais conduzidos com o intuito de contribuir para o entendimento do problema relacionado ao escoamento de óleos pesados através de dutos operando em águas frias. $\mathrm{O}$ trabalho é parte de um projeto onde este problema é também estudado por modelos computacionais de diferentes níveis de complexidade. 
Como será descrito nos capítulos que se seguem, os estudos experimentais foram conduzidos em duto construído em escala reduzida observando a faixa de parâmetros adimensionais de operação do duto real. Foi utilizado um fluido modelo de laboratório que apresentava propriedades similares ao petróleo, notadamente a função que relaciona a dependência entre viscosidade e temperatura. Os resultados obtidos, além de contribuírem para o entendimento do problema físico podem ser utilizados para validar os simuladores computacionais construídos em outras etapas do projeto do qual o presente estudo fez parte.

\section{1.}

\section{Organização do trabalho}

Este trabalho está organizado em seis capítulos. No presente capítulo será apresentada uma revisão bibliográfica da literatura sobre escoamento em dutos de fluidos com viscosidade dependente da temperatura.

O Capítulo 2 é dedicado à apresentação das equações que governam o problema em questão. O objetivo da análise destas equações é determinar os parâmetros adimensionais que governam o problema, informação necessária para o projeto do modelo em escala reduzida construído para a condução dos estudos experimentais. No Capítulo 3, a seção de testes projetada e os equipamentos utilizados são apresentados em detalhes.

No Capítulo 4 são apresentados os procedimentos experimentais adotados para a validação da seção de testes construída e para a condução dos testes propriamente ditos.

No Capítulo 5 os resultados experimentais obtidos são apresentados e comentados e, no Capítulo 6, são expostas as conclusões do trabalho.

\section{2. \\ Revisão bibliográfica}

Como já mencionado, embora os óleos pesados normalmente apresentem comportamento Newtoniano, sua viscosidade é forte função da temperatura. Portanto, o cálculo da perda de carga ao longo dos oleodutos devem incluir a solução da equação de energia e a dependência da viscosidade com a temperatura. 
Contribuições relevantes para o escoamento laminar com baixo número de Reynolds e elevadas variações de viscosidade foram feitas por Ockendon \& Ockendon [1] onde uma descrição assintótica foi dada para o escoamento bidimensional permanente de um fluido newtoniano governado por um fluxo de massa constante em um canal retangular em que as paredes sofriam variações bruscas de temperatura. Efeitos de inércia foram descartados e aproximações da teoria de lubrificação foram feitas a partir das equações de quantidade de movimento e energia. Sob essas condições, Ockendon \& Ockendon descreveram assintoticamente os campos de velocidade e temperatura para o caso particular em que a viscosidade do fluido dependia exponencialmente da temperatura e grandes variações de viscosidade eram observadas.

Richardson [2] deu continuidade ao trabalho de Ockendon \& Ockendon realizando estudos sobre escoamento permanente de polímeros em tubulações com seção circular, incluindo efeitos de dissipação viscosa e solidificação próxima às paredes resfriadas dos dutos. Empregou um modelo em que a viscosidade dependia exponencialmente da temperatura e da taxa de cisalhamento, examinando também o caso de grandes variações de viscosidade em escoamentos bidimensionais permanentes. Ao considerar apenas taxas de cisalhamento elevadas, observou que um aumento na vazão pode conduzir a uma diminuição da queda de pressão, mas não investigou este fenômeno detalhadamente.

Whitehead e Helfrich [3] induziram um escoamento de xarope de milho por uma fenda com paredes resfriadas e consideraram a viscosidade do fluido linearmente dependente da temperatura. Consideraram um modelo unidimensional simplificado em que o escoamento é representado por uma média na seção transversal. Obtiveram para variações de viscosidade suficientemente altas submetidas a determinadas quedas de pressão, três soluções em regime permanente para velocidade. Além disso, análises de estabilidade tanto em tubulações quanto em fendas foram realizadas. Este trabalho em que o escoamento é representado por uma média na seção transversal foi continuado por Helfrich [4] ao realizar uma análise detalhada de estabilidade linear e cálculos de desenvolvimento não linear do escoamento.

Wylie \& Lister [5] estudaram o escoamento num canal com paredes resfriadas e viscosidade dependente da temperatura. Os autores abordaram o escoamento de forma bidimensional e tridimensional, e realizaram análises de estabilidade linear em regime. 
Giessler et al. [6] desenvolveram um modelo unidimensional que descreve o escoamento laminar em tubo de um fluido altamente viscoso representando vidro fundido, onde o escoamento é fortemente governado pelas forças de Lorentz. Foi levada em consideração a dependência não linear da viscosidade com a temperatura e condutibilidade elétrica.

Quinones \& Carvalho [7], desenvolveram um modelo assintótico para estudar o transporte de óleos pesados em águas profundas, sob a ocorrência de altas taxas de transferência de calor. O escoamento foi considerado laminar e a viscosidade variando exponencialmente com a temperatura. O modelo incluía equações unidimensionais para distribuição de temperatura e pressão ao longo da tubulação para uma dada vazão de escoamento.

A revisão bibliográfica apresentada mostrou que ainda são poucos os trabalhos realizados com uma abordagem experimental do problema, e aplicada a área de escoamentos em oleodutos. 


\section{2 \\ Fundamentação Teórica do Problema}

Neste capítulo será apresentada de forma breve uma análise das equações que governam o problema em estudo, qual seja, o escoamento de um fluido com viscosidade fortemente dependente da temperatura através de um duto onde há troca de calor com o meio externo. A análise destas equações é necessária para a determinação dos parâmetros adimensionais que governam o problema. Estes parâmetros são fundamentais para o projeto e operação dos experimentos, como será descrito no próximo capítulo.

Deve ser ressaltado que não fizeram parte do escopo do presente trabalho estudos analíticos ou numéricos do problema, mas somente estudos experimentais. Estudos numéricos foram realizados por outro grupo de pesquisadores, como parte do projeto no qual o presente estudo se inclui. Estes resultados numéricos serão apresentados no capítulo de resultados do presente trabalho com o intuito de enriquecer as análises dos experimentos e oferecer comparações entre medições e previsões.

A Figura 2.1 apresenta de forma esquemática a configuração estudada. Considera-se o escoamento laminar de um fluido Newtoniano através de um duto longo de comprimento $L$ e seção reta circular de diâmetro $D_{i}$. O fluido é bombeado com vazão conhecida e temperatura de entrada $T_{e}$. O fluido quente no interior do duto troca calor com o ambiente externo frio na temperatura $T_{\infty}$. O tubo está inclinado de um ângulo $\alpha$ com a direção horizontal. As propriedades termofísicas relevantes do fluido são a massa específica, $\rho$, o calor específico à pressão constante, $c_{p}$, e a condutividade térmica, $k$. O material da parede do tubo possui condutividade térmica $k_{s}$, e a troca térmica convectiva do tubo com o ambiente externo é representada pelo coeficiente convectivo, $h_{e}$.

A viscosidade dinâmica do fluido, $\mu$, é considerada como dependente da temperatura, sendo o estudo da influência desta dependência a motivação principal do presente trabalho. 


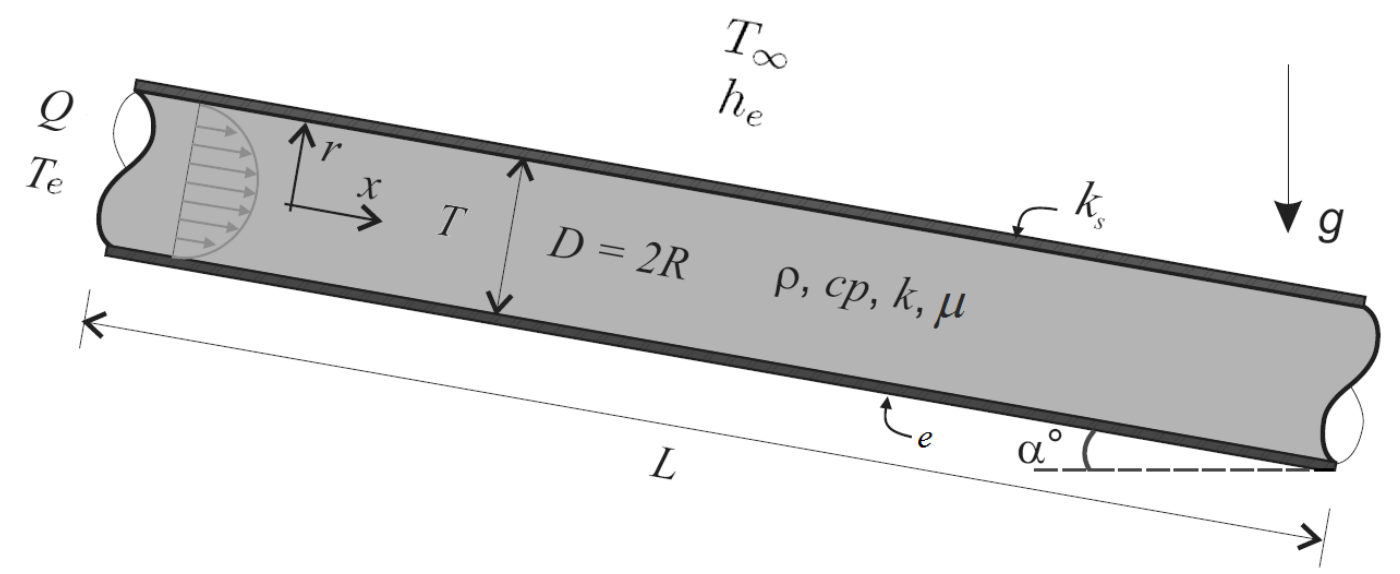

Figura 2.1 - Representação esquemática do problema estudado.

A seguir são apresentadas as equações de conservação de massa, quantidade de movimento linear e energia que governam o problema. Estas equações foram escritas para a condição de escoamento em regime permanente para fluido Newtoniano com massa específica constante, exceto no termo de empuxo, o que caracteriza a aproximação de Boussinesq. Calor específico e condutividade térmica foram considerados constantes.

- Conservação de massa:

$\vec{\nabla} \cdot \vec{u}=0$

- Equação da quantidade de movimento linear:

$\rho_{r e f} \vec{u} \cdot \vec{\nabla} \vec{u}=-\vec{\nabla} p+\rho_{r e f}\left[1-\beta_{r e f}\left(T-T_{r e f}\right)\right] \vec{g}+\vec{\nabla} \cdot[2 \mu \overline{\bar{D}}]$

onde,

$\overline{\bar{D}}=\frac{1}{2}\left[\vec{\nabla} \vec{u}+\vec{\nabla} \vec{u}^{T}\right]$

Na equação de quantidade de movimento linear, $\overline{\bar{D}}$ é o tensor taxa de deformação, $\beta$ é o coeficiente de expansão térmica do fluido e $\vec{g}$ é o vetor aceleração da gravidade. 
- Equação da energia:

$\rho_{r e f} c_{p}(\vec{u} \cdot \vec{\nabla} T)=k \vec{\nabla}^{2} T+\Phi$

onde $\Phi=\overline{\bar{D}}: \overline{\bar{\tau}}$ é a função dissipação viscosa.

Como condições de contorno para a solução do sistema de equações apresentado acima considera-se que a velocidade e temperatura sejam conhecidas na entrada do tubo. Nas paredes internas do tubo é imposta a condição de não deslizamento para a velocidade. Na saída do tubo considera-se que a difusão axial de calor e quantidade de movimento linear são nulas.

A troca de calor com o meio externo define a condição de contorno térmica a ser aplicada à parede interna do tubo. Assim, na parede interna:

$-\left.k \frac{\partial T}{\partial n}\right|_{S}=U_{e f}\left(T_{S}-T_{\infty}\right)$

onde $k$ é condutividade térmica do fluido, $\left.k \frac{\partial T}{\partial n}\right|_{S}$ é o gradiente de temperatura avaliado na superfície $S$ da parede do tubo, $T$ é a temperatura da parede interna do tubo, $T_{\infty}$ é a temperatura do ambiente externo, e $U_{e f}$ é o coeficiente efetivo de troca de calor. $U_{e f}$ é baseado na área interna do tubo que considera a resistência condutiva da parede do tubo com condutividade $k_{s}$ e o coeficiente convectivo externo de troca de calor, $h_{e}$. O coeficiente efetivo é dado por:

$\frac{1}{A_{i} U_{e f}}=\frac{1}{A_{e} h_{e}}+R_{\text {cond }}$

onde $A_{i}$ e $A_{e}$ são, respectivamente, as áreas superficiais interna e externa do tubo e $R_{\text {cond }}$ é a resistência condutiva da parede. Para o caso de um tubo circular de diâmetro interno $D_{i}$ e diâmetro externo $D_{e}$ o coeficiente efetivo é expresso por: 
$\frac{1}{U_{e f}}=\frac{D_{i} / D_{e}}{h_{e}}+\frac{D_{i} \ln \left(D_{e} / D_{i}\right)}{2 k_{s}}$

Finalmente, para a definição completa do problema, é necessário definir uma função que represente a dependência da viscosidade com a temperatura. A função selecionada, sugerida no trabalho de Quinones \& Carvalho (2010) [7], é apresentada a seguir, onde $A, B$ e $\mu_{0}$ são parâmetros a serem ajustados a dados experimentais de viscosidade em função de temperatura para o fluido em estudo:

$\mu(T)=\mu_{0} e^{\left(\frac{A}{T+B}\right)}$

Uma adimensionalização das equações e condições de contorno descritas acima, utilizando o diâmetro do tubo para adimensionalizar os comprimentos, fornece as seguintes equações adimensionais,

$\vec{\nabla} \cdot \vec{u}^{*}=0$

$\vec{u}^{*} \cdot \vec{\nabla} \vec{u}^{*}=-\frac{1}{2} \vec{\nabla} p^{*}+\frac{G r}{\operatorname{Re}^{2}}\left[\theta-\theta_{r e f}\right] \vec{e}_{i}+\frac{1}{\operatorname{Re}} \vec{\nabla} \cdot\left[2 \mu^{*} \overline{\overline{D^{*}}}\right]$

$\vec{u}^{*} \cdot \vec{\nabla} \theta=\frac{1}{\operatorname{Re} \cdot \operatorname{Pr}} \vec{\nabla}^{2} \theta+\frac{E c}{\operatorname{Re}} \phi^{*}$

Nas equações acima os operadores foram devidamente adimensionalizados, apesar de representados com mesmos símbolos usados nas equações com dimensão. As seguintes definições de parâmetros adimensionais foram utilizadas,

$$
\begin{aligned}
& \vec{x}^{*}=\frac{\vec{x}}{D_{i}} \\
& \vec{u}^{*}=\frac{\vec{u}}{u_{i n}}
\end{aligned}
$$


$p^{*}=\frac{p}{0,5 \rho_{r e f} u_{i n}^{2}}$

$\operatorname{Re}=\frac{\rho_{r e f} u_{i n} D_{i}}{\mu_{r e f}}$

$G r=\frac{|\vec{g}| \beta_{r e f}\left(T_{e}-T_{\infty}\right) D_{i}^{3}}{v_{r e f}^{2}}$

$\operatorname{Pr}=\frac{\mu_{r e f} c_{p}}{k}$

$E c=\frac{u_{i n}^{2}}{c_{p}\left(T_{e}-T_{\infty}\right)}$

$\theta=\frac{T-T_{\infty}}{T_{e}-T_{\infty}}$

A condição de contorno térmica na parede interna do duto, quando adimensionalizada, torna-se:

$\frac{\partial \theta}{\partial n^{*}}=\frac{U_{e f} D_{i}}{k} \theta=U_{e f}^{*} \theta$

As condições de contorno hidrodinâmicas e térmicas aplicadas no fim do duto não fornecem parâmetros adimensionais adicionais. Porém, a posição adimensional de aplicação destas condições, $L / D_{i}$, é um parâmetro adimensional a ser especificado para a solução do problema.

A função que descreve a dependência da viscosidade com a temperatura pode ser representada em forma adimensional:

$\mu^{*}=\mu_{0}^{*} e^{\left(\frac{A^{*}}{\theta+B^{*}}\right)}$ 
com,

$$
\begin{aligned}
& A^{*}=\frac{A}{T_{e}-T_{\infty}} \\
& B^{*}=\frac{B-T_{\infty}}{T_{e}-T_{\infty}} \\
& \mu_{0}^{*}=\frac{\mu_{0}}{\mu_{r e f}}
\end{aligned}
$$

A análise das equações que governam o problema em estudo revela que a solução para os campos de pressão, velocidade e temperatura para o duto depende de dez parâmetros adimensionais, quais sejam, a inclinação do tubo, $\alpha$, o número de Reynolds, Re, o número de Prandtl, $P r$, o número de Grashof, $G r$, o número de Eckert, $E c$, o coeficiente de troca térmica adimensional, $U_{e f}^{*}$, do comprimento adimensional do duto, $L / D_{i}$, e dos três coeficientes adimensionais que definem a dependência da viscosidade com a temperatura, $A^{*}, B^{*}$ e $\mu_{0}^{*}$.

O conhecimento destes parâmetros é fundamental para o projeto do experimento que será descrito no próximo capítulo. 


\section{3 \\ Montagem Experimental}

Neste capítulo será descrita a seção de testes projetada e construída para a condução dos ensaios. Como pôde ser observado no capítulo anterior, o problema em estudo depende de dez parâmetros adimensionais, o que torna um estudo paramétrico completo uma tarefa inviável dentro do horizonte de tempo disponível para a conclusão do trabalho. Assim, para o estudo conduzido, foram selecionados os parâmetros adimensionais que seriam variados e aqueles que seriam mantidos constantes e, portanto, cuja influência não seria investigada.

O projeto do experimento foi iniciado pela escolha do fluido de trabalho. Procurou-se um fluido que apresentasse um comportamento de variação da viscosidade com a temperatura semelhante àquele encontrado nos petróleos pesados de campo. Além disso, o fluido selecionado deveria ter propriedades termofísicas estáveis e conhecidas, além de ser transparente para permitir a medição de perfis de velocidade utilizando técnicas ópticas.

Antes de apresentarmos os componentes da seção de testes, é conveniente uma apresentação geral que facilitará a compreensão do detalhamento que se seguirá.

A Figura 3.1 apresenta uma descrição esquemática simplificada da seção de testes projetada. O fluido de trabalho aquecido é bombeado por um longo tubo feito em material com baixa condutividade térmica. $O$ fluido é mantido em temperatura elevada por meio de um banho termostático. A tubulação por onde circula a glicerina é envolta por um tubo de maior diâmetro por onde circula água gelada, formando uma geometria anular. Desse modo é possível controlar as condições de troca de calor que promovem o resfriamento do fluido de trabalho e a conseqüente variação de viscosidade, cuja influência no escoamento é o foco do presente estudo. No modelo de laboratório, a água de refrigeração simula o ambiente marinho ao qual a linha é exposta nas instalações de campo. Pressão, temperatura e vazão eram medidos de modo a permitir a determinação da relação entre queda de pressão e vazão. Medidas de perfis radiais de velocidade e temperatura foram realizadas em duas estações axiais no interior do tubo não indicadas na figura simplificada, mas que serão detalhadas mais adiante. 


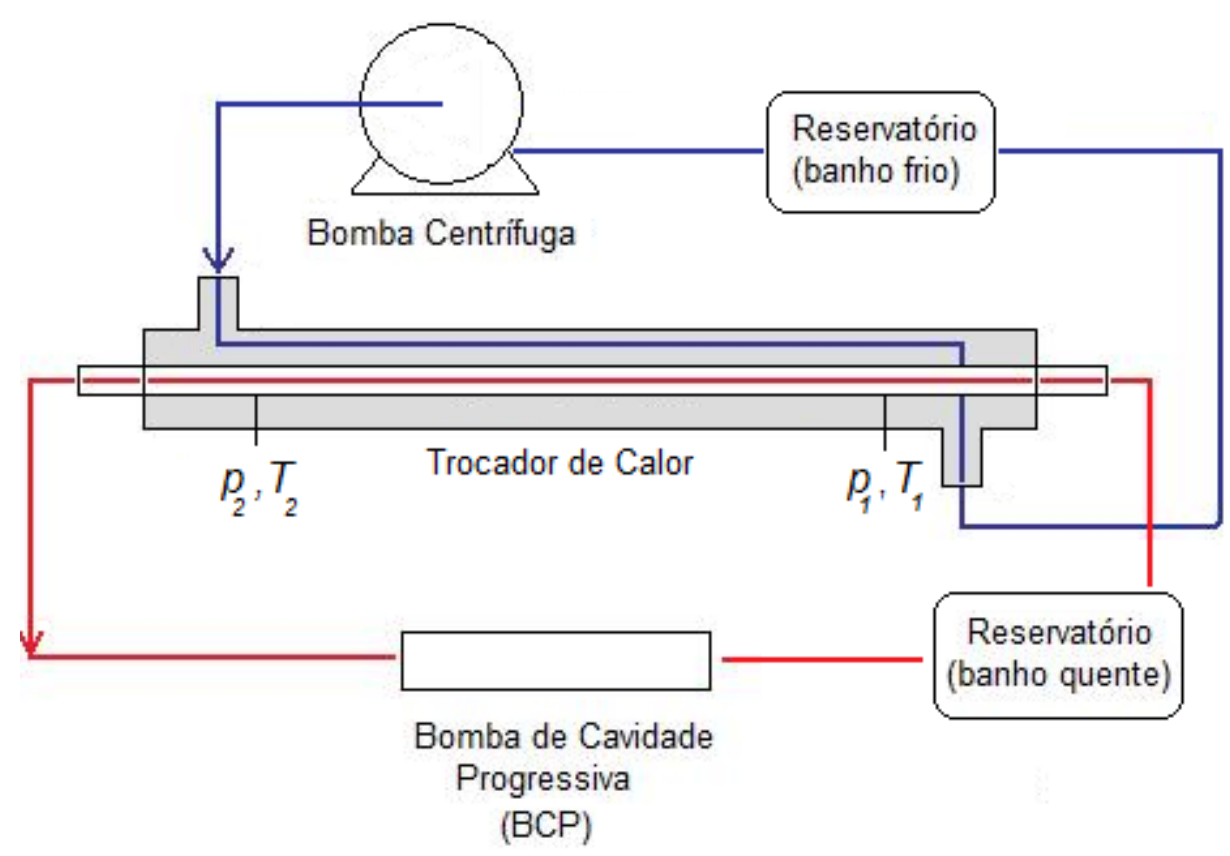

Figura 3.1 - Descrição esquemática simplificada da seção de testes projetada

\section{1. \\ Fluido de trabalho}

O fluido de trabalho selecionado para a condução dos ensaios foi uma solução de $95 \%$ de glicerina e $5 \%$ de água. Este fluido apresentou forte dependência de sua viscosidade com a temperatura, característica fundamental para o estudo conduzido. Além disso, por ser transparente à luz, permitiu a utilização da técnica óptica de velocimetria laser-Doppler na medição de perfis de velocidade.

A solução selecionada foi caracterizada no Laboratório de Reologia da PUC-Rio, através do levantamento da curva de viscosidade em função da temperatura. A curva foi determinada em um reômetro de tensão controlada da marca Anton Paar, modelo Paar Physica MCR301, entre as temperaturas $5^{\circ} \mathrm{C}$ e $75^{\circ} \mathrm{C}$, região de interesse do experimento, a uma taxa de aquecimento de $1^{\circ} \mathrm{C} /$ min e sob uma taxa de deformação de $100 \mathrm{~s}^{-1}$.

As medidas foram utilizadas para a determinação das constantes da equação exponencial selecionada para modelar a variação da viscosidade,

$\mu(T)=\mu_{0} e^{\left(\frac{A}{T+B}\right)}$ 
A Figura 3.2 apresenta os resultados obtidos da caracterização da viscosidade da mistura água-glicerina. Os valores obtidos para as constantes foram $\mu_{0}=7,90 \times 10^{-6} \mathrm{~kg} / \mathrm{ms}, A=1777 \mathrm{~K}$ e $B=-140,5 \mathrm{~K}$.

É importante mencionar que a adição de $5 \%$ de água na glicerina teve o objetivo de estabilizar as propriedades da solução, no que diz respeito à absorção de umidade do ar. Testes iniciais foram conduzidos com glicerina pura onde observou-se uma apreciável variação das propriedades termofísicas ao longo dos testes. A adição de água à glicerina produz uma mistura com propriedades significativamente mais insensíveis à absorção de umidade, produzindo um fluido de trabalho adequado para os propósitos do experimento.

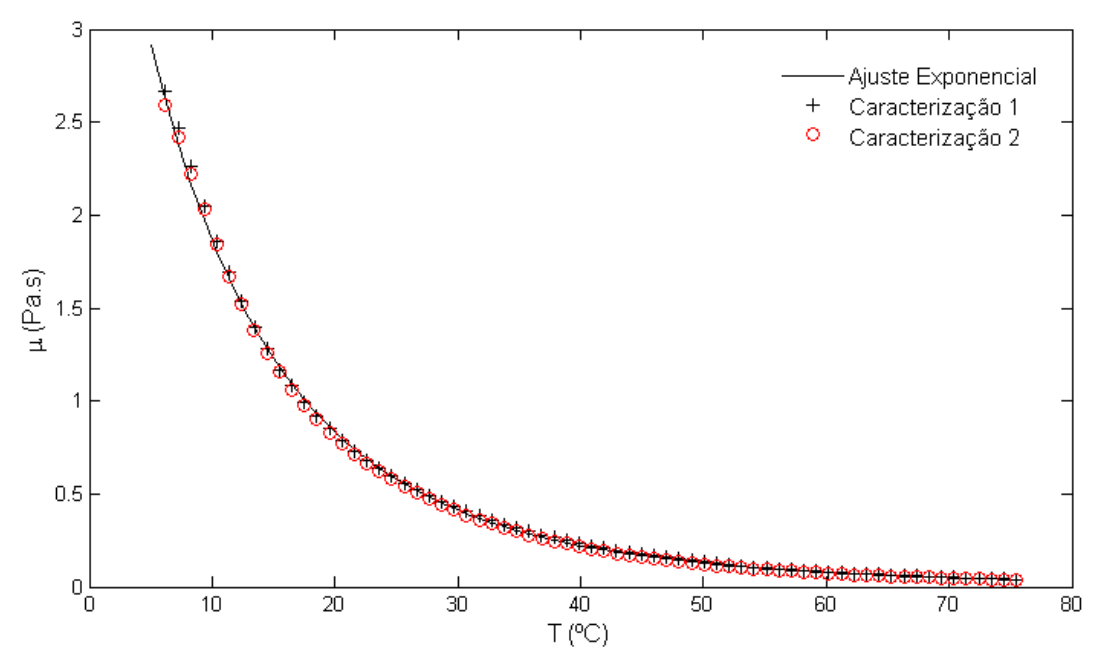

Figura 3.2 - Variação da viscosidade com a temperatura da solução de $95 \%$ de glicerina e $5 \%$ de água utilizado nos experimentos.

A massa específica de referência da mistura $(\rho)$ à $70^{\circ} \mathrm{C}$ foi determinada no Laboratório de Reologia da PUC-Rio. O coeficiente de expansão térmica, $\beta$, e a condutividade térmica, $k$, são valores tabelados encontrados na literatura [9]. O calor específico foi extrapolado para as condições de trabalho a partir de dados encontrados na literatura [8]. Estas propriedades são apresentadas na Tabela 3.1. 
Tabela 3.1 - Propriedades termofísicas do fluido de trabalho à $70^{\circ} \mathrm{C}$, temperatura de entrada e referência no trabalho. Solução $95 \%$ glicerina e $5 \%$ água.

\begin{tabular}{cc}
\hline$\rho\left(\mathrm{kg} / \mathrm{m}^{3}\right)$ & 1221 \\
$c_{p}(\mathrm{~J} / \mathrm{kg} \cdot \mathrm{K})$ & 2782 \\
$k(\mathrm{~W} / \mathrm{m} \cdot \mathrm{K})$ & 0,29 \\
$\beta\left({ }^{\circ} \mathrm{C}^{-1}\right)$ & $6,15 \times 10^{-4}$ \\
\hline
\end{tabular}

\section{2.}

\section{Seção de testes}

A solução de glicerina era mantida aquecida em um tanque isolado termicamente e equipado com um controlador de temperatura. A saída do tanque era ligada à entrada do tubo principal interno. Uma bomba de deslocamento positivo do tipo de cavidades progressivas tinha sua admissão ligada à outra extremidade do tubo interno promovendo o bombeio da solução de glicerina através do tubo principal e retornando o fluido ao tanque aquecido, formando um circuito fechado. A opção pela montagem do sistema de bombeio trabalhando no modo de sucção foi motivada pela necessidade de minimizar as perdas de calor para o ambiente do fluido saindo do reservatório quente. Nesta montagem, a entrada do tubo pode ser conectada diretamente ao tanque de armazenagem do fluido quente.

O resfriamento da solução de glicerina era promovido pelo bombeio de solução fria de água e etileno glicol pela seção anular do trocador de calor. Uma bomba centrífuga era utilizada para bombear a solução refrigerante de um banho termostático frio, através do trocador de calor e de volta ao banho. A Figura 3.3 apresenta uma vista geral da seção de testes construída. A seguir, cada componente da seção de testes será descrito em detalhes. 


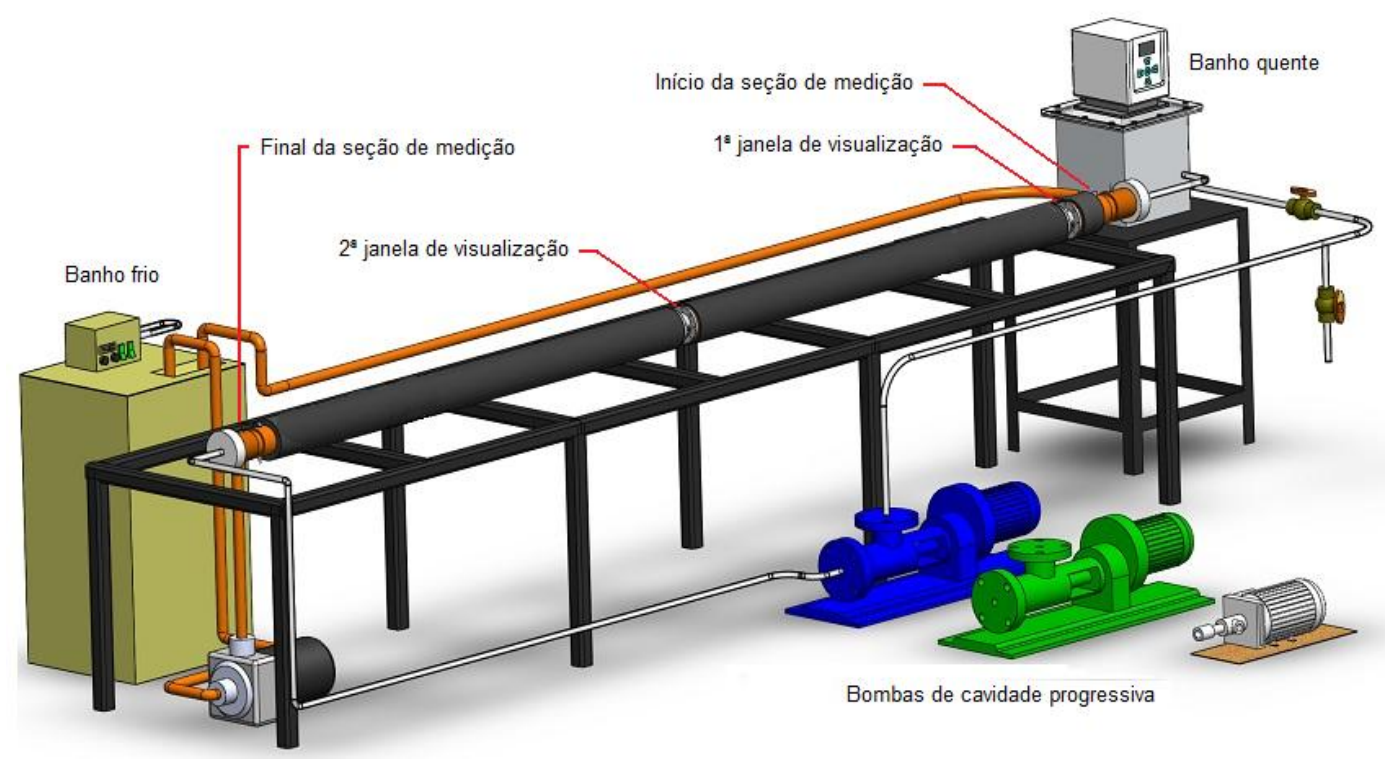

Figura 3.3 - Vista em perspectiva da seção experimental.

\section{3. \\ Trocador de Calor}

O trocador de calor tubo-dentro-de-tubo foi fabricado a partir de tubos com medidas padrão do fabricante Tigre. Para o tubo interno, o tubo principal, foi selecionada a linha Aquatherm, com diâmetros interno e externo de 11,8 e 15 $m m$, respectivamente. Esta linha de tubos da Tigre é destinada a aplicações com água quente sendo fabricada de policloreto de vinila clorado (CPVC) e apresenta baixa condutividade térmica oferecendo bom isolamento térmico, como desejado para o objetivo do projeto. O comprimento do tubo utilizado era de 3 metros, o que equivale a um comprimento de 254 diâmetros. Este comprimento é suficiente para promover o desenvolvimento hidrodinâmico do escoamento, caso o escoamento fosse isotérmico.

A tubulação externa do trocador de calor foi construída a partir de um tubo de PVC com diâmetros interno e externo de 53,4 e $60 \mathrm{~mm}$, respectivamente. A tubulação externa era selada em suas extremidades por flanges de PVC. A Figura 3.4 apresenta uma vista em corte de um dos flanges montados na extremidade do tubo. Os números na figura auxiliam a descrição de cada peça que compõe o flange. Estes flanges, número (1) na figura, também serviam para centralizar o tubo interno no espaço anular. Ao longo do comprimento do trocador de calor foram instaladas 3 peças para manter o tubo interno centralizado (7). Fluido de refrigeração entrava na seção anular através da 
abertura (8) no flange. Uma abertura semelhante no flange montado no final do tubo permitia a saída do fluido de refrigeração.

Temperatura e pressão no escoamento da solução de glicerina eram medidos na entrada e na saída do tubo interno. Para isso portas de acesso foram projetadas, como indicado nos itens (2) e (3) na Figura 3.4. Um sensor do tipo termopar, fabricado a partir de fios de Cromel-Constantan de $75 \mu \mathrm{m}$ de diâmetro e montado em um tubo fino de aço inox, foi posicionado na linha de centro do tubo. Uma tomada de pressão instalada na parede do tubo interno era conectada ao sensor de pressão por meio de uma mangueira plástica. Na região de saída do tubo foram instaladas tomadas de pressão e temperatura semelhantes às instaladas na região de entrada. A distância entre estas duas seções de medição de temperatura e pressão era de a $2840 \mathrm{~mm}$. A temperatura de entrada da solução de refrigeração era monitorada por um termopar instalado na posição (6) indicada na figura. O flange de saída também foi instrumentado de modo similar para monitorar a temperatura de saída do fluido de refrigeração.

O percurso da solução de glicerina desde o tanque aquecido até a posição onde estavam instalados os sensores de pressão e temperatura foi isolado termicamente por meio de uma camisa fabricada a partir de um tubo de PVC instalado em volta do tubo interno, como pode ser observado na Figura 3.4, item (5). O espaço anular no interior da camisa continha ar, um bom isolante térmico. Este isolamento da região de entrada tinha por objetivo reduzir a potência requerida no banho termostático para a manutenção da temperatura de entrada da solução de glicerina nos níveis elevados necessários para os testes. Isolamento de borracha elastomérica de $30 \mathrm{~mm}$ de espessura foi instalado na parte externa do tubo externo com o objetivo de minimizar a troca de calor da solução fria de refrigeração com o ambiente do laboratório, minimizando a potência de refrigeração do banho termostático frio. Este isolamento é indicado como item (4) na Figura 3.4. Detalhes com as principais dimensões do projeto se encontram no Apêndice B do presente trabalho. 


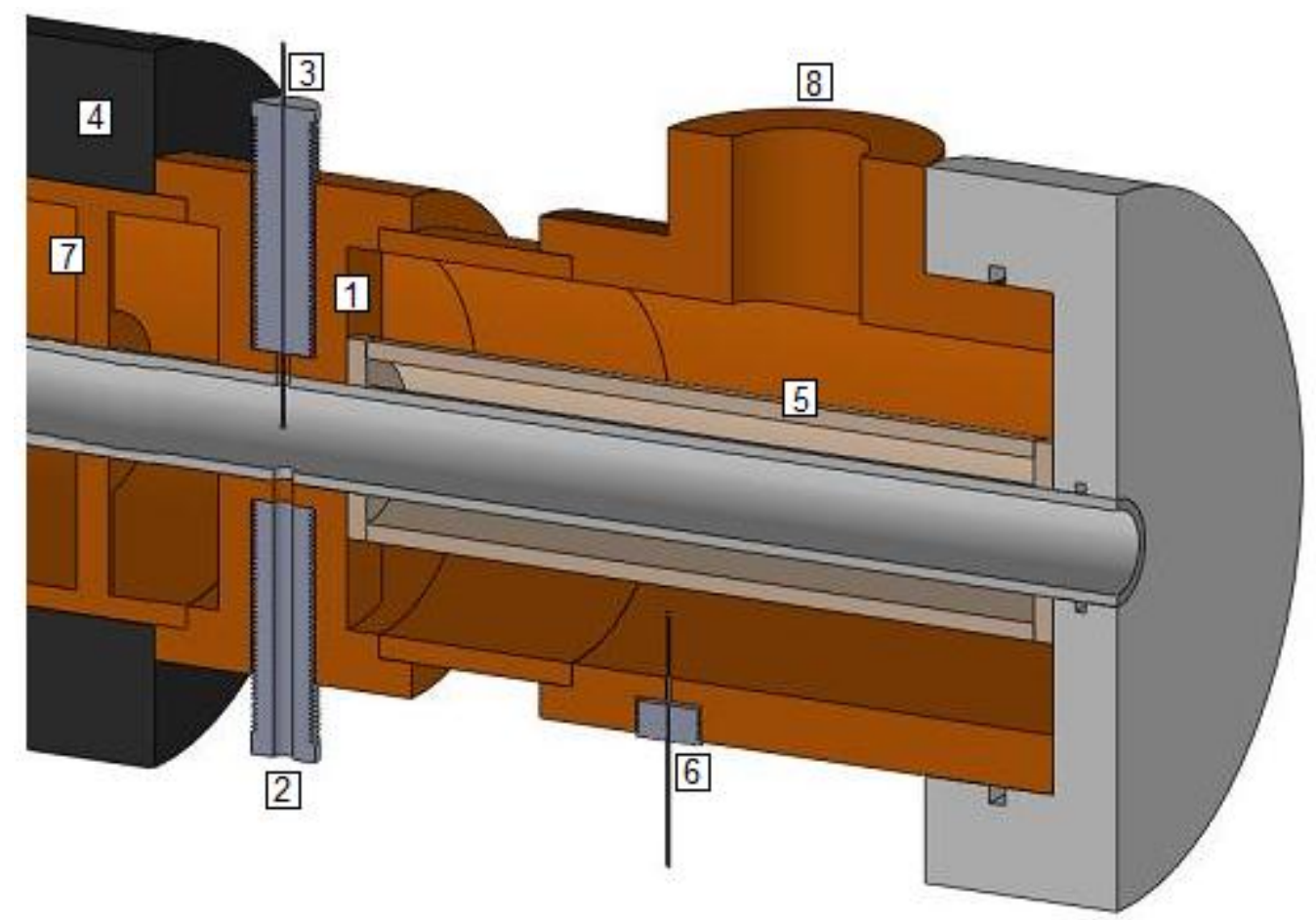

Figura 3.4 - Vista em corte de umas das extremidades do trocador de calor.

\section{4 . \\ Circuito do Fluido de Trabalho}

A solução de glicerina e água era mantida em um tanque de aço inox com capacidade de 10 litros e isolado termicamente. A temperatura do fluido no tanque era controlada por uma unidade termostática Thermo Fisher ScientificHAAKE modelo DC30. Para auxiliar o processo de aquecimento da glicerina, uma placa aquecedora e agitadora da Fisatom, modelo 754A - 1000W, foi posicionada por baixo do reservatório térmico.

Três diferentes bombas de cavidades progressivas com diferentes capacidades foram utilizadas para o bombeio do fluido de testes: modelos NM011A, NM011B e 4N02 da Netzsch, com faixas de vazão 360 a $1450 \mathrm{ml} / \mathrm{min}, 50$ a $440 \mathrm{ml} / \mathrm{min}$ e 6,7 a $85 \mathrm{ml} / \mathrm{min}$, respectivamente. Em cada bomba foi instalado um inversor de frequência, modelo CFW08 da WEG, para controlar a sua rotação.

O retorno do fluido de trabalho para o tanque de armazenagem era feito por meio de mangueira de borracha de $1 / 2$ " devidamente isolada termicamente. 


\section{5. \\ Circuito do Fluido Refrigerante}

O fluido refrigerante utilizado no trocador de calor foi uma solução $50 \%$ água e etileno-glicol. Devido às baixas temperaturas de operação no experimento, a presença o etileno-glicol mantinha o fluido de trabalho sempre na fase líquida.

O controle da temperatura do fluido refrigerante bombeado para a seção de testes foi feito por dois banhos termostáticos trabalhando em conjunto. $\mathrm{O}$ primeiro, servindo também como reservatório térmico do circuito de resfriamento do trocador de calor, era o banho termostático da marca Neslab, modelo ULT-80. O segundo banho foi o Thermo Haake, modelo Phoenix C25P, utilizado com uma serpentina de cobre instalada na extremidade da sua linha de circulação $e$ imersa no reservatório do banho Neslab, auxiliando no resfriamento do fluido refrigerante.

O fluido refrigerante circulava pelo trocador de calor por meio de uma bomba centrífuga Dancor modelo CP-6R NEMA, acionada por um motor elétrico de $1 \mathrm{CV}$, cuja rotação era controlada por um inversor de frequência WEG modelo CFW08. O sentido do fluxo do fluido refrigerante era o inverso do fluido de trabalho, produzindo um arranjo em contra-corrente no trocador de calor.

\section{6. \\ Sensores de Temperatura e Pressão}

Todos os sensores de temperatura utilizados no experimento foram termopares do tipo $\mathrm{E}$ (Cromel-Constantan) fabricados a partir de fios de $75 \mu \mathrm{m}$ de diâmetro, com isolamento de teflon. Os termopares foram ligados diretamente ao sistema de aquisição de dados Agilent, utilizando a compensação eletrônica de zero e curva de calibração fornecida pelo próprio instrumento.

A medida da queda de pressão no escoamento foi realizado utilizando-se um medidor de pressão diferencial piezorresistivo da marca Zürich, modelo PSI.EX.H.DIF, para faixa de 0 a $1 \mathrm{mca}$ com incerteza de $\pm 0,1 \%$ do fundo de escala. As tomadas de pressão ligadas ao medidor eram separadas por uma distância de $2840 \mathrm{~mm}$.

Um manômetro de mercúrio de tubo em $U$, com escala de -100 a $100 \mathrm{mmHg}$ e resolução de $1 \mathrm{~mm}$, foi instalado em paralelo ao medidor de pressão Zürich, permitindo redundância nas medidas de pressão dos ensaios. $O$ 
circuito de ligação entre o sensor de pressão, manômetro e as tomadas de pressão na seção de testes foi feito com tubos flexíveis de polietileno de $3 / 8$ " de diâmetro externo.

\section{7. \\ Medida de Vazão}

A medida da vazão da solução de glicerina e água circulando pelo tubo principal da seção de testes foi realizada utilizando o método gravimétrico. Antes dos ensaios, todas as três bombas de cavidades progressivas utilizadas tiveram suas curvas vazão versus rotação levantadas pelo processo gravimétrico. Assim, o valor da vazão para um dado ensaio para um valor específico do número de Reynolds, era ajustado utilizando-se a curva de calibração da bomba em uso. Uma vez estabilizado o experimento, leituras da vazão eram realizadas pelo método gravimétrico, desviando-se a vazão da solução para um recipiente de vidro previamente pesado. A massa escoada para o recipiente em um dado intervalo de tempo era determinada por nova pesagem. Uma balança Gehaka modelo AG200 com resolução de $1 \mathrm{mg}$ foi utilizada nas pesagens. Um cronômetro com resolução de $0,5 s$ foi utilizado para a medição do tempo de escoamento do fluido.

\section{8. \\ Sistema de Aquisição de Dados}

As leituras dos sensores de temperatura e pressão foram realizadas de modo automatizado por um sistema de aquisição de dados modelo 34970A da AGILENT. Um programa de controle escrito na plataforma Labview foi desenvolvido para gerenciar o processo de aquisição de dados.

\section{9.}

\section{Medição dos Perfis Radiais de Velocidade e Temperatura}

Além da medição da queda de pressão e das temperaturas na linha de centro do tubo nos planos de entrada e saída do escoamento da solução de glicerina, os experimentos conduzidos tiveram como objetivo a medição de perfis radiais de temperatura e velocidade em diferentes posições axiais ao longo do escoamento. Perfis radiais de velocidade e temperatura oferecem informações mais detalhadas que as medidas globais, o que pode ajudar a melhor 
compreender os efeitos da viscosidade variável sobre o escoamento. Além disso, perfis radiais fornecem meios para uma validação mais rigorosa dos códigos computacionais desenvolvidos no âmbito do projeto do qual o presente trabalho é parte.

A técnica selecionada para a medição dos perfis de velocidade foi a Velocimetria laser-Doppler - LDV, do inglês laser-Doppler velocimetry. Esta técnica óptica foi selecionada após uma análise das alternativas disponíveis, quais sejam o tubo de Pitot e anemometria de fio/filme quente. Ambas as técnicas não são recomendadas para os baixos níveis de velocidade esperados para os experimentos, exigindo correções que podem comprometer o nível de incerteza experimental das medidas.

Velocimetria laser-Doppler é uma técnica óptica tradicional disponível comercialmente e fornecida por alguns poucos fabricantes internacionais. Consiste na análise da variação da frequência (efeito Doppler) da luz espalhada por pequenas partículas traçadoras adicionadas ao escoamento quando estas passam pelo volume de medição formado pelo cruzamento de dois feixes de luz laser. Detalhes sobre esta técnica podem ser obtidos em diversas referências, como por exemplo [10].

O sistema LDV utilizado nos experimentos é de fabricação da TSI, sendo formado por um laser de íon de Argônio INNOVA 70 com potência de 5W de fabricação da SpectraPhysics. O sistema era capaz de medir simultaneamente dois componentes da velocidade em um mesmo ponto, apesar de nos experimentos realizados apenas o componente axial da velocidade ter sido medido. A fonte laser emite radiação nas faixas de comprimento de onda do azul ao violeta. O componente verde do laser era separado em dois feixes que se cruzavam no ponto de medição formando um volume de medição na forma de um elipsóide de revolução com eixos maior e menor da ordem de 200 e 100 $\mu$ m, respectivamente. Esta dimensão do volume de medição foi considerada satisfatória para a resolução espacial desejada para as medições dos perfis de velocidade dentro do tubo. O sistema óptico para a formação do volume de medição fornecido pela TSI, produzia um semi-ângulo de convergência dos feixes de 3,97 graus, a uma distância de trabalho (distância do plano da lente ao volume de medição) de $350 \mathrm{~mm}$.

O desafio para a realização da medição de perfis de velocidade residia na dificuldade de acesso dos feixes laser ao interior do tubo interno. No caso particular de nosso experimento, a geometria do trocador de calor tubo-dentro- 
de-tubo obrigava que o feixe para atingir o escoamento de solução de glicerina no interior do tubo interno passasse pela parede do tubo externo, pela água de refrigeração escoando no espaço anular e pela parede do tubo interno. Mesmo que janelas transparentes fossem instaladas nas paredes dos tubos interno e externo, ainda assim a passagem do feixe através de meios ópticos diferentes como, ar, água-etileno glicol e glicerina-água, provocaria refrações no feixe que prejudicariam as medições. Ainda no caminho óptico do feixe, as janelas curvas relativamente espessas produziriam refrações adicionais nos feixes.

Uma janela de visualização foi especialmente projetada e construída para permitir o acesso óptico para os feixes do LDV ao interior do tubo interno, minimizando os efeitos de refração. Esta janela é apresentada em vista explodida no desenho da Figura 3.5.

A janela de visualização é constituída de uma união flangeada que era inserida em uma dada posição axial do trocador de calor onde se desejava realizar as medições de perfil de velocidade. Para isso, os tubos interno e externo do trocador de calor foram seccionados, permitindo a instalação da janela de visualização. As partes do tubo externo resultantes recebiam flanges que se adaptavam aos flanges da janela de visualização. Anéis de vedação de borracha, indicados como (1) na figura, garantiam a vedação do conjunto.

As duas partes do tubo interno seccionado (2) foram conectadas a cada um dos lados de um bloco de PVC usinado como mostrado na figura. Anéis de vedação de borracha inseridos nas canaletas (3) garantiam a vedação. O bloco de PVC foi fixado na posição central da janela de visualização pelos tubos de PVC indicados na figura com os números (7) e (11). O tubo de acrílico com um furo circular em sua parede lateral (4) foi introduzido no bloco de PVC entre as duas partes do tubo interno. Quando montado em posição dentro do bloco, o furo no tubo de acrílico coincidia com o furo (5) no bloco de PVC e com o tubo (7). Uma vez montada a janela, a água de refrigeração continuava escoando no espaço anular contornando o bloco de PVC, enquanto a solução de glicerina e água escoava no tubo interno.

$\mathrm{Na}$ superfície interior do tubo de acrílico foi cuidadosamente colado um filme plástico fino transparente (6), com espessura de $0,1 \mathrm{~mm}$, obtido de uma transparência utilizada para apresentações com retro projetores. O filme cobria toda a superfície interna do tubo de acrílico e, quando montado, apresentava o mesmo diâmetro interno que o tubo de CPVC por onde escoava a solução de glicerina. Em outras palavras, a conexão não oferecia degraus que pudessem 
perturbar o escoamento no interior do tubo interno. A função deste filme era permitir acesso óptico ao interior do tubo produzindo refração desprezível nos feixes laser ao passarem na superfície curva devido à pequena espessura oferecida pelo filme. Para diminuir ainda mais os efeitos de refração, o furo (5) foi preenchido com a mesma solução de glicerina que escoava no interior do tubo interno. Um disco plano de acrílico (8) vedava por meio de um anel de borracha o furo (5) quando pressionado pelo tubo roscado (9). Assim, os dois feixes do laser entravam pelo tubo (7), cruzavam a superfície plana de acrílico (8), cruzam o tubo (5) preenchido com glicerina, cruzavam o filme fino e penetravam no interior do tubo com a solução de glicerina. A montagem minimizava a refração do feixe, pois o mesmo fluido ocupava os dois lados do filme fino transparente.

Devido ao fato do nível de pressão no interior do tubo interno ser diferente da pressão exterior, era possível que o filme fino transparente que dá acesso óptico ao feixe laser fosse deformado pelo diferencial de pressão imposto sobre suas faces interna e externa. Para evitar este problema, a pressão nos dois lados do filme fino foi equilibrada pela comunicação oferecida pelo canal de pequeno diâmetro usinado no bloco de PVC (10) que conectava o interior do tubo com o fluido aprisionado no tubo (5).

A sonda do sistema LDV foi posicionada sobre a janela de visualização de modo que o par de feixes penetrava verticalmente no interior do tubo. A sonda foi montada sobre uma mesa de coordenadas automatizada acionada por um motor de passo, que permitia deslocamentos radiais do volume de medição dentro do tubo interno com resolução de $0,01 \mathrm{~mm}$.

A janela de visualização foi projetada para permitir a medição simultânea dos perfis de velocidade e temperatura. Para isso, uma sonda de termopar foi construída a partir de fios de Cromel e Constantan de $75 \mu \mathrm{m}$ revestidos de Teflon. O termopar foi introduzido em um tubo de aço inox de $2 \mathrm{~mm}$ de diâmetro externo e $1 \mathrm{~mm}$ de diâmetro interno. Além disso, o tubo de inox possui uma ponta de $10 \mathrm{~mm}$ feita em resina epóxi com o objetivo de anular possíveis efeitos de condução de calor pelo tubo de aço. Além de isolar termicamente a ponta do termopar do tubo de inox, a resina epóxi mantinha-o fixo em sua posição garantindo a integridade das medidas realizadas pelo sensor.

O tubo de inox era introduzido no canal (11) que dava acesso ao interior do tubo interno. Um anel de vedação de borracha vedava a passagem da solução de glicerina, permitindo, porém, o movimento radial da sonda. Uma montagem 
realizada conectando um parafuso micrométrico ao tubo inox, conforme mostra a Figura 3.6, foi feita a fim de permitir os movimentos radiais da sonda de temperatura com resolução de $0,01 \mathrm{~mm}$. Por sua vez, este conjunto era acoplado no canal (11) mostrado na Figura 3.5, que apresenta uma vista explodida da janela de visualização.

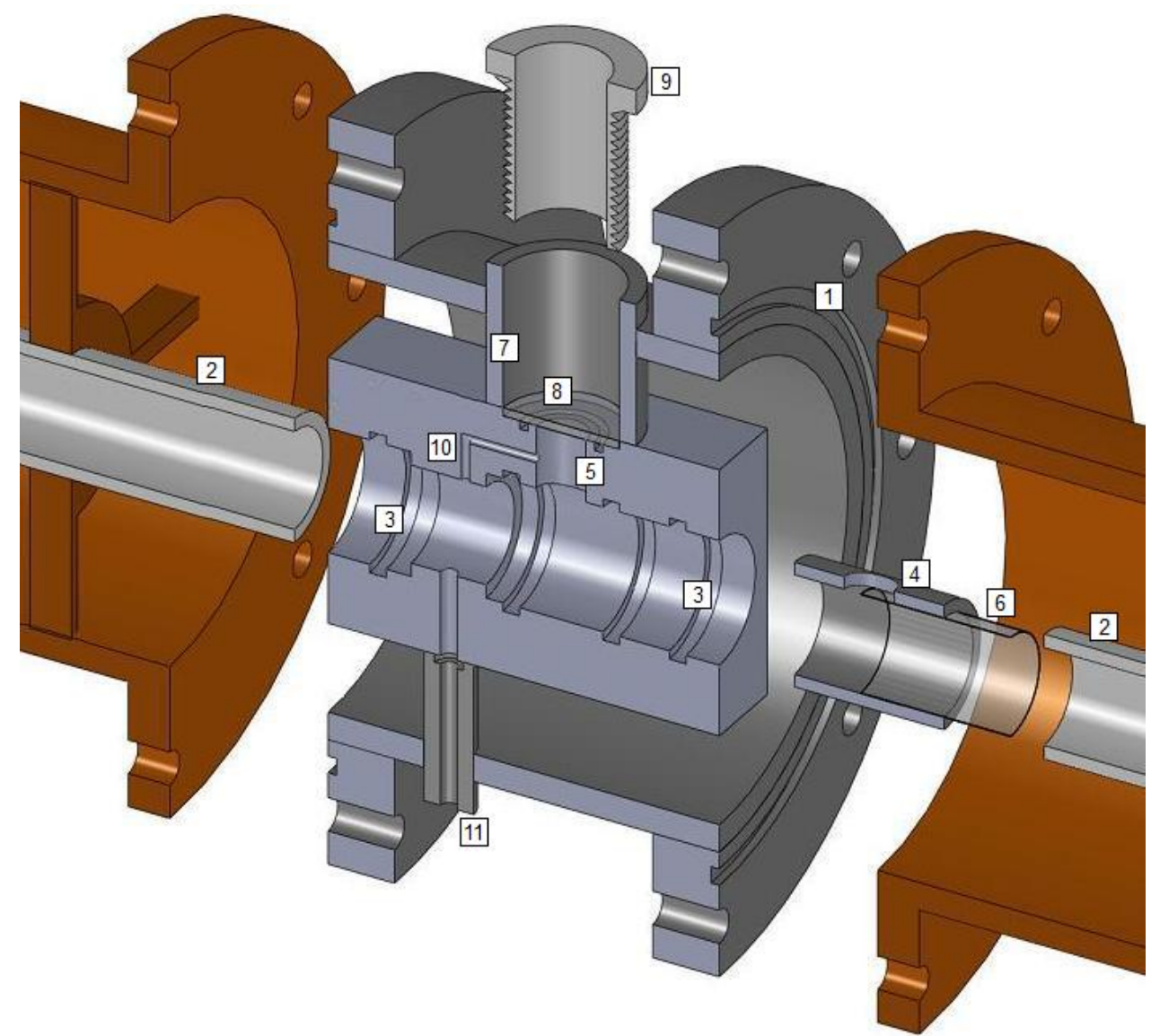

Figura 3.5 - Seção longitudinal da janela de visualização. 


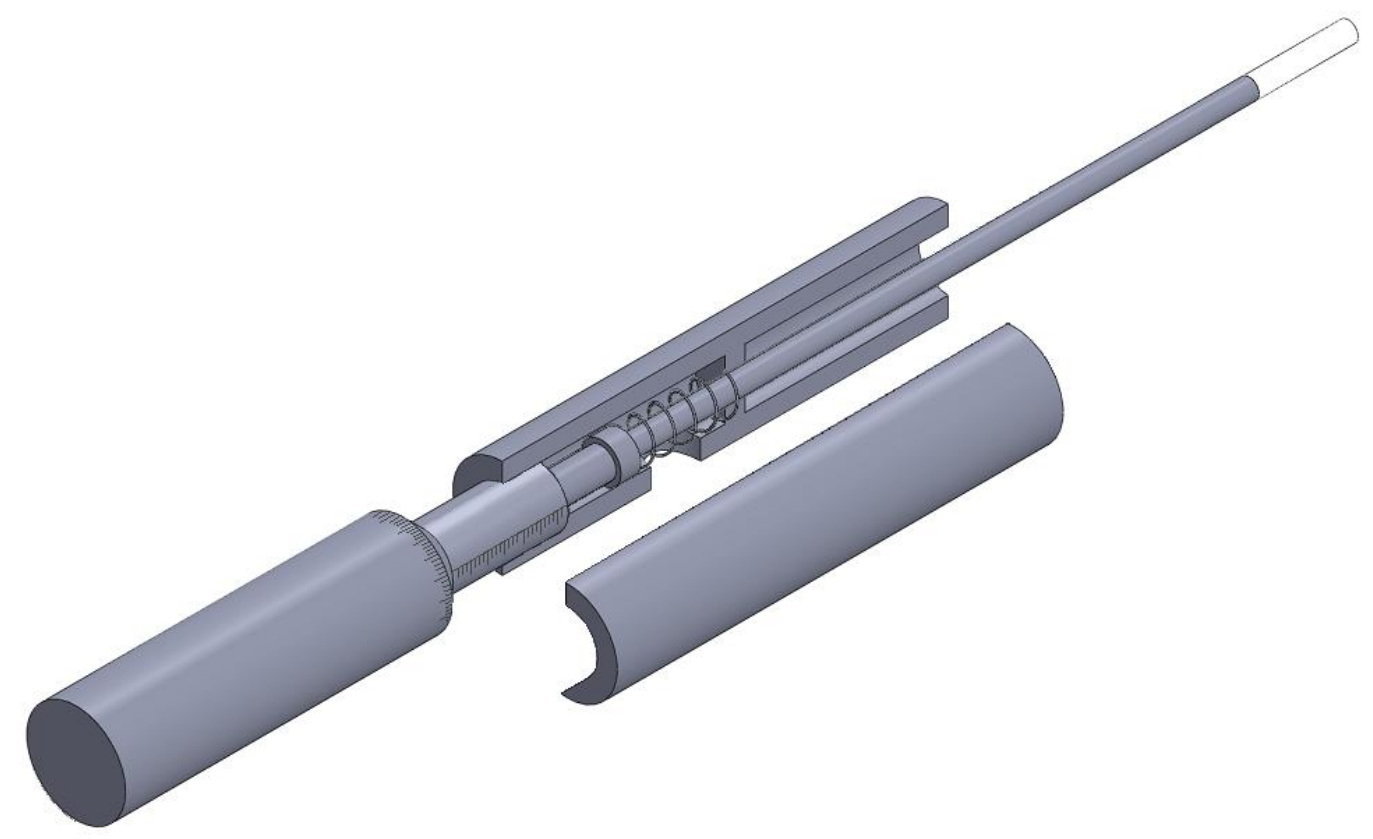

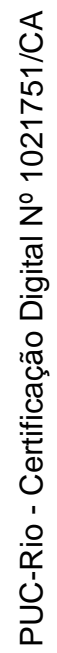

Figura 3.6 - Vista em corte do mecanismo utilizado para a medição dos perfis de temperatura. 


\section{4 \\ Procedimento Experimental}

Neste capítulo serão descritos os procedimentos adotados na condução dos experimentos voltados para a medição de queda de pressão e de perfis de velocidade e temperatura no escoamento em duto de fluido com viscosidade variável com a temperatura.

\section{1.}

\section{Preparação dos Experimentos}

Os experimentos eram iniciados pela preparação da solução de trabalho na proporção de $95 \%$ de glicerina e $5 \%$ de água. A solução preparada era introduzida no reservatório aquecido. O controlador do reservatório tinha sua temperatura ajustada para a temperatura de trabalho, tipicamente da ordem de $70^{\circ} \mathrm{C}$. Em seguida uma das três bombas de cavidades progressivas selecionada para um dado teste era acionada fazendo circular a solução na vazão desejada para o teste.

A bomba centrífuga responsável pela circulação do fluido de refrigeração era acionada bombeando fluido dos banhos termostáticos frios, previamente ligados e equilibrados em temperatura da ordem de $5^{\circ} \mathrm{C}$. A vazão da bomba centrífuga era controlada até que a diferença entre a temperatura de entrada e saída do fluido de refrigeração na seção de testes fosse inferior a $0,5^{\circ} \mathrm{C}$, o que garantia que a troca de calor da solução de glicerina no interior do tubo interno se daria para um ambiente virtualmente isotérmico.

Após ter sido ligado, o experimento era monitorado pelas leituras das temperaturas de entrada e saída dos dois fluidos, até que a condição de regime permanente fosse atingida. Também a leitura do diferencial de pressão registrada pelo manômetro entre as tomadas posicionadas nas regiões de entrada e saída da seção de testes eram monitoradas para a verificação da obtenção da condição de regime permanente. Verificou-se que o tempo necessário para o equilíbrio da leitura da queda de pressão era sempre superior ao tempo necessário para o equilíbrio das leituras das temperaturas. 
Ao longo de todo o período de obtenção da condição de regime permanente e do período de medição propriamente dito, as medidas de temperatura e queda de pressão eram registradas pelo sistema de aquisição de dados.

Findo o período de aquisição de dados, a medição da vazão mássica escoando no sistema era realizada pelo método gravimétrico. Para isso, o escoamento da solução de glicerina retornando para o reservatório aquecido era desviado para um pequeno reservatório de plástico cujo peso vazio era conhecido. O tempo para encher o reservatório era medido com um cronômetro e o reservatório pesado. A diferença do peso cheio e o peso vazio, dividida pelo tempo de enchimento, fornecia a vazão mássica desejada.

Após a conclusão de um dado ensaio, uma amostra da solução de glicerina e água era retirada e armazenada em um recipiente fechado para posterior caracterização de sua massa específica e viscosidade.

\section{2. \\ Redução dos Dados Para o Experimento de Queda de Pressão}

Os resultados de queda de pressão em função da vazão foram apresentados em termos do número de Reynolds e da queda de pressão adimensional. A seguir é descrito o procedimento de redução de dados utilizado para calcular os parâmetros de interesse do experimento.

\subsection{1.}

\section{Dados Medidos}

Os dados medidos durante um experimento típico estão relacionados na Tabela 4.1.

Tabela 4.1 - Relação dos dados medidos em cada experimento.

\footnotetext{
$T_{e}(i)$ - Temperatura da entrada da solução de glicerina em função do tempo.

$T_{s}(i)$ - Temperatura da saída da solução de glicerina em função do tempo.

$T_{r e}(i)$ - Temperatura da entrada da solução refrigeração em função do tempo.

$T_{r s}(i)$ - Temperatura da saída da solução de refrigeração em função do tempo.

$\Delta P(i) \quad$ - Diferencial de pressão entre as tomadas de pressão em função do tempo.

$m_{0} \quad$ - Massa do reservatório de pesagem vazio.

$m_{f} \quad$ - Massa do reservatório de pesagem cheio de solução de glicerina.

$\Delta t \quad$ - Tempo de enchimento do reservatório de pesagem.
} 
A temperatura média de entrada da solução de glicerina era calculada como:

$\bar{T}_{e}=\frac{1}{N} \sum_{1}^{N} T_{e}(i)$

onde $N$ representa ao número de registros de temperatura medidos após a obtenção da condição de regime permanente.

De maneira análoga para o cálculo das outras temperaturas médias e queda de pressão média:

$\bar{T}_{s}=\frac{1}{N} \sum_{1}^{N} T_{s}(i)$

$\bar{T}_{r e}=\frac{1}{N} \sum_{1}^{N} T_{r e}(i)$

$\bar{T}_{r s}=\frac{1}{N} \sum_{1}^{N} T_{r s}(i)$

$\Delta \bar{P}=\frac{1}{N} \sum_{1}^{N} \Delta P(i)$

A vazão mássica da solução de glicerina era obtida pelo processo gravimétrico como:

$\dot{m}=\frac{m_{f}-m_{0}}{\Delta t}$

A viscosidade da solução de glicerina era avaliada na entrada do tubo na temperatura média de entrada, $\bar{T}_{e}$, utilizando a curva medida para a solução utilizada, na forma apresentada na seção 6.1,

$\mu\left(\bar{T}_{e}\right)=\mu_{0} e^{\left(\frac{A}{\overline{\bar{T}}_{e}+B}\right)}$

A massa específica, condutividade térmica, calor específico e o coeficiente de expansão térmica na temperatura média de entrada, foram apresentados na 
seção 3.1. A partir das propriedades termofísicas do fluido de trabalho os adimensionais que governam o problema foram calculados.

O número de Prandtl para a solução de glicerina na temperatura da entrada foi obtido como,

$\operatorname{Pr}=\frac{\mu_{r e f} c_{p}}{k}$

O número de Reynolds avaliado nas condições da entrada do tubo foi calculado com base no diâmetro interno do tubo, $D_{i}$,

$$
\operatorname{Re}=\frac{4 \dot{m}}{\pi D_{i} \mu_{r e f}}
$$

A queda de pressão no escoamento medida foi adimensionalizada como,

$$
\Delta P^{*}=\frac{\Delta \bar{P}}{0,5 \rho_{r e f} \bar{u}_{e}^{2}}
$$

onde $\bar{u}_{e}$ é a velocidade média do fluido na entrada, calculada como,

$$
\bar{u}_{e}=\frac{4 \dot{m}}{\rho_{r e f} \pi D_{i}^{2}}
$$

Outros parâmetros adimensionais que governam o problema, mas que não foram variados ao longo dos experimentos, foram também calculados para servir de referência para futuras comparações com outros experimentos ou com soluções computacionais.

O número de Eckert foi calculado com as propriedades avaliadas na temperatura de entrada como,

$$
E c=\frac{\bar{u}_{e}^{2}}{c_{p}\left(\bar{T}_{e}-\bar{T}_{r s}\right)}
$$


O número de Grashof foi calculado para a posição horizontal do tubo com as propriedades avaliadas na temperatura de entrada como,

$G r=\frac{|\vec{g}| \beta\left(\bar{T}_{e}-\bar{T}_{r s}\right) D_{i}^{3}}{v^{2}}$

onde $|\vec{g}|$ é o módulo do vetor aceleração da gravidade local e $v$ e $\beta$ são respectivamente a viscosidade dinâmica e o coeficiente de expansão térmica da solução de glicerina.

O coeficiente de troca térmica adimensional é também um parâmetro do problema que, embora tenha sido mantido constante ao longo dos experimentos, não foi medido pois requer para sua determinação conhecimento dos valores dos coeficientes convectivos de troca de calor interno e externo, valores não disponíveis. De qualquer modo, a título de referência, foram adotados valores de correlações empíricas da literatura para a estimativa destes coeficientes de troca térmica, assim como valor da literatura para $k_{s}$, a condutividade do material da parede do tubo interno, o CPVC. Assim,

$U_{e f}^{*}=\frac{U_{e f} D_{i}}{k}$

onde,

$U_{e f}=\frac{1}{\frac{D_{i} / D_{e}}{h_{e}}+\frac{D_{i} \ln \left(D_{e} / D_{i}\right)}{2 k_{s}}}$

O comprimento adimensional entre os pontos de medição de pressão é também parâmetro não variado do problema, avaliado por $L / D_{i}$, com $L$ sendo a distância conhecida entre as tomadas de pressão.

Finalmente, os parâmetros adimensionais que caracterizam a dependência da viscosidade do fluido de trabalho com a temperatura, definidos nas equações 2.22, 2.23, 2.24 do Capítulo 2, devem ser informados. Como o fluido de trabalho não foi variado, estes parâmetros permaneceram constantes ao longo dos experimentos. 


$$
\begin{aligned}
& A^{*}=\frac{A}{\bar{T}_{e}-\bar{T}_{r s}} \\
& B^{*}=\frac{B-\bar{T}_{r s}}{\bar{T}_{e}-\bar{T}_{r s}} \\
& \mu_{0}^{*}=\frac{\mu_{0}}{\mu\left(\bar{T}_{e}\right)}
\end{aligned}
$$

\subsection{2.}

\section{Amostra de Cálculo}

Nesta seção é apresentada uma amostra dos procedimentos de cálculo utilizados para determinar os parâmetros adimensionais do problema, utilizando dados de uma corrida experimental típica.

Para um dado ponto a ser ensaiado, primeiramente esperava-se o experimento entrar em condição de regime permanente. Alcançado este patamar, então os dados eram medidos:

Tabela 4.2 - Relação dos dados medidos no experimento para um determinado caso típico.

\begin{tabular}{cc}
\hline $\bar{T}_{e}\left({ }^{\circ} \mathrm{C}\right)$ & 70,05 \\
$\bar{T}_{s}\left({ }^{o} \mathrm{C}\right)$ & 30,75 \\
$\bar{T}_{r e}\left({ }^{\circ} \mathrm{C}\right)$ & 4,72 \\
$\bar{T}_{r s}\left({ }^{o} \mathrm{C}\right)$ & 5,03 \\
$\Delta \bar{P}(P a)$ & $2,79 \times 10^{3}$ \\
$m_{0}(g)$ & 4,53 \\
$m_{f}(g)$ & 302,94 \\
$\Delta t(s)$ & 137
\end{tabular}

Os valores médios de temperatura e pressão apresentados na tabela acima foram calculados a partir de 100 amostras de dados, $N=100$, para o cálculo dos valores médios das temperaturas e pressão.

De posse desses dados, a vazão mássica e a viscosidade da solução de glicerina eram calculadas: 


$$
\begin{aligned}
& \dot{m}=\frac{m_{f}-m_{0}}{\Delta t}=2,18 \times 10^{-3} \mathrm{~kg} / \mathrm{s} \\
& \mu\left(\bar{T}_{e}\right)=\mu_{0} e^{\left(\frac{A}{\bar{T}_{e}+B}\right)}=7,90 \times 10^{-6} e^{\left(\frac{1777}{343,20-140,50}\right)}=5,07 \times 10^{-2} \text { Pa.s }
\end{aligned}
$$

A partir das propriedades termofísicas do fluido de trabalho, apresentadas na Tabela 3.1 e das propriedades geométricas da seção, $D_{i}=0,0118 m$, $D_{e}=0,0150 m$ e $L=2,840 m$, calculavam-se os adimensionais que governam o problema:

$$
\begin{aligned}
& \operatorname{Pr}=\frac{\mu c_{p}}{k}=\frac{0,0507 \times 2782}{0,29}=486 \\
& \operatorname{Re}=\frac{4 \dot{m}}{\pi D_{i} \mu}=\frac{4 \times 2,18 \times 10^{-3}}{3,14 \times 0,0118 \times 0,0507} \cong 4,6 \\
& \bar{u}_{e}=\frac{4 \dot{m}}{\rho \pi D_{i}^{2}}=\frac{4 \times 2,18 \times 10^{-3}}{1221 \times 3,14 \times 0,0118^{2}}=16,3 \times 10^{-3} \mathrm{~m} / \mathrm{s} \\
& \Delta P^{*}=\frac{\Delta \bar{P}}{0,5 \rho \bar{u}_{e}^{2}}=\frac{0,5 \times 1221 \times\left(16,3 \times 10^{-3}\right)^{2}}{0,79 \times 10^{3}}=1,72 \times 10^{4} \\
& E c=\frac{\bar{u}_{e}^{2}}{c_{p}\left(\bar{T}_{e}-\bar{T}_{r s}\right)}=\frac{\left(16,3 \times 10^{-3}\right)^{2}}{2782 \times(70,05-5,03)}=1,47 \times 10^{-9} \\
& G r=\frac{|\vec{g}| \beta\left(\bar{T}_{e}-\bar{T}_{r s}\right) D_{i}^{3}}{v^{2}}=\frac{9,81 \times 6,15 \times 10^{-4}(70,05-5,03) \times 0,0118^{3}}{(0,0507 / 1221)^{2}}=3,7 \times 10^{2}
\end{aligned}
$$

Para definição do coeficiente de troca térmica adimensional, foram adotados valores da literatura [14] para a estimativa do coeficiente convectivo de 
transferência de calor no espaço anular, $h_{e}$, assim com o valor da literatura para $k_{s}$ [11], a condutividade do material da parede do tubo interno, o CPVC. Assim,

$$
\begin{aligned}
U_{e f} & =\frac{1}{\frac{D_{i} / D_{e}}{h_{e}}+\frac{D_{i} \ln \left(D_{e} / D_{i}\right)}{2 k_{s}}}=\frac{1}{\frac{0,0118 / 0,015}{80}+\frac{0,0118 \times \ln (0,015 / 0,0118)}{2 \times 0,14}} \\
U_{e f} & =50,1 \mathrm{~W} / \mathrm{m}^{2} \mathrm{~K}
\end{aligned}
$$

Logo,

$$
U_{e f}^{*}=\frac{U_{e f} D_{i}}{k}=\frac{50,1 \times 0,0118}{0,29}=2,04
$$

O comprimento adimensional entre os pontos de medição de pressão é dado por:

$$
\frac{L}{D_{i}}=\frac{2,84}{0,0118}=241
$$

Por fim, os parâmetros adimensionais que caracterizam a dependência da viscosidade do fluido de trabalho com a temperatura:

$$
\begin{aligned}
& A^{*}=\frac{A}{\bar{T}_{e}-\bar{T}_{r s}}=\frac{1777}{70,05-5,03}=27,3 \\
& B^{*}=\frac{B-\bar{T}_{r s}}{\bar{T}_{e}-\bar{T}_{r s}}=\frac{-140,5-(5,03+273,15)}{70,05-5,03}=-6,4 \\
& \mu_{0}^{*}=\frac{\mu_{0}}{\mu\left(\bar{T}_{e}\right)}=\frac{7,9 \times 10^{-6}}{5,07 \times 10^{-4}}=1,6 \times 10^{-2}
\end{aligned}
$$




\section{3. Procedimento Experimental Para Medição de Perfis de Velocidade}

A medição dos perfis radiais de velocidade em diferentes posições axiais do duto foi realizada utilizando-se um sistema de velocimetria laser-Doppler, como descrito no capítulo 3.

O procedimento para estas medições era iniciado pela montagem da janela de visualização descrita no capítulo 3 na posição axial onde se desejava realizar as medições. Após montagem e verificação do alinhamento dos tubos com a janela de visualização, a seção de testes era preenchida com o fluido de trabalho e deixada estabilizar para atingir a condição de regime permanente, seguindo os mesmos procedimentos já descritos para as medições de queda de pressão.

Para o funcionamento adequado da técnica LDV é necessário que o fluido possua partículas traçadoras que espalhem a luz laser. Partículas traçadoras de $10 \mu \mathrm{m}$ de diâmetro foram distribuídas dentro do tanque de armazenagem de fluido quente e levadas pelo escoamento atingindo uma distribuição uniforme no fluido após algum tempo. Estas partículas são feitas de vidro, sendo ocas e recobertas com prata, garantem bom sinal para o LDV. A densidade destas partículas era da ordem de 1,5. A concentração destas partículas era bastante baixa de modo a não alterar as propriedades termofísicas da solução de glicerina. Tipicamente $5 \mathrm{~g}$ de partículas eram distribuídas nos cerca de 10 litros de solução de glicerina que preenchiam a seção de testes.

A sonda óptica do LDV era montada sobre uma mesa de coordenadas automatizada de dois eixos, um vertical e um paralelo ao eixo da seção de testes. O alinhamento cuidadoso da sonda era necessário para que a bissetriz do ângulo formado entre os dois feixes laser fosse ortogonal ao plano da abertura de acrílico por onde os feixes atingiam o interior do tubo interno. A Figura 4.1 apresenta uma vista dos feixes laser (1) passando pela janela plana (2). Após montado, o movimento vertical da mesa de coordenadas deslocava o volume de medição na direção radial dentro do tubo, possibilitando o levantamento do perfil de velocidade. 


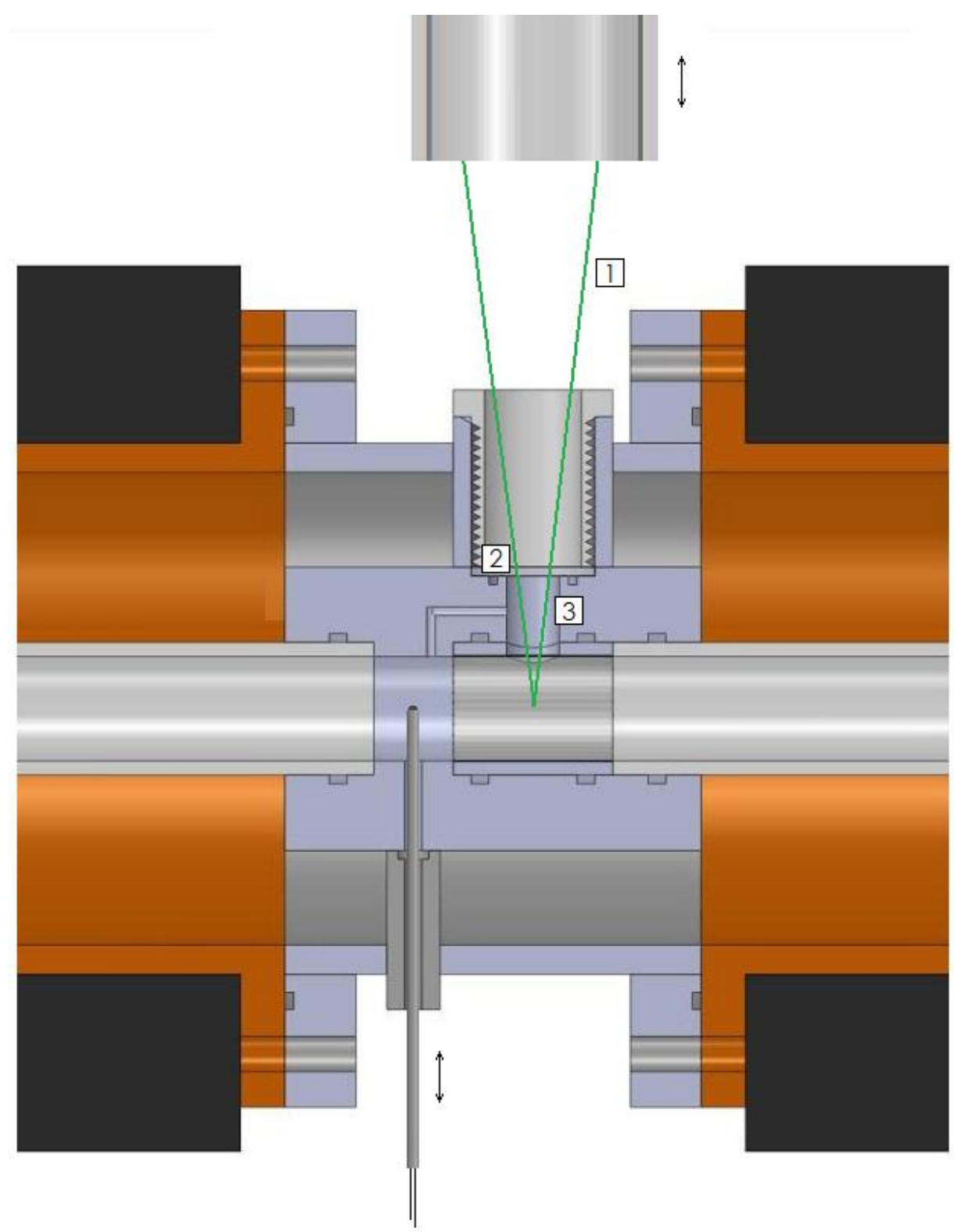

Figura 4.1 - Vista em corte da janela de visualização com a presença dos feixes laser da sonda LDV.

Para atingir o interior do tubo contendo a solução de glicerina, os feixes laser atravessam diversos meios ópticos, a saber, o ar do laboratório, a janela plana de acrílico, o corpo de solução de glicerina estagnada dentro do tubo circular e o filme fino transparente. Devido à refração pela passagem nestes meios e ao ângulo de entrada dos feixes característico da sonda LDV, um deslocamento vertical da sonda presa à mesa de coordenadas não corresponde ao mesmo deslocamento do volume de medição dentro da solução de glicerina no interior do tubo.

Uma correção para este efeito foi obtida pela aplicação da Lei de Snell, do conhecimento dos índices de refração de cada meio e do ângulo de incidência 
dos feixes. No cálculo, a refração pela passagem do feixe pelo filme foi desprezada devido à sua pequena espessura. Assim, como indica a Figura 4.2, a refração do feixe foi calculada considerando-se a passagem do ar para o acrílico e para a glicerina.

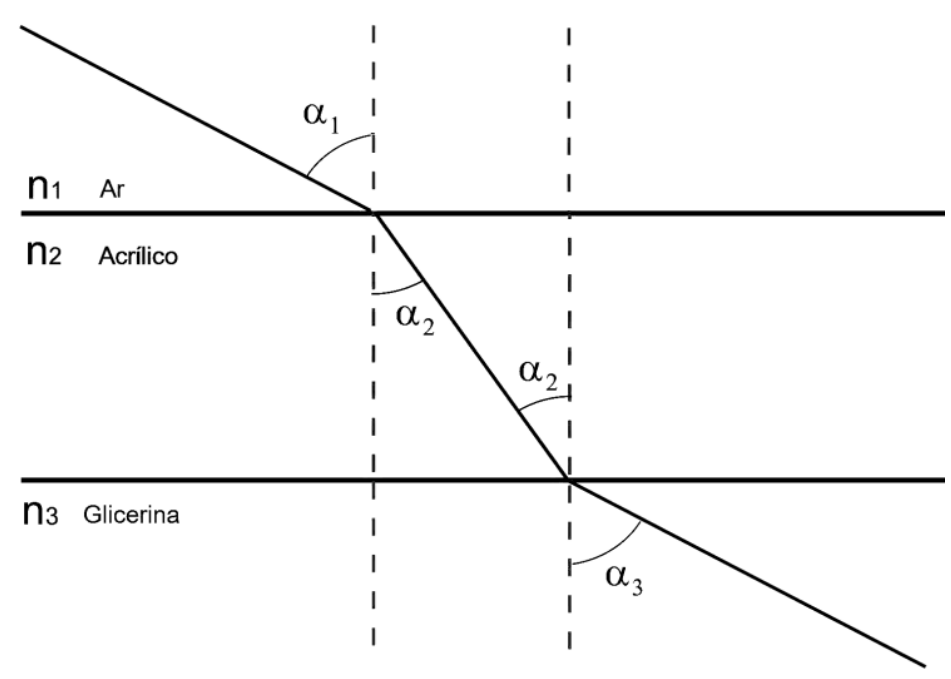

Figura 4.2 - Refração ocorrida nos feixes laser da sonda LDV até atingir a região de medição.

Os cálculos realizados utilizando o ângulo do feixe igual a 3,97graus, índice de refração do ar, do acrílico e da solução de glicerina iguais a, respectivamente, $1,000,1,492$ e 1,456 [12], indicaram que um deslocamento vertical da sonda de $1 \mathrm{~mm}$ corresponde a um deslocamento do volume de medição de $1,45 \mathrm{~mm}$ dentro do tubo com solução de glicerina, ou seja, para se medir o perfil de velocidade do escoamento no interior do tubo com $11,8 \mathrm{~mm}$ de diâmetro interno, era necessário um deslocamento vertical de $8,14 \mathrm{~mm}$ da sonda na mesa de coordenadas.

Outro ponto relevante para a determinação do perfil de velocidade está relacionado com a correta determinação da posição da parede interna do tubo. No presente trabalho adotou-se um procedimento para determinar a posição da parede interna no qual o volume de medição era posicionado na região central do tubo e a taxa de medição de velocidade pelo LDV era monitorada. A sonda era então cuidadosamente movimentada em direção à parede enquanto uma queda na taxa de medição era verificada. Esta queda é esperada e está relacionada com a diminuição do valor da velocidade nas regiões mais próximas à parede. Quando a posição da parede é atingida o sinal do LDV cessa. Esta 
posição foi registrada na mesa de coordenadas e tomada como referência para as medições do perfil de velocidade.

Em cada ponto de medição do perfil de velocidade eram medidos cerca de 1000 valores da velocidade axial. Como já mencionado, a taxa de medição (número de medidas de velocidade por segundo) variava com a posição do volume de medição no tubo. Para posições próximas às paredes do tubo, onde a taxa de medição era baixa, um tempo maior de medição era utilizado a fim de realizar mais medidas, no entanto caia para 100 a média de valores aquisitados em cada ponto desta região.

Após a armazenagem das medidas na memória do computador que controlava o LDV, as médias temporais dos registros medidos de velocidade instantânea em função do tempo eram computadas para cada posição radial medida.

Como forma de verificação da qualidade das medidas de perfil de velocidade realizadas, a vazão volumétrica cruzando a seção de medição era calculada pela integração numérica do perfil de velocidade medido e comparada com a vazão volumétrica do experimento medida pelo método gravimétrico. Neste procedimento de integração, assumiu-se simetria circunferencial do perfil de velocidade.

\section{4. Procedimento Experimental Para Medição de Perfis de Temperatura}

A medição dos perfis radiais de temperatura foi realizada utilizando-se a sonda de termopar descrita no capítulo 3. A sonda era introduzida na janela de visualização em posição diametralmente oposta àquela por onde os feixes laser penetravam, como indicado na Figura 4.1.

A principal etapa no procedimento adotado para a medição dos perfis de temperatura era a determinação da posição da parede interna do tubo, utilizada como referência para a posição da sonda de temperatura. Para a determinação da posição da parede, o parafuso micrométrico que movimentava a sonda era acionado no sentido de levar a junção de medição da sonda em direção à parede. A posição da parede podia ser sentida pelo endurecimento do movimento do micrômetro. Outra indicação que a posição da parede interna do tubo havia sido atingida podia ser obtida pelo acompanhamento da leitura da sonda de temperatura à medida que a sonda era movimentada. No experimento 
realizado, onde o fluido frio de refrigeração envolve o tubo interno, o ponto de menor valor da temperatura localiza-se na superfície interna da parede.

Após o posicionamento da sonda de temperatura na parede interna do tubo, iniciava-se o movimento de recuo da sonda pela movimentação do micrômetro. Em cada posição visitada, as leituras de temperatura eram registradas por um intervalo de tempo pré-definido no sistema de aquisição de dados. Devido às pequenas dimensões da junção da sonda de termopar, seu tempo de resposta era bastante baixo, o que levava a um rápido equilíbrio da leitura da sonda em uma dada posição axial. Tipicamente, informações de temperatura em cada posição radial eram registradas por cerca 30 segundos, o necessário para estabilização do sensor na posição.

Após o registro das leituras do perfil de temperatura pelo sistema de aquisição de dados, a média temporal da temperatura em cada ponto era computada.

A fim de confirmar que as medidas de temperatura não sofriam interferências externas causadas pelo procedimento adotado para o levantamento do perfil de temperatura, dois ensaios com base nos procedimentos descritos acima foram realizados, porém com o mecanismo de medição das temperaturas instalado por vez em posições radiais opostas, $0^{\circ} \mathrm{e}$ $180^{\circ}$. Quando a sonda estava instalada na posição $0^{\circ}$, as leituras de temperaturas próximas à parede inferior do tubo se davam com a sonda toda exposta às baixas temperaturas da solução refrigerante, e as medições realizadas nas regiões mais próximas à parede superior do tubo se davam com a sonda exposta às altas temperaturas do próprio escoamento da solução de glicerina. No entanto, quando o acesso era realizado pela posição radial $180^{\circ}$, o inverso ocorria, ou seja, as medidas realizadas próximo à parede inferior do tubo se davam com a sonda exposta às temperaturas altas da solução de glicerina, e as medidas de temperatura nas regiões mais próximas a parede superior do tubo se davam com a sonda exposta às baixas temperaturas da solução refrigerante do trocador de calor. A Figura 7.3Figura 4.3 mostra que os resultados obtidos para o perfil radial de temperatura extraído por ambas posições de acesso da sonda de medição, $0^{\circ}$ e $180^{\circ}$, apresentam uma boa concordância, eliminando qualquer suspeita quanto a interferência do procedimento experimental nos resultados. 


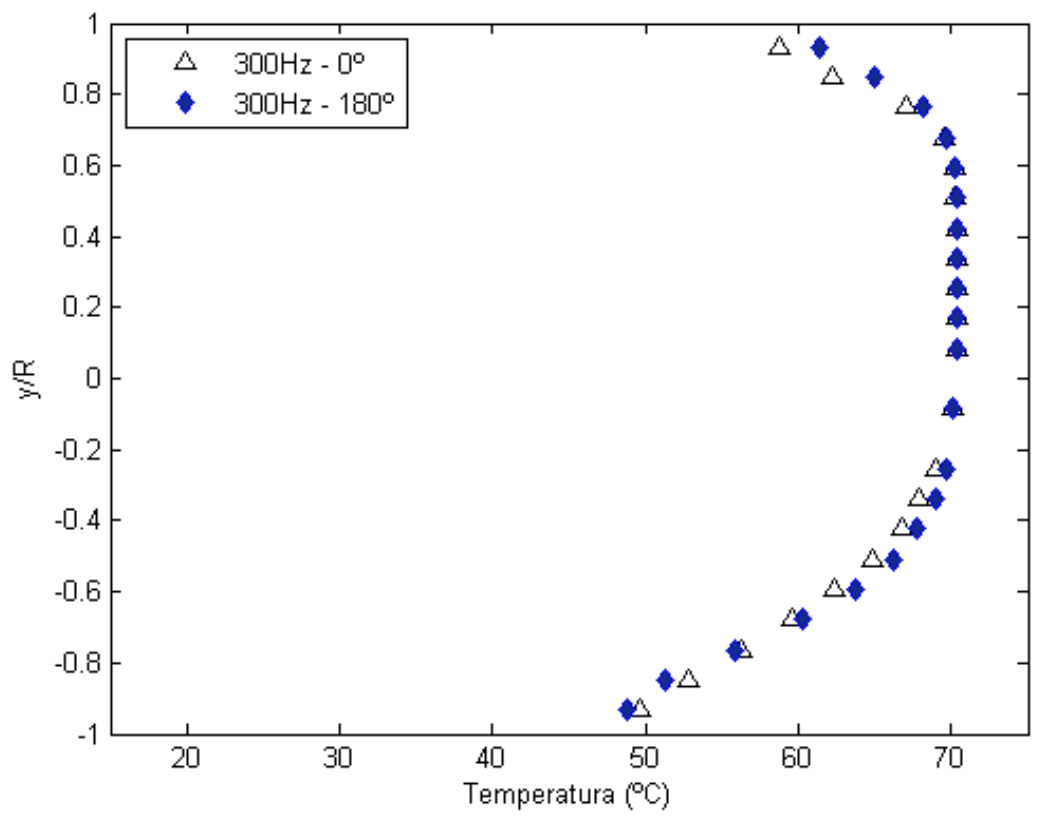

Figura 4.3 - Perfis radiais de temperatura da solução de glicerina para a coordenadas radias $0^{\circ}$ e $180^{\circ}$, para os mesmo valor da vazão. Temperatura de entrada da glicerina: $70^{\circ} \mathrm{C}$. Temperatura da água de refrigeração: $5^{\circ} \mathrm{C}$. 
5

\section{Resultados}

Nesse capítulo serão apresentados e analisados os resultados experimentais obtidos para a queda de pressão, perfis de temperatura e velocidade para o escoamento em duto horizontal de fluido com viscosidade dependente da temperatura. Para auxiliar na interpretação do comportamento térmico e hidrodinâmico do problema, os resultados experimentais serão comparados com soluções numéricas realizadas por outro grupo de pesquisadores que trabalham no projeto de pesquisa do qual o presente estudo fez parte. A fim de auxiliar a compreensão dos resultados, a figura abaixo apresenta esquematicamente algumas medidas características da seção de testes que serão recorrentemente referenciadas.

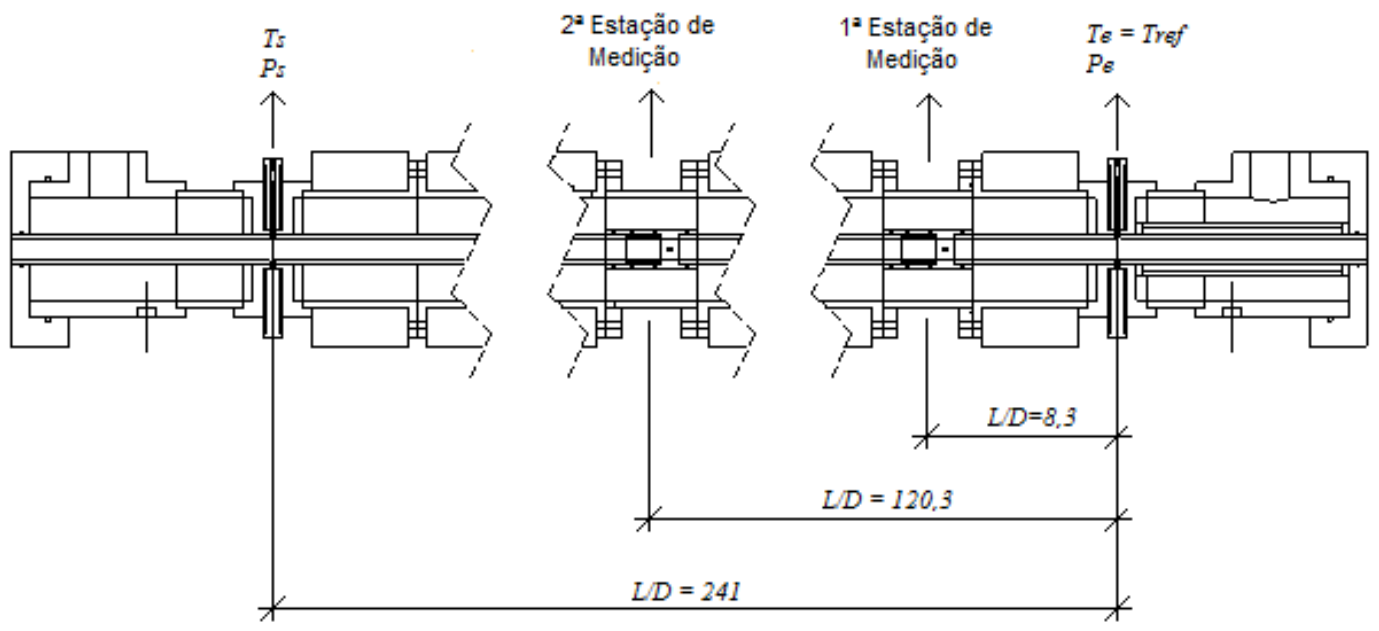

Figura 5.1 - Coordenadas dos principais pontos de medição da seção de testes.

\section{1.}

\section{Validação da Seção de Testes e Procedimento Experimental}

Testes preliminares foram realizados com o objetivo de validar a seção de testes construída, assim como os procedimentos experimentais adotados. $O$ teste selecionado para a validação foi um ensaio de medição da queda de pressão em função da vazão, para a condição de escoamento isotérmico. Para a condução deste teste a temperatura da solução de glicerina e do fluido de 
refrigeração foram ajustadas para o valor de $30^{\circ} \mathrm{C}$. Este valor foi escolhido por estar dentro da faixa de controle dos dois banhos termostáticos utilizados nos experimentos para definir as temperaturas da solução quente de glicerina e fria do fluido de refrigeração.

A comparação foi feita com a solução exata da equação de Navier-Stokes para escoamento laminar hidrodinamicamente desenvolvido em tubo,

$\Delta P_{\text {teórico }}=\frac{128 Q \mu_{\text {ref }} L}{\pi D^{4}}$

onde,

$Q=\frac{\dot{m}}{\rho_{\text {ref }}}$

A Tabela 5.1 apresenta os resultados obtidos nos testes de validação.

Tabela 5.1 - Comparação entre os resultados teóricos e experimentais para queda de pressão.

\begin{tabular}{cccccc}
\hline$Q(\mathrm{ml} / \mathrm{min})$ & $u(\mathrm{~m} / \mathrm{s})$ & $\operatorname{Re}$ & $\Delta P_{\text {té́rico }}(\mathrm{Pa})$ & $\Delta P_{\exp }(\mathrm{Pa})$ & Diferença $(\%)$ \\
$7,67 \times 10^{1}$ & $1,17 \times 10^{-2}$ & 0,32 & $4,14 \times 10^{3}$ & $3,95 \times 10^{3}$ & 4,64 \\
$1,01 \times 10^{2}$ & $1,54 \times 10^{-2}$ & 0,42 & $5,46 \times 10^{3}$ & $5.31 \times 10^{3}$ & 2,86 \\
$1,26 \times 10^{2}$ & $1,92 \times 10^{-2}$ & 0,52 & $6,79 \times 10^{3}$ & $6.64 \times 10^{3}$ & 2,29 \\
$1,53 \times 10^{2}$ & $2,33 \times 10^{-2}$ & 0,63 & $8,26 \times 10^{3}$ & $7.99 \times 10^{3}$ & 3,26 \\
$1,77 \times 10^{2}$ & $2,70 \times 10^{-2}$ & 0,73 & $9,57 \times 10^{3}$ & $9.35 \times 10^{3}$ & 2,32 \\
\hline
\end{tabular}

Os valores apresentados na tabela indicam que os resultados experimentais estão cerca de $3,5 \%$ abaixo dos resultados teóricos. Considerando-se os níveis de incertezas experimentais estimados no Apêndice A da ordem de $\pm 4 \%$ para as medidas da queda de pressão, a seção de testes construída e os procedimentos experimentais adotados podem ser considerados validados.

\section{2.}

\section{Resultados de Queda de Pressão}

Os resultados experimentais obtidos para a queda de pressão ao longo do tubo em função da vazão serão apresentados nesta seção. Estes resultados foram obtidos a partir de experimentos conduzidos com a solução de glicerina 
entrando no tubo a $70^{\circ} \mathrm{C}$, e com o fluido de refrigeração no exterior do tubo mantido a $5^{\circ} \mathrm{C}$. Um só fluido foi testado, sendo este a solução de $95 \%$ de glicerina e $5 \%$ de água. A manutenção destes parâmetros constantes, além da geometria da seção de testes que também não foi variada, implica que, dos dez parâmetros adimensionais que governam o problema, como mostrado no Capítulo 2, apenas a influência de um deles foi estudada: o número de Reynolds. Logo a influência deste parâmetro sobre a queda de pressão adimensional e a temperatura adimensional de saída do fluido foi o foco dos estudos do presente trabalho.

A Tabela 5.2 apresenta os resultados experimentais obtidos. Na tabela são indicadas a vazão volumétrica de cada experimento, a temperatura de saída do fluido e a queda de pressão medida entre as tomadas de pressão. Também estão indicados os valores de razões de parâmetros adimensionais, tais como aparecem nas equações adimensionalizadas apresentadas no Capítulo 2, o que fornece uma estimativa para a importância relativa de cada termo no problema em estudo.

Nos testes cujos resultados são apresentados na tabela, os seguintes valores de parâmetros adimensionais foram mantidos constantes: $\alpha=0^{\circ}$ (tubo horizontal), $\operatorname{Pr}=486, E c=1,47 \times 10^{-9}, G r=3,7 \times 10^{2}, L / D_{i}=241, A^{*}=27,3$, $B^{*}=-6,4$ e $\mu_{0}^{*}=1,6 \times 10^{-2}$. O coeficiente efetivo de troca térmica adimensional, $U_{e f}^{*}$, também foi mantido constante e com valor aproximado de 2,04. Neste cálculo utilizou-se um valor de $243 \mathrm{~W} / \mathrm{m}^{2} \mathrm{~K}$ para o coeficiente convectivo externo ao tubo, $h_{e}$, e de $0,14 \mathrm{~W} / \mathrm{mK}$ para a condutividade térmica $\left(k_{s}\right)$ do tubo de CPVC.

Os baixos valores observados para o parâmetro $E c / \mathrm{Re}$ indicam que os efeitos de dissipação viscosa são irrelevantes na faixa de parâmetros estudada. O parâmetro que controla a importância da convecção natural, $G r / \operatorname{Re}^{2}$, é visto como sendo decrescente, à medida que o número de Reynolds aumenta, indicando que para baixas vazões a convecção natural pode ter um papel importante no escoamento em estudo. 
Tabela 5.2 - Resultados experimentais para o escoamento da solução de 95\% glicerina e $5 \%$ de água. Temperatura de entrada da solução: $70^{\circ} \mathrm{C}$. Temperatura da água de refrigeração: $5^{\circ} \mathrm{C}$. Distância adimensional entre tomadas de pressão, $L / D_{i}=241$.

\begin{tabular}{|c|c|c|c|c|c|c|c|c|c|}
\hline \multicolumn{2}{|c|}{$Q(m l / \min )$} & $T_{\text {saida }}\left({ }^{\circ} \mathrm{C}\right)$ & $\Delta P(P a)$ & $\mathrm{Re}$ & $\operatorname{Re}(D / L)$ & $E c / \operatorname{Re}$ & $G r / \operatorname{Re}^{2}$ & $\theta_{s}$ & $\overline{\Delta P /\left(0,5 \rho u^{2}\right)}$ \\
\hline \multirow{10}{*}{ 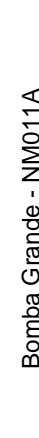 } & $1.42 \mathrm{E}+03$ & 69,28 & $7.19 \mathrm{E}+03$ & $6.17 \mathrm{E}+01$ & $2.56 \mathrm{E}-01$ & 4.24E-09 & $9.79 \mathrm{E}-02$ & $9.88 \mathrm{E}-01$ & $2.50 \mathrm{E}+02$ \\
\hline & $1.28 \mathrm{E}+03$ & 69,24 & $6.60 \mathrm{E}+03$ & $5.53 \mathrm{E}+01$ & $2.30 \mathrm{E}-01$ & 3.79E-09 & $1.22 \mathrm{E}-01$ & $9.87 \mathrm{E}-01$ & $2.85 \mathrm{E}+02$ \\
\hline & $1.13 \mathrm{E}+03$ & 69,13 & $6.07 \mathrm{E}+03$ & $4.89 \mathrm{E}+01$ & 2.03E-01 & 3.35E-09 & 1.56E-01 & $9.86 \mathrm{E}-01$ & $3.36 \mathrm{E}+02$ \\
\hline & $9.82 \mathrm{E}+02$ & 68,86 & $5.50 \mathrm{E}+03$ & $4.25 \mathrm{E}+01$ & 1.77E-01 & $2.91 \mathrm{E}-09$ & 2.07E-01 & $9.82 \mathrm{E}-01$ & $4.03 E+02$ \\
\hline & $8.71 \mathrm{E}+02$ & 68,65 & $5.07 \mathrm{E}+03$ & $3.77 \mathrm{E}+01$ & 1.57E-01 & 2.59E-09 & 2.62E-01 & $9.80 \mathrm{E}-01$ & $4.71 \mathrm{E}+02$ \\
\hline & $7.60 \mathrm{E}+02$ & 68,01 & $4.61 \mathrm{E}+03$ & $3.29 \mathrm{E}+01$ & 1.37E-01 & 2.25E-09 & 3.45E-01 & $9.68 \mathrm{E}-01$ & $5.63 \mathrm{E}+02$ \\
\hline & $6.49 \mathrm{E}+02$ & 67,30 & $4.18 \mathrm{E}+03$ & $2.81 \mathrm{E}+01$ & 1.17E-01 & 1.93E-09 & 4.72E-01 & 9.57E-01 & $7.00 \mathrm{E}+02$ \\
\hline & $5.39 \mathrm{E}+02$ & 65,85 & $3.71 \mathrm{E}+03$ & $2.33 E+01$ & $9.69 \mathrm{E}-02$ & $1.60 \mathrm{E}-09$ & 6.86E-01 & $9.35 \mathrm{E}-01$ & $9.01 \mathrm{E}+02$ \\
\hline & $4.65 \mathrm{E}+02$ & 64,31 & $3.43 E+03$ & $2.01 E+01$ & 8.37E-02 & $1.38 \mathrm{E}-09$ & $9.22 \mathrm{E}-01$ & $9.11 \mathrm{E}-01$ & $1.12 \mathrm{E}+03$ \\
\hline & $3.91 \mathrm{E}+02$ & 61,92 & $3.19 \mathrm{E}+03$ & $1.69 \mathrm{E}+01$ & 7.04E-02 & 1.16E-09 & $1.30 \mathrm{E}+00$ & $8.75 \mathrm{E}-01$ & $1.47 \mathrm{E}+03$ \\
\hline \multirow{18}{*}{ 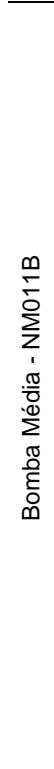 } & $4.29 \mathrm{E}+02$ & 63,59 & $3.32 \mathrm{E}+03$ & $1.86 \mathrm{E}+01$ & $7.71 \mathrm{E}-02$ & 1.27E-09 & $1.08 \mathrm{E}+00$ & $9.00 \mathrm{E}-01$ & $1.28 \mathrm{E}+03$ \\
\hline & $4.04 \mathrm{E}+02$ & 62,78 & $3.23 \mathrm{E}+03$ & $1.75 \mathrm{E}+01$ & 7.27E-02 & $1.20 \mathrm{E}-09$ & $1.22 \mathrm{E}+00$ & 8.89E-01 & $1.40 \mathrm{E}+03$ \\
\hline & $3.79 \mathrm{E}+02$ & 61,83 & $3.14 \mathrm{E}+03$ & $1.64 \mathrm{E}+01$ & $6.82 \mathrm{E}-02$ & 1.12E-09 & $1.39 \mathrm{E}+00$ & 8.73E-01 & $1.54 \mathrm{E}+03$ \\
\hline & $3.54 \mathrm{E}+02$ & 60,76 & $3.04 \mathrm{E}+03$ & $1.54 \mathrm{E}+01$ & $6.38 \mathrm{E}-02$ & $1.05 \mathrm{E}-09$ & $1.59 \mathrm{E}+00$ & 8.57E-01 & $1.71 \mathrm{E}+03$ \\
\hline & $3.30 \mathrm{E}+02$ & 59,57 & $2.98 \mathrm{E}+03$ & $1.43 \mathrm{E}+01$ & 5.93E-02 & $9.79 \mathrm{E}-10$ & $1.83 \mathrm{E}+00$ & 8.39E-01 & $1.93 E+03$ \\
\hline & $3.05 E+02$ & 58,05 & $2.93 \mathrm{E}+03$ & $1.32 \mathrm{E}+01$ & 5.49E-02 & $9.06 \mathrm{E}-10$ & $2.14 \mathrm{E}+00$ & 8.17E-01 & $2.22 \mathrm{E}+03$ \\
\hline & $2.80 \mathrm{E}+02$ & 56,50 & $2.86 \mathrm{E}+03$ & $1.21 \mathrm{E}+01$ & $5.04 \mathrm{E}-02$ & $8.31 \mathrm{E}-10$ & $2.54 \mathrm{E}+00$ & 7.91E-01 & $2.57 \mathrm{E}+03$ \\
\hline & $2.55 \mathrm{E}+02$ & 54,62 & $2.78 \mathrm{E}+03$ & $1.11 \mathrm{E}+01$ & 4.60E-02 & $7.58 \mathrm{E}-10$ & $3.05 \mathrm{E}+00$ & 7.62E-01 & $3.00 \mathrm{E}+03$ \\
\hline & $2.31 \mathrm{E}+02$ & 52,18 & $2.74 \mathrm{E}+03$ & $9.99 \mathrm{E}+00$ & 4.15E-02 & $6.85 \mathrm{E}-10$ & $3.74 \mathrm{E}+00$ & $7.25 \mathrm{E}-01$ & $3.62 \mathrm{E}+03$ \\
\hline & $2.06 \mathrm{E}+02$ & 49,54 & $2.69 \mathrm{E}+03$ & $8.92 \mathrm{E}+00$ & 3.71E-02 & $6.11 \mathrm{E}-10$ & $4.69 \mathrm{E}+00$ & $6.84 \mathrm{E}-01$ & $4.46 \mathrm{E}+03$ \\
\hline & $1.81 \mathrm{E}+02$ & 46,16 & $2.64 \mathrm{E}+03$ & $7.85 \mathrm{E}+00$ & 3.26E-02 & $5.38 \mathrm{E}-10$ & $6.06 \mathrm{E}+00$ & $6.33 \mathrm{E}-01$ & $5.68 \mathrm{E}+03$ \\
\hline & $1.57 \mathrm{E}+02$ & 42,21 & $2.63 \mathrm{E}+03$ & $6.78 \mathrm{E}+00$ & 2.82E-02 & 4.64E-10 & $8.14 \mathrm{E}+00$ & $5.71 \mathrm{E}-01$ & $7.58 \mathrm{E}+03$ \\
\hline & $1.32 \mathrm{E}+02$ & 37,06 & $2.69 \mathrm{E}+03$ & $5.71 \mathrm{E}+00$ & 2.37E-02 & $3.91 \mathrm{E}-10$ & $1.15 \mathrm{E}+01$ & 4.93E-01 & $1.09 \mathrm{E}+04$ \\
\hline & $1.07 \mathrm{E}+02$ & 30,75 & $2.80 \mathrm{E}+03$ & $4.64 \mathrm{E}+00$ & 1.93E-02 & 3.17E-10 & $1.74 \mathrm{E}+01$ & $3.96 \mathrm{E}-01$ & $1.72 E+04$ \\
\hline & $8.23 \mathrm{E}+01$ & 23,40 & $3.01 \mathrm{E}+03$ & $3.56 \mathrm{E}+00$ & $1.48 \mathrm{E}-02$ & $2.44 \mathrm{E}-10$ & $2.94 \mathrm{E}+01$ & 2.82E-01 & $3.13 E+04$ \\
\hline & $5.75 \mathrm{E}+01$ & 15,12 & $3.38 \mathrm{E}+03$ & $2.49 \mathrm{E}+00$ & $1.04 \mathrm{E}-02$ & $1.71 \mathrm{E}-10$ & $6.01 \mathrm{E}+01$ & $1.54 \mathrm{E}-01$ & $7.21 \mathrm{E}+04$ \\
\hline & $4.52 \mathrm{E}+01$ & 10,91 & $3.61 \mathrm{E}+03$ & $1.96 \mathrm{E}+00$ & $8.13 \mathrm{E}-03$ & $1.34 \mathrm{E}-10$ & $9.77 \mathrm{E}+01$ & $9.09 \mathrm{E}-02$ & $1.25 \mathrm{E}+05$ \\
\hline & $3.28 \mathrm{E}+01$ & 8,20 & $3.75 E+03$ & $1.42 \mathrm{E}+00$ & $5.90 \mathrm{E}-03$ & $9.74 \mathrm{E}-11$ & $1.85 \mathrm{E}+02$ & 4.88E-02 & $2.46 \mathrm{E}+05$ \\
\hline \multirow{10}{*}{ 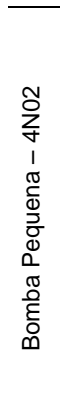 } & $5.75 \mathrm{E}+01$ & 15,13 & $3.39 \mathrm{E}+03$ & $2.49 \mathrm{E}+00$ & $1.03 \mathrm{E}-02$ & $1.70 \mathrm{E}-10$ & $6.03 \mathrm{E}+01$ & $1.56 \mathrm{E}-01$ & $7.24 \mathrm{E}+04$ \\
\hline & $5.32 \mathrm{E}+01$ & 13,64 & $3.43 \mathrm{E}+03$ & $2.30 \mathrm{E}+00$ & 9.57E-03 & $1.58 \mathrm{E}-10$ & $7.04 \mathrm{E}+01$ & 1.33E-01 & $8.56 \mathrm{E}+04$ \\
\hline & $4.89 \mathrm{E}+01$ & 12,26 & $3.38 \mathrm{E}+03$ & $2.12 \mathrm{E}+00$ & $8.79 \mathrm{E}-03$ & $1.45 \mathrm{E}-10$ & $8.35 \mathrm{E}+01$ & $1.12 \mathrm{E}-01$ & $1.00 \mathrm{E}+05$ \\
\hline & $4.45 \mathrm{E}+01$ & 10,82 & $3.52 \mathrm{E}+03$ & $1.93 \mathrm{E}+00$ & 8.02E-03 & $1.32 \mathrm{E}-10$ & $1.01 \mathrm{E}+02$ & $8.98 \mathrm{E}-02$ & $1.25 \mathrm{E}+05$ \\
\hline & $4.02 \mathrm{E}+01$ & 9,33 & $3.61 \mathrm{E}+03$ & $1.74 \mathrm{E}+00$ & $7.24 \mathrm{E}-03$ & 1.19E-10 & $1.23 \mathrm{E}+02$ & $6.78 \mathrm{E}-02$ & $1.57 \mathrm{E}+05$ \\
\hline & $3.59 \mathrm{E}+01$ & 8,04 & $3.74 \mathrm{E}+03$ & $1.55 \mathrm{E}+00$ & $6.46 \mathrm{E}-03$ & $1.06 \mathrm{E}-10$ & $1.55 \mathrm{E}+02$ & 4.82E-02 & $2.05 \mathrm{E}+05$ \\
\hline & $3.16 \mathrm{E}+01$ & 6,96 & $3.78 \mathrm{E}+03$ & $1.37 \mathrm{E}+00$ & $5.68 \mathrm{E}-03$ & $9.34 \mathrm{E}-11$ & $2.00 \mathrm{E}+02$ & 3.13E-02 & $2.67 \mathrm{E}+05$ \\
\hline & $2.72 \mathrm{E}+01$ & 6,01 & $3.82 \mathrm{E}+03$ & $1.18 \mathrm{E}+00$ & 4.90E-03 & $8.06 \mathrm{E}-11$ & $2.69 \mathrm{E}+02$ & 1.67E-02 & $3.63 E+05$ \\
\hline & $2.29 \mathrm{E}+01$ & 5,25 & $3.68 \mathrm{E}+03$ & $9.93 \mathrm{E}-01$ & 4.12E-03 & $6.78 \mathrm{E}-11$ & $3.80 \mathrm{E}+02$ & 5.77E-03 & $4.94 \mathrm{E}+05$ \\
\hline & $1.86 \mathrm{E}+01$ & 4,85 & $3.36 \mathrm{E}+03$ & $8.05 \mathrm{E}-01$ & 3.35E-03 & $5.50 \mathrm{E}-11$ & $5.78 \mathrm{E}+02$ & $6.14 \mathrm{E}-05$ & $6.86 \mathrm{E}+05$ \\
\hline
\end{tabular}


Os resultados mostrados na Tabela 5.2 são apresentados em forma gráfica na Figura 5.2. Nesta figura optou-se por uma primeira apresentação das variáveis com dimensões para que os níveis de pressão e vazão pudessem ser avaliados. Assim, a queda de pressão entre as tomadas de pressão dada em $P a$, é apresentada como função da vazão volumétrica da solução de glicerina dada em $\mathrm{ml} / \mathrm{min}$. Escalas logarítmicas foram utilizadas.

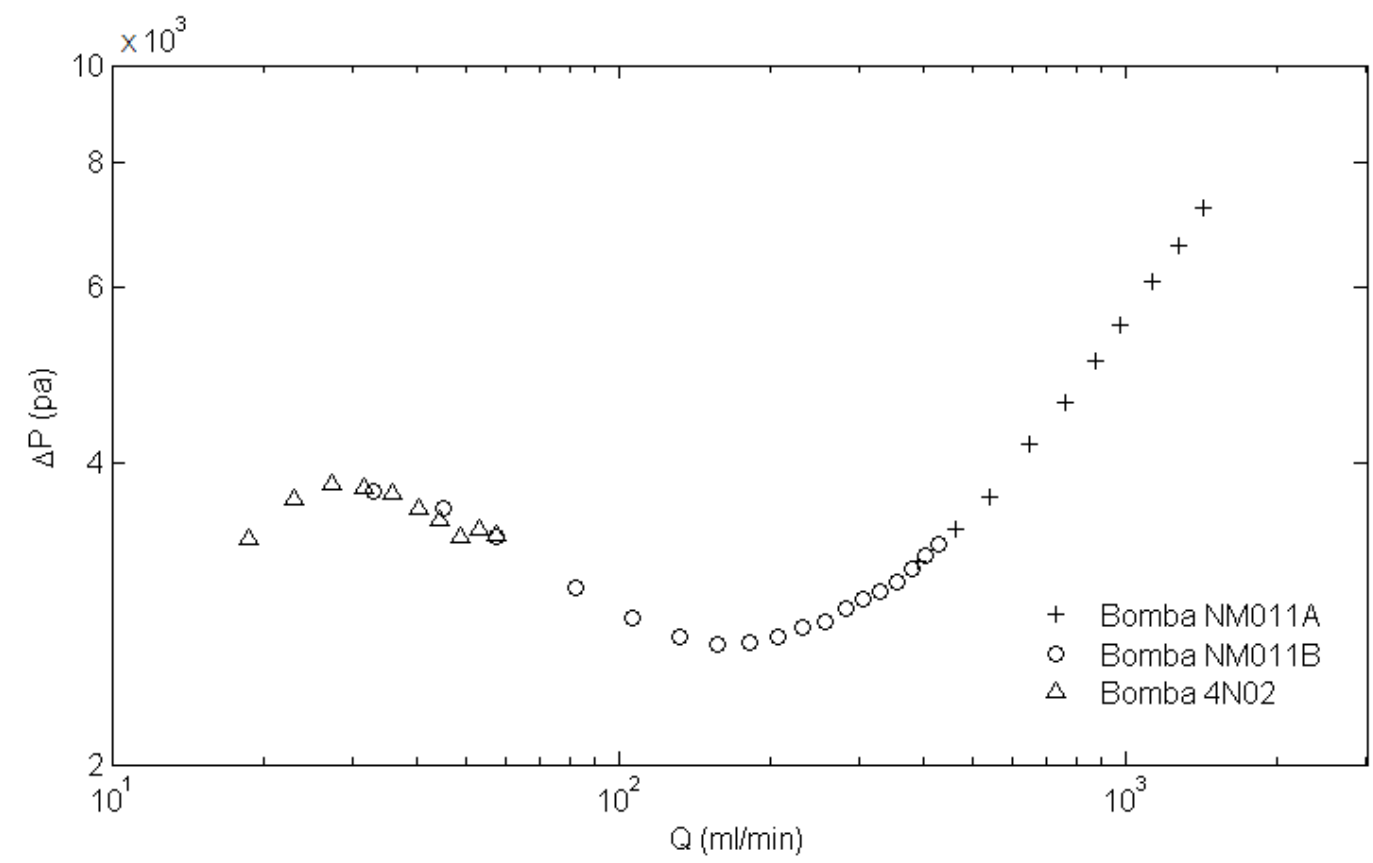

Figura 5.2 - Resultados experimentais para a queda de pressão em função da vazão para o escoamento da solução de glicerina. Temperatura de entrada da glicerina: $70^{\circ} \mathrm{C}$. Temperatura do fluido de refrigeração: $5^{\circ} \mathrm{C} . L / D_{i}=241$.

Três conjuntos de pontos são indicados na Figura 5.2 representados por diferentes símbolos, correspondendo a vazões obtidas com as três bombas de cavidades progressivas utilizadas nos ensaios. A faixa de vazão correspondente a cada bomba está indicada também no lado esquerdo da Tabela 5.2. Esta distinção das vazões obtidas com cada bomba foi incluída na apresentação para comprovar que os mesmos resultados eram obtidos com diferentes bombas, como pode ser atestado pela observação das regiões de superposição de vazões. Esta foi uma verificação adicional da seção de testes e procedimentos experimentais adotados.

Uma observação geral dos resultados apresentados na Figura 5.2 indica que a variação da viscosidade do fluido ao longo do escoamento altera completamente o comportamento da queda de pressão em função da vazão, 
quando comparado ao escoamento hidrodinamicamente desenvolvido. A curva apresentada desvia-se significativamente da relação linear e monotônica esperada para o escoamento laminar desenvolvido.

Uma análise mais detalhada dos resultados da Figura 5.2 revela informações relevantes sobre aspectos físicos do problema em estudo.

Para a região de altas vazões, observa-se uma dependência linear entre a queda de pressão e a vazão, um comportamento característico dos escoamentos hidrodinamicamente desenvolvidos onde a viscosidade é independente da temperatura. De fato, nesta região de altas vazões espera-se que a temperatura do fluido permaneça aproximadamente constante ao longo do tubo devido às taxas de troca de calor por convecção axial serem predominantes quando comparadas ao fluxo radial. Assim, a quase totalidade do escoamento se dá com a solução de glicerina a temperatura constante e, portanto, sem efeito de variação de viscosidade.

No outro extremo da figura, na faixa de vazões mais baixas, espera-se também uma relação linear entre a queda de pressão e a vazão. Neste caso, a perda de calor para o ambiente domina, pois a convecção axial é baixa e o fluido no interior da tubulação atinge o valor da temperatura próxima a do ambiente externo na região próxima à entrada do duto. Infelizmente, as vazões necessárias para verificar esta tendência estão abaixo dos valores que poderiam ser atingidos de forma estável com a menor bomba disponível. Os resultados computacionais que serão apresentados mais adiante comprovam a expectativa da dependência linear para a queda de pressão e a vazão na faixa de baixas vazões. Os resultados apresentados na figura encaminham-se para este comportamento linear, mas não chegam a demonstrá-lo. Uma vez que nesta faixa de vazões muito baixas, a temperatura do fluido ao longo do comprimento do tubo é também constante e próxima da temperatura fria externa, a viscosidade se mantém constante ao longo de grande parte do escoamento e a relação linear característica do escoamento desenvolvido é obtida.

É na região de vazões intermediárias que a relação entre queda de pressão e vazão deixa de ser linear. Nesta faixa de vazões, para as condições do experimento em questão, há variações significativas na temperatura do fluido ao longo do comprimento do tubo, o que implica numa correspondente variação axial e radial da viscosidade do fluido, impedindo que o regime de escoamento hidrodinamicamente desenvolvido se estabeleça. Como pode ser observado pelas duas inflexões apresentadas na curva de vazão em função da queda de pressão, é possível nesta região intermediária obter-se o mesmo valor da queda 
de pressão para valores da vazão diferindo em ordens de grandeza, um comportamento que contrariaria o resultado de uma análise menos aprofundada do problema. Na prática, isso pode causar problemas no controle e operação de linhas de transporte de óleos.

Como pode ser observado nos resultados apresentados, os experimentos conduzidos em escala reproduziram o comportamento de campo reportado pelos operadores de linhas isoladas submarinas para a transferência de óleos viscosos, comportamento que motivou o presente estudo.

A Figura 5.3 apresenta os mesmos resultados experimentais apresentados na Figura 5.2, porém utilizando as variáveis adimensionais. $\mathrm{Na}$ abscissa foi utilizado o parâmetro $\operatorname{Re} D / L$ por sugestão do trabalho de [7]. Naquele trabalho de simulação numérica, mostrou-se que resultados para diferentes valores do comprimento adimensional do tubo, $L / D$, são bem correlacionados quando apresentados em termos do chamado número de Reynolds reduzido, $\operatorname{Re} D / L$. No presente trabalho adotamos o mesmo adimensional, apesar de não termos realizados testes com outros valores de $L / D$.

As mesmas observações feitas em relação ao comportamento da queda de pressão em função da vazão para a apresentação na forma dimensional dos resultados da Figura 5.2 se aplicam aos resultados adimensionais da Figura 5.3.

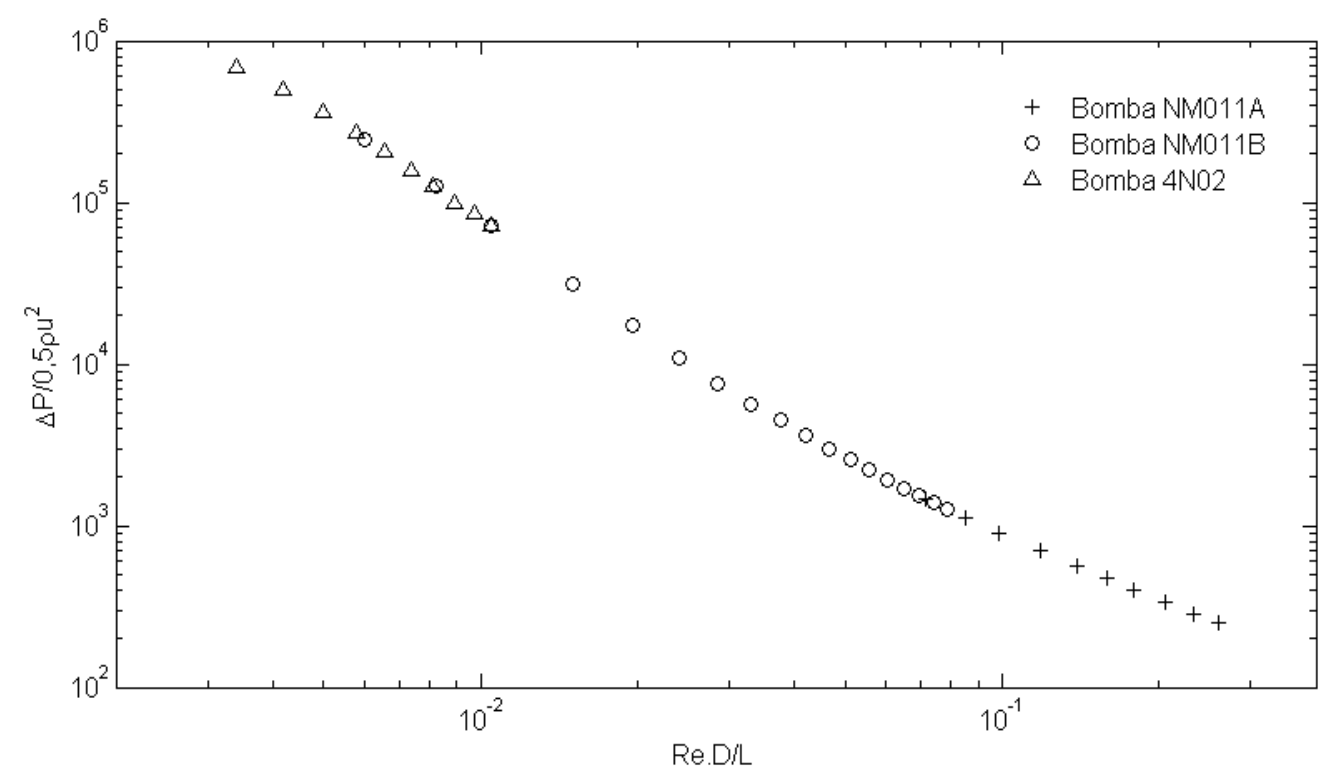

Figura 5.3 - Resultados adimensionais medidos de vazão versus queda de pressão para o escoamento de glicerina. Temperatura de entrada da glicerina igual a $70^{\circ} \mathrm{C}$. Temperatura da água de refrigeração igual a $5^{\circ} \mathrm{C} . L / D_{i}=241$. 


\section{3.}

\section{Resultado de Temperatura de Saída da Solução de Glicerina}

A temperatura da solução de glicerina na região próxima a seção de saída do escoamento foi monitorada por um único sensor de temperatura posicionado na linha de centro do tubo. Os resultados obtidos para a variação desta temperatura com a vazão são apresentados nas Figuras 6.3 e 6.4, respectivamente, em forma dimensional e adimensional. Estas informações sobre a temperatura de saída podem ser úteis para a verificação de simulações computacionais do problema.

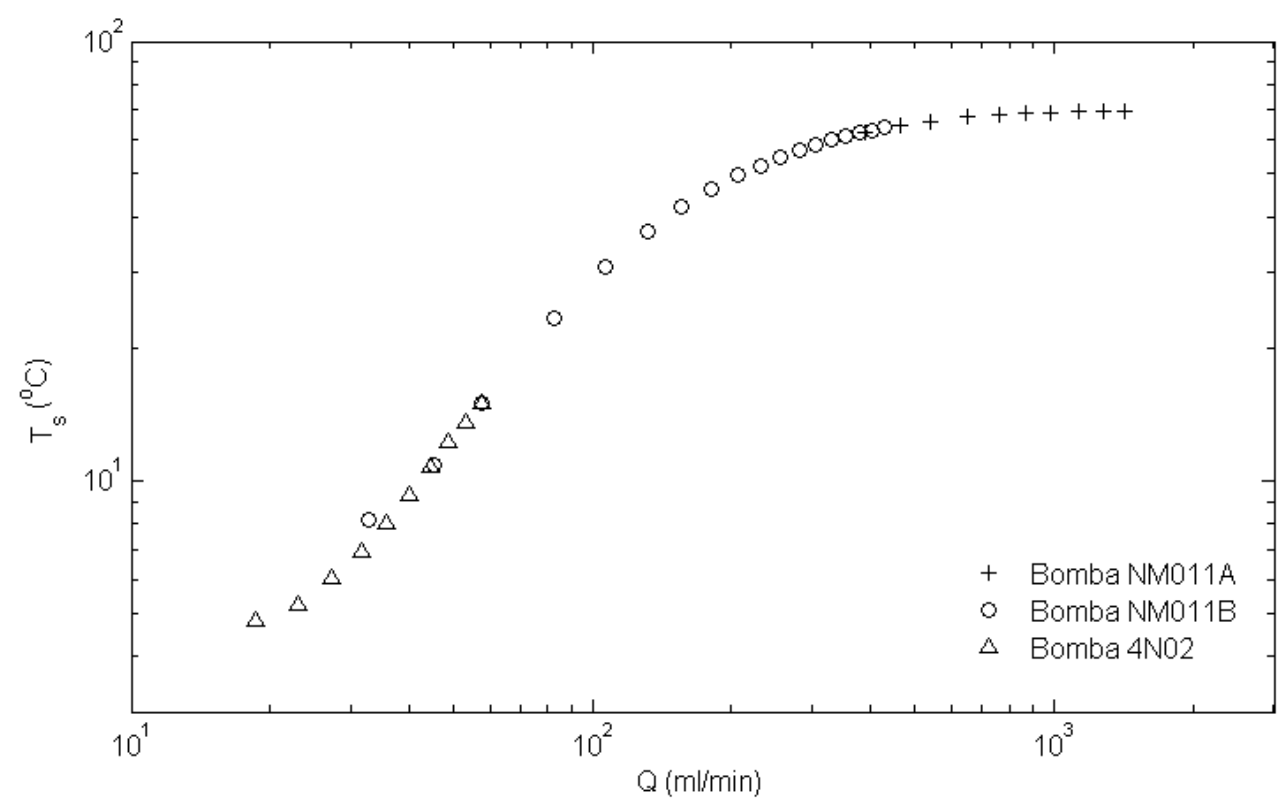

Figura 5.4 - Temperatura de saída da solução de glicerina medida no centro do tubo em função da vazão. Temperatura de entrada da glicerina: $70^{\circ} \mathrm{C}$. Temperatura da água de refrigeração: $5^{\circ} \mathrm{C} . L / D_{i}=241$. 


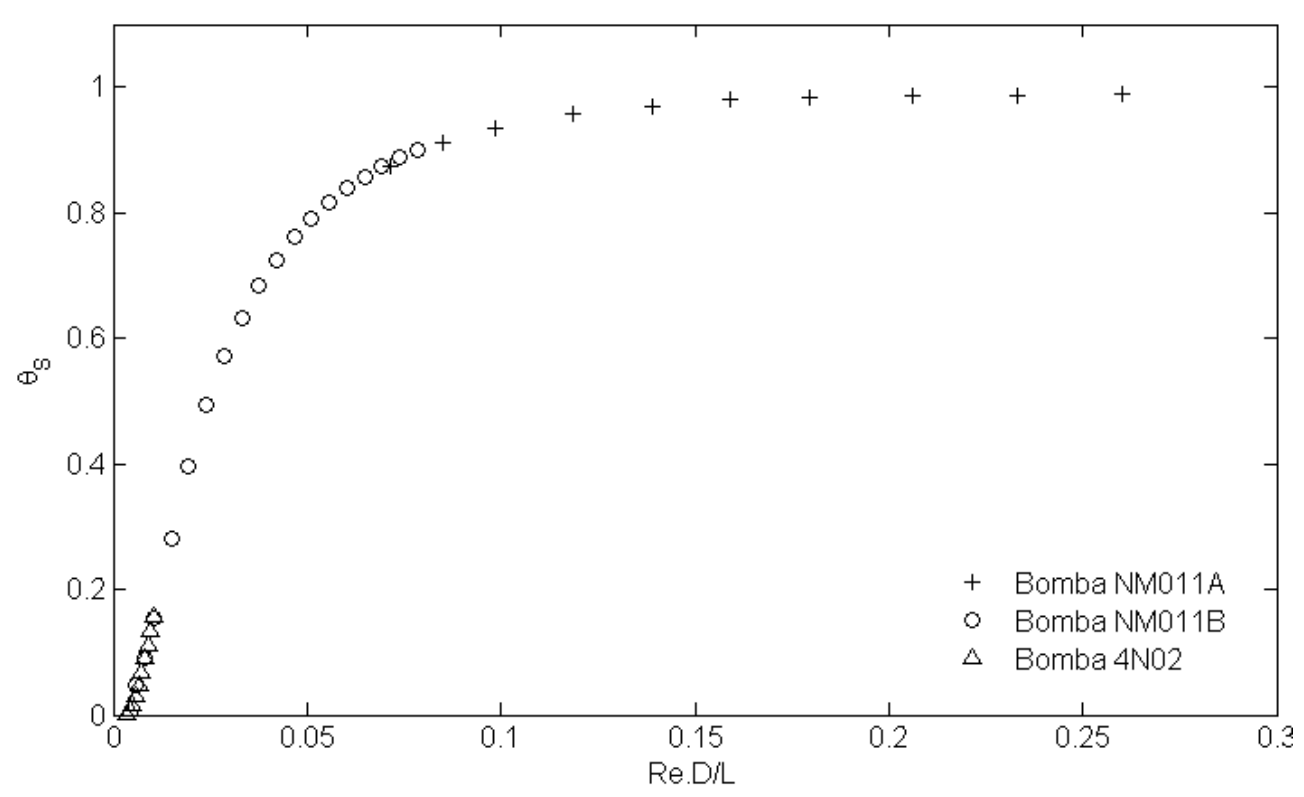

Figura 5.5 - Temperatura adimensional de saída da solução de glicerina medida no centro do tubo em função da vazão. Temperatura de entrada da glicerina: $70^{\circ} \mathrm{C}$. Temperatura da água de refrigeração: $5^{\circ} \mathrm{C} . L / D_{i}=241$.

A análise dos resultados apresentados nas Figuras 5.4 e 5.5 comprova os argumentos apresentados quando da interpretação dos resultados de queda de pressão, indicando que para altas vazões a temperatura de saída da solução tende ao valor da temperatura de entrada da solução, e que para vazões baixas a temperatura de saída se aproxima da temperatura do meio externo.

\section{4 .}

Resultados dos Perfis de Temperatura e Velocidade

Os resultados para os perfis radiais de temperatura e velocidade medidos com a sonda de termopar e a técnica de velocimetria laser-Doppler, serão apresentados nesta seção. Os perfis de velocidade e temperatura foram medidos para duas posições axiais ao longo do tubo $x=98$ e $1420 \mathrm{~mm}$, posições medidas a partir da seção de entrada. Estes valores correspondem às posições axiais adimensionais $x / D_{i}=8,3$ e 120,3 . 


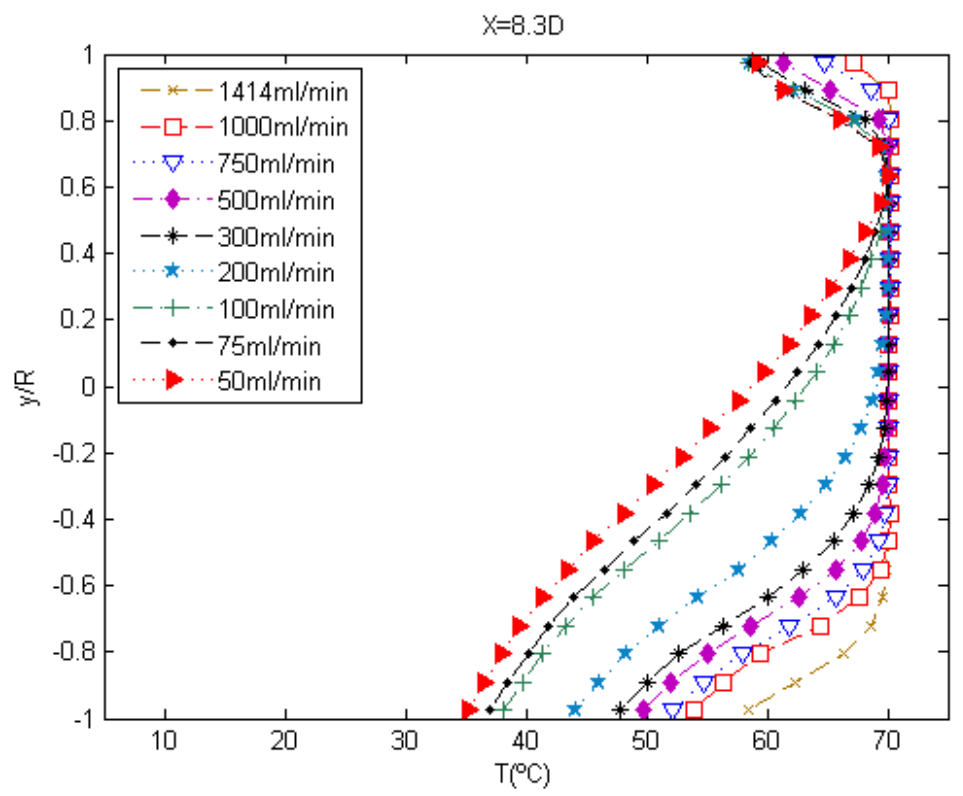

Figura 5.6 - Perfis radiais de temperatura da solução de glicerina para a coordenada axial $x=98 \mathrm{~mm}\left(x / D_{i}=8,3\right)$, para diferentes valores da vazão. Temperatura de entrada da glicerina: $70^{\circ} \mathrm{C}$. Temperatura da água de refrigeração: $5^{\circ} \mathrm{C}$.

A Figura 5.6 apresenta o resultado das medidas dos perfis radiais de temperatura para a coordenada axial $x=98\left(x / D_{i}=8,3\right)$, para valores da vazão volumétrica da solução de glicerina variando de 50 a $1414 \mathrm{ml} / \mathrm{min}$, o que corresponde a uma variação no número de Reynolds de 2 a 62 . No gráfico, a temperatura do fluido em graus Celsius é apresentada em função da coordenada radial $y / R$, onde $R$ é o raio interno do tubo. É importante ressaltar que este perfil, assim como os outros que são apresentados neste capítulo, foram medidos no plano diametral vertical do tubo.

A principal informação apresentada pelos resultados da Figura 5.6 diz respeito à forte assimetria em relação ao eixo do tubo $(y / R=0)$ apresentada pelos perfis de temperatura, para toda a faixa de vazões investigada. Observando-se, por exemplo, o perfil de temperatura para a menor vazão, $50 \mathrm{ml} / \mathrm{min}(\operatorname{Re}=2)$, verifica-se que a temperatura varia de cerca de $35^{\circ} \mathrm{C}$ junto à parede inferior do tubo, até $60^{\circ} \mathrm{C}$ junto à parede superior. Para esse caso, a posição onde a temperatura assume seu máximo valor encontra-se em um pico pronunciado localizado em $y / R=0,7$, que fica na parte superior do tubo. À medida que a vazão aumenta, nota-se uma tendência à diminuição da assimetria dos perfis de temperatura. No entanto, mesmo para o máximo valor de vazão 
investigado, $1414 \mathrm{ml} / \mathrm{min}(\mathrm{Re}=62)$, a temperatura varia de cerca de $58^{\circ} \mathrm{C}$ na parede inferior até $68^{\circ} \mathrm{C}$ na parede superior. Para a vazão máxima, não é mais observado um pico pronunciado no perfil de temperatura que se apresenta plano na maior parte da seção do tubo. Nesse caso, gradientes acentuados são notados somente nas regiões próximas às paredes. Cabe ressaltar também que a temperatura máxima em todos os casos foi de aproximadamente $70^{\circ} \mathrm{C}$, o que corresponde à temperatura de entrada da glicerina na seção de testes.

Com base nos perfis de temperatura é possível estimar os valores de viscosidade da solução de glicerina ao longo do raio do duto, conforme mostrado na Figura 5.7. Para este cálculo utilizou-se a equação 3.1, que modela o comportamento da viscosidade da glicerina. As constantes da equação foram obtidas seguindo o mesmo procedimento já descrito no Capítulo 3. Nota-se um comportamento inverso ao da variação da temperatura, de modo que os valores de viscosidade mais elevados ocorrem nas regiões próximas à parede inferior. No caso de vazão mais baixa a viscosidade atinge valores próximos a 1 Pa.s na parede inferior, enquanto que no meio da tubulação o valor é quase 10 vezes menor. Isso mostra um elevado gradiente de viscosidade ao longo do perfil, o que, em princípio, pode causar distorções no perfil de velocidade.

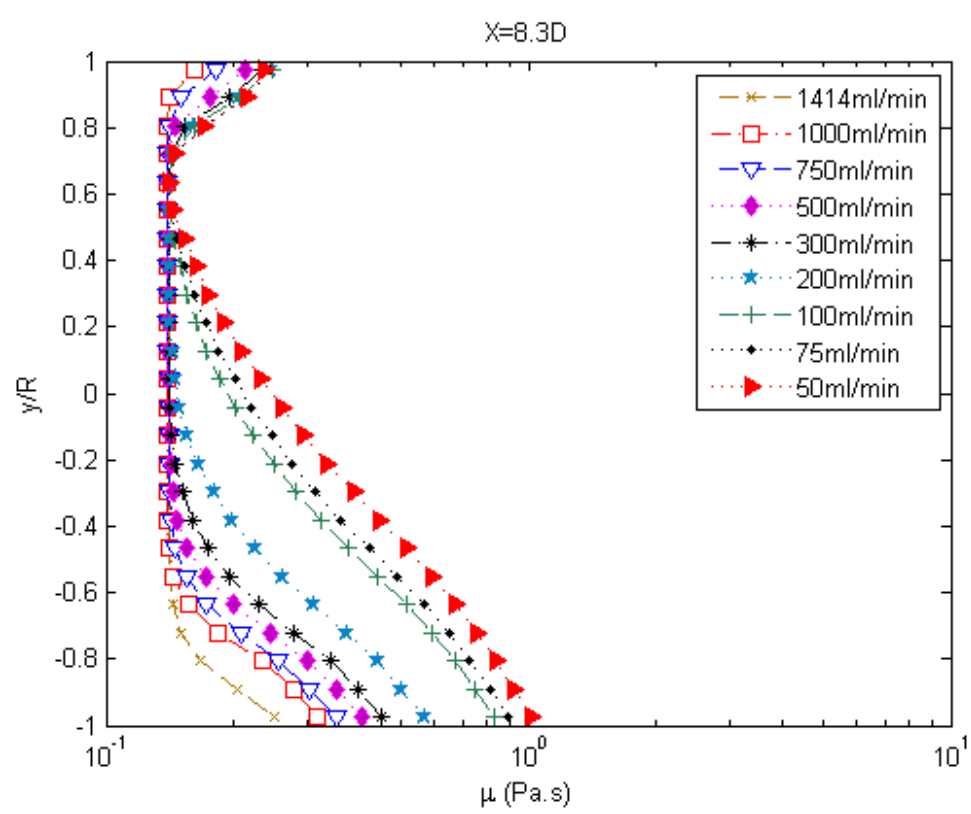

Figura 5.7 - Perfis radiais de viscosidade da solução para a coordenada axial $x=98 \mathrm{~mm}$ $\left(x / D_{i}=8,3\right)$, para diferentes valores da vazão. Temperatura de entrada da glicerina: $70^{\circ} \mathrm{C}$. Temperatura da água de refrigeração: $5^{\circ} \mathrm{C}$. 
Conjectura-se que a assimetria nos perfis de temperatura seja atribuída à presença de escoamentos secundários na seção transversal induzidos por convecção natural. O fluido em contato com as paredes frias do tubo tem sua densidade aumentada movimentando-se em direção à parte mais baixa do duto. Já na região central, mais aquecida, o movimento é ascendente indo pela parte central até a geratriz superior do tubo. A Figura 5.8 ilustra esse mecanismo. Estas correntes circulares têm como efeito o aquecimento do fluido na parte superior do tubo e o resfriamento na parte inferior, como indicam os perfis de temperatura medidos.

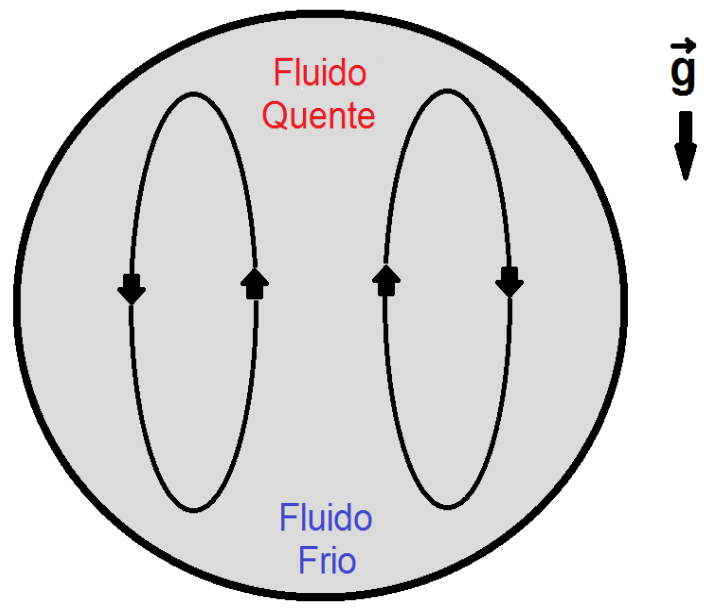

Figura 5.8 - Desenho esquemático das correntes induzidas pela convecção natural devido ao resfriamento do fluido pelas paredes do tubo.

Na coordenada axial $x=1420\left(x / D_{i}=120,3\right)$, os perfis apresentados na Figura 5.9(a) mostram um aumento da variação de temperatura quando comparados com a região mais próxima à entrada. Nos casos de vazão mais baixa o nível de temperatura foi reduzido devido à maior exposição à troca de calor com as paredes frias do duto, de modo que no caso de vazão mais baixa (50 $\mathrm{ml} / \mathrm{min}$ ) a maior temperatura medida foi de aproximadamente $30^{\circ} \mathrm{C}$. Consequentemente, os gradientes radiais de temperaturas também sofreram uma redução considerável. Tal comportamento é mais facilmente observado na Figura 5.9(b), que mostra a variação em relação à maior temperatura do perfil $\left(T_{\max }\right)$. Nessa figura nota-se claramente que a diferença entre $T_{\max }$ e a temperatura na parede inferior aumenta com a redução da vazão até aproximadamente $200-300 \mathrm{ml} / \mathrm{min}$, abaixo disso a diferença de temperatura 
cai e atinge o menor valor para a vazão de $50 \mathrm{ml} / \mathrm{min}$. Esse comportamento é diferente daquele observado na primeira estação, onde a diferença de temperatura aumentou à medida que se reduziu as vazões.

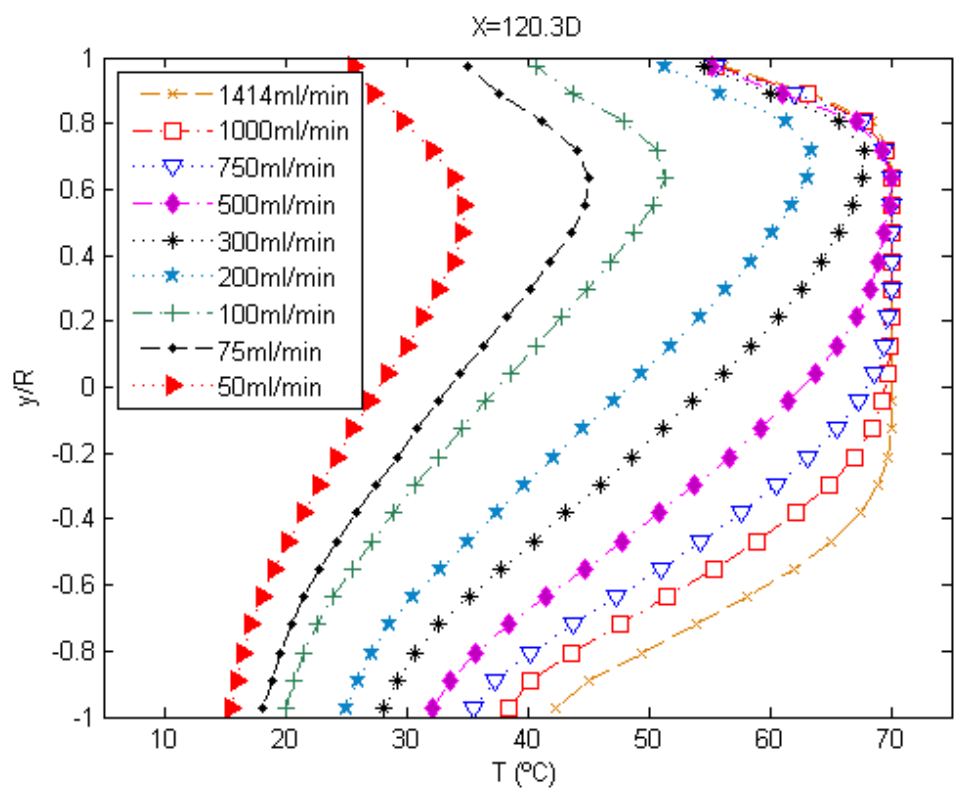

(a)

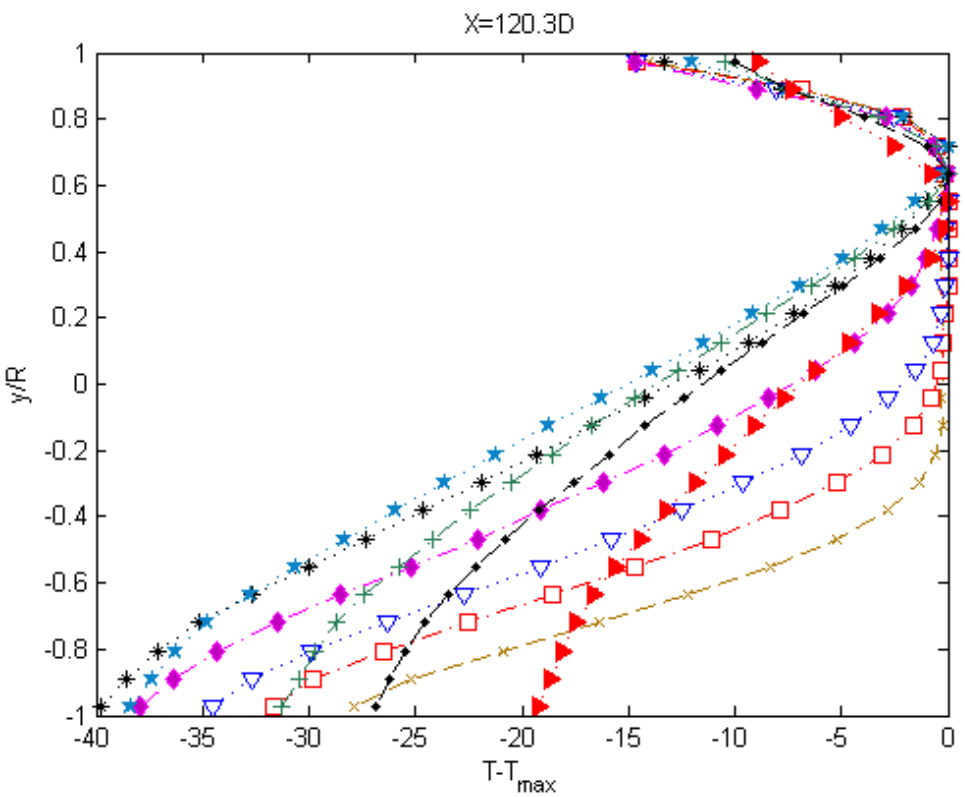

(b)

Figura 5.9 - Perfis radiais de temperatura da solução de glicerina para a coordenada axial $x=1420 \mathrm{~mm}\left(x / D_{i}=120,3\right)$ e para diferentes valores da vazão. Figura (a): Temperatura total medida. Figura (b): Variação em relação a máxima temperatura do perfil. Temperatura de entrada da glicerina: $70^{\circ} \mathrm{C}$. Temperatura da água de refrigeração: $5^{\circ} \mathrm{C}$. 
A influência da variação de temperatura sobre o perfil de viscosidade pode ser observada através da Figura 5.10, para a posição $x / D_{i}=120,3$. Nesta estação os valores de viscosidade são consideravelmente maiores do que aqueles obtidos na entrada. $\mathrm{Na}$ parede inferior a viscosidade varia de aproximadamente 0,65 a 5 Pa.s para os casos de maior e menor vazão, respectivamente. Ainda que os gradientes de temperatura tenham sido afetados devido à redução do nível de temperatura, a viscosidade média ao longo do perfil continua aumentando à medida que se reduz a vazão, comportamento similar ao observado próximo à entrada.

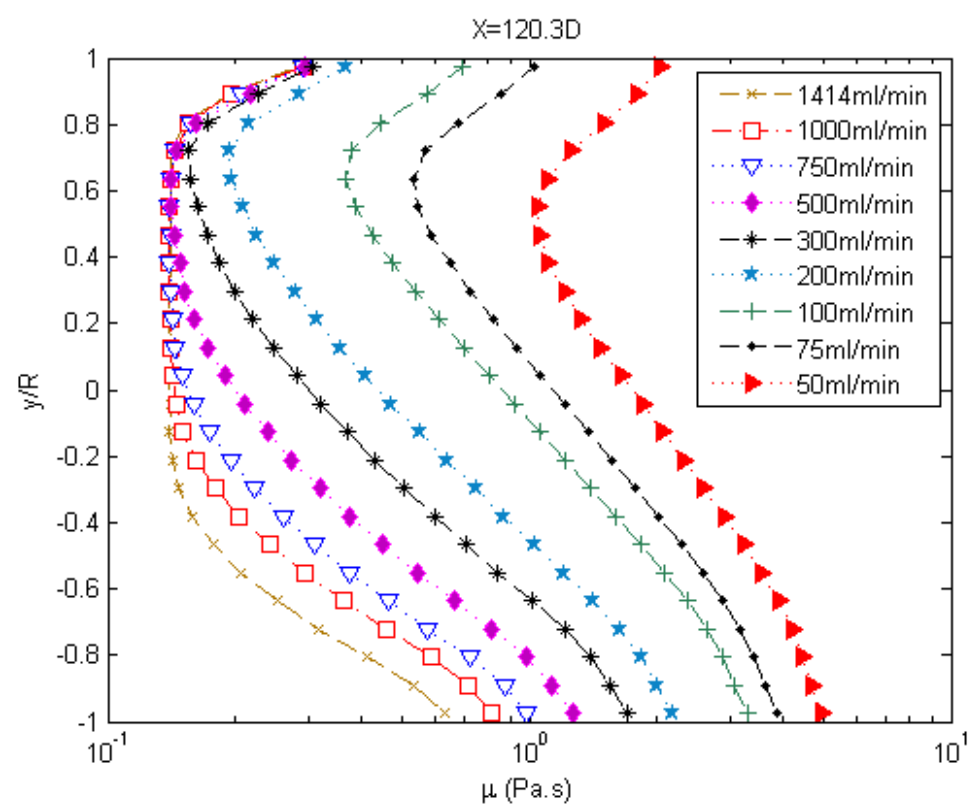

Figura 5.10 - Perfis radiais de viscosidade da solução para a coordenada axial $x=1420 \mathrm{~mm}\left(x / D_{i}=120,3\right)$, para diferentes valores da vazão. Temperatura de entrada da glicerina: $70^{\circ} \mathrm{C}$. Temperatura da água de refrigeração: $5^{\circ} \mathrm{C}$.

Perfis radiais da componente axial da velocidade foram medidos nas mesmas posições axiais e vazões que os de temperatura, os resultados são apresentados nas Figura 5.11 e Figura 5.12. Na região de entrada, os perfis da Figura 5.11(a) indicam que os efeitos de convecção natural sobre o campo de velocidade são menos pronunciados que no campo de temperatura. Mesmo assim, efeitos importantes podem ser notados, principalmente nos casos de vazão mais baixa. Isso é mais facilmente notado comparando-se os perfis de velocidade normalizada, conforme mostrado na Figura 5.11(b). Para melhorar a clareza na exposição dos dados optou-se por mostrar somente casos que 
fossem bem representativos do comportamento do escoamento na faixa de vazões medida. Como referência incluiu-se, também, um perfil parabólico de velocidades que foi calculado assumindo escoamento laminar, desenvolvido e com viscosidade constante. Os resultados mostram que para baixas vazões o perfil é assimétrico com o máximo da velocidade localizado próximo à coordenada $y / R=0,2$, ou seja, na parte superior do tubo. À medida que a vazão aumenta, os perfis tendem à simetria, com o valor máximo da velocidade localizado sobre o eixo do tubo. Pode-se observar que para as maiores vazões não há diferença apreciável em relação ao perfil teórico do escoamento desenvolvido com propriedades constantes.

O efeito da troca de calor sobre o escoamento é mais perceptível nos perfis de velocidade medidos na posição axial $x / D_{i}=120,3$. Nesta posição vêse junto à parede um aumento da região onde prevalece o fluido mais frio, consequentemente o perfil de velocidade fica retardado nessas regiões devido ao maior valor da viscosidade local. Para conservar massa, o retardamento do fluido junto à parede é compensado por um aumento da velocidade na região central do tubo. Sendo assim, os perfis nessa estação apresentam uma forma mais afilada quando comparados com os da entrada. Estas observações podem ser confirmadas nas Figura 5.12(a) e (b). Esse efeito de retardamento do escoamento fica evidente quando se compara os perfis medidos com o perfil parabólico.

É interessante observar na Figura 5.12 que em $x / D_{i}=120,3$ o pico de velocidades é deslocado em direção a parede superior do tubo até aproximadamente a vazão de $200 \mathrm{ml} / \mathrm{min}$. Abaixo dessa faixa de vazão os perfis tendem assintoticamente à simetria. A razão para este comportamento pode estar relacionada tanto à convecção natural, como às diferenças de viscosidade na seção transversal do tubo. De fato, os dois efeitos estão relacionados, pois as correntes convectivas são responsáveis pelo gradiente de temperatura, e consequentemente pela variação de viscosidade. No entanto, devido à baixa velocidade do escoamento, a relevância de cada um desses mecanismos diretamente sobre o perfil de velocidades não é clara. 


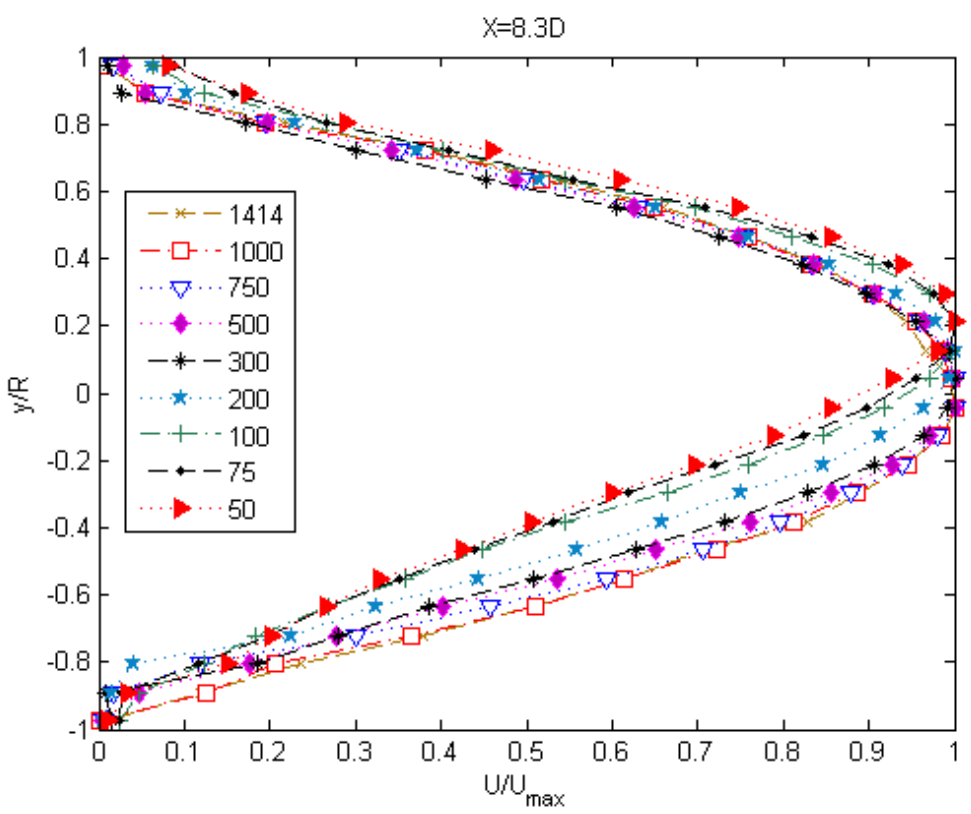

(a)

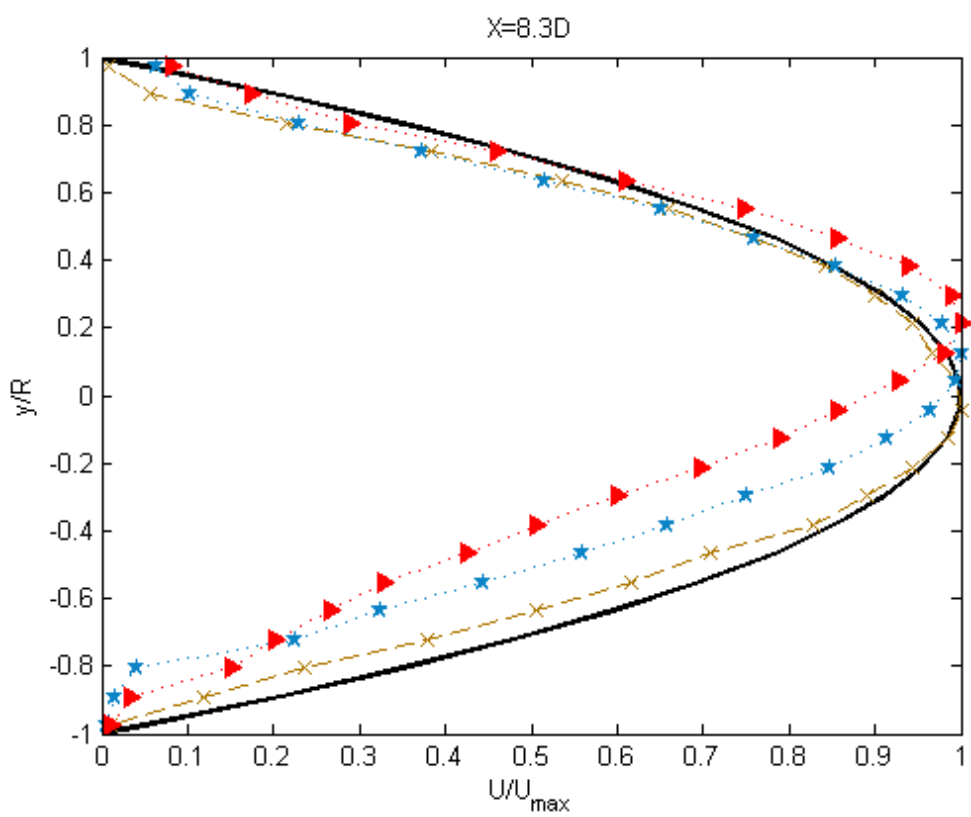

(b)

Figura 5.11 - Perfis radiais de velocidade da solução de glicerina para a coordenada axial $x=98 m m\left(x / D_{i}=8,3\right)$, para diferentes valores da vazão. (a) Componente axial da velocidade. Figura (b) Componente axial da velocidade normalizada. Linha contínua perfil parabólico teórico Temperatura de entrada da glicerina: $70^{\circ} \mathrm{C}$. Temperatura da água de refrigeração: $5^{\circ} \mathrm{C}$. 


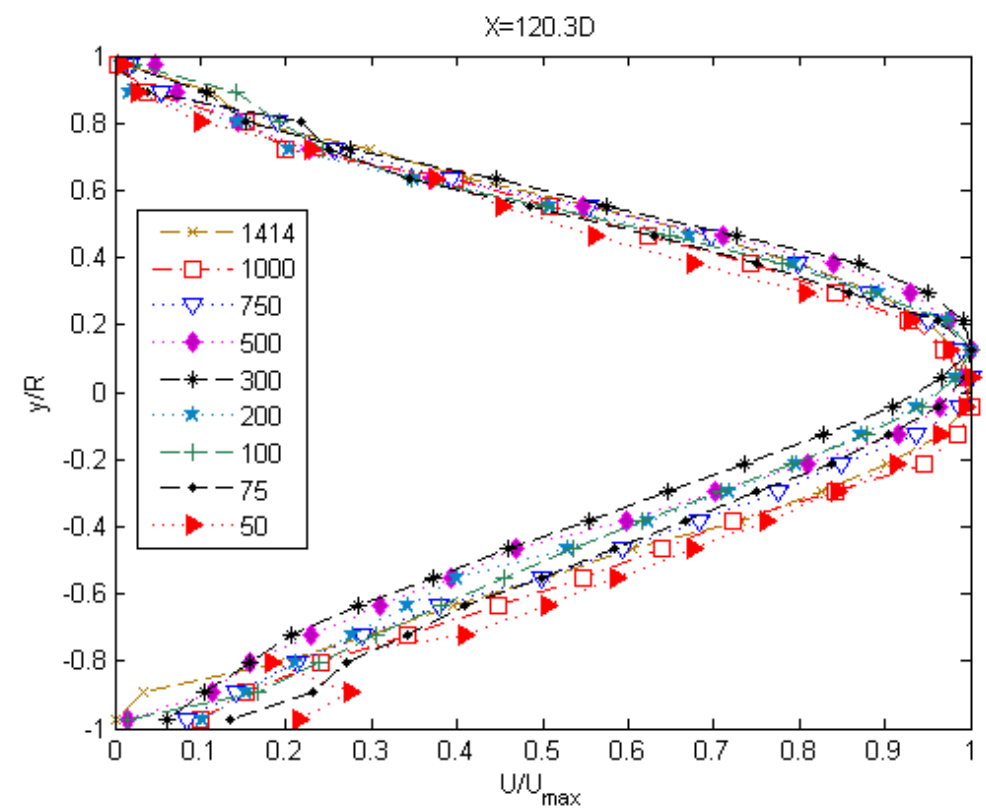

(a)

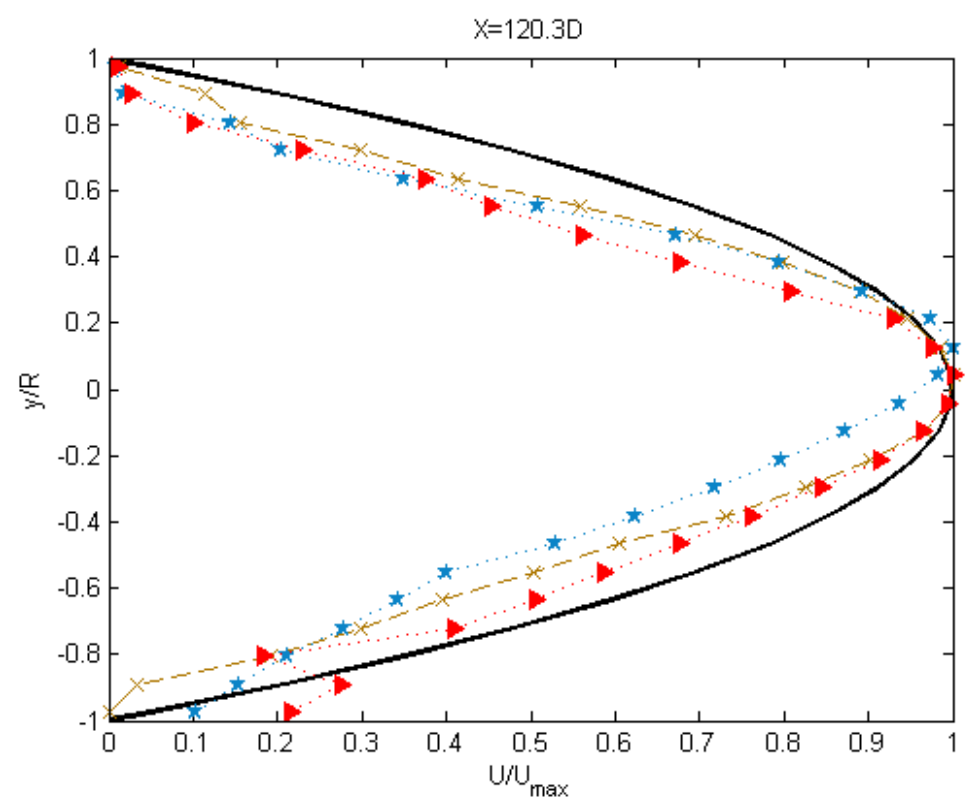

(b)

Figura 5.12 - Perfis radiais de velocidade da solução de glicerina para a coordenada axial $x=1420 \mathrm{~mm}\left(x / D_{i}=120,3\right)$, para diferentes valores da vazão. Figura (a): Velocidade axial total. Figura (b): Linha contínua - perfil parabólico teórico; símbolos perfil de velocidade normalizado. Temperatura de entrada da glicerina: $70^{\circ} \mathrm{C}$. Temperatura da água de refrigeração: $5^{\circ} \mathrm{C}$.

A influência da viscosidade na distorção do perfil de velocidade está relacionada à variação dessa propriedade na seção transversal do duto. Como regiões de viscosidade mais alta tendem a oferecer maior resistência ao 
escoamento, julga-se que o perfil de velocidades fique mais assimétrico nos casos com as maiores diferenças na viscosidade da solução de glicerina. Essa conjectura é suportada pelas curvas mostradas na Figura 5.13, onde a variação da viscosidade da solução é apresentada para as diferentes vazões e em cada uma das posições de medição. A variação apresentada corresponde à diferença entre a máxima viscosidade (localizada na parte inferior do tubo) e a mínima (localizada na posição de máximo do perfil de temperatura). Os dados foram normalizados em relação média do perfil de viscosidades. Isso foi necessário para mostrar uma variação relativa, já que ela é mais importante para o escoamento e também porque os valores absolutos de viscosidade são muito diferentes, o que dificulta a comparação.

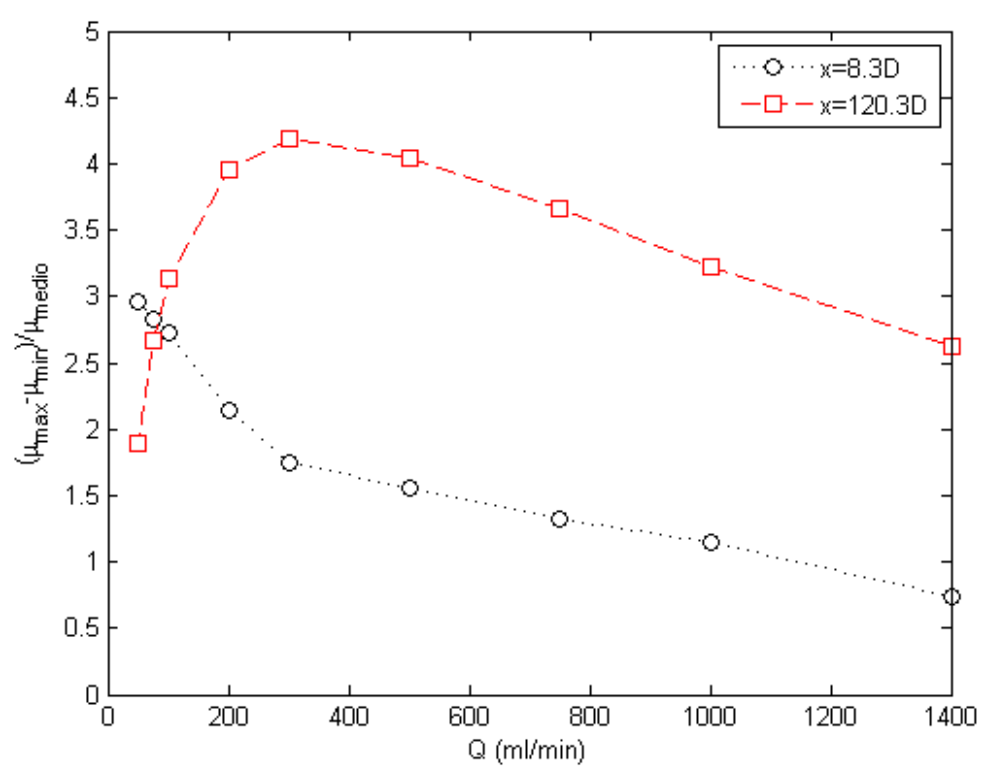

Figura 5.13 - - Variação de viscosidade ao longo do diâmetro para diferentes valores da vazão. Estimativa com base na correlação 3.1 e no perfil de temperaturas medido experimentalmente. Valores normalizados em relação à média do perfil de viscosidades.

A Figura 5.13 mostra que na região de entrada, as maiores variações de viscosidade ocorrem para as vazões mais baixas. Já na posição $x / D_{i}=120,3$, a variação máxima ocorre em vazões próximas a 200-300 $\mathrm{ml} / \mathrm{min}$. Isso concorda com os resultados experimentais e pode ser uma explicação plausível para o mecanismo responsável pela distorção dos perfis de velocidade. 
Outra possível conjectura é a de distorção devido à variação de intensidade das correntes convectivas. Para analisar esse efeito utiliza-se os adimensionais Grashof e o Reynolds, conforme definido nos capítulos anteriores. A relevância de correntes convectivas na velocidade do escoamento pode ser estimada através da razão $G r / \operatorname{Re}^{2}$. A Figura 5.14 mostra os valores dessa razão calculados a partir da máxima variação de temperatura em uma dada seção reta do tubo e da velocidade média do escoamento. A dimensão característica utilizada no cálculo foi o diâmetro interno do tubo. A Figura 5.14 mostra que na estação mais afastada há um aumento da razão $G r / \operatorname{Re}^{2}$ para vazões acima de $200 \mathrm{ml} / \mathrm{min}$ em comparação com a seção de entrada. Isso sugere um aumento da influência das correntes convectivas. Mesmo assim, as alterações nos valores da razão $G r / \operatorname{Re}^{2}$ ainda são pequenas e, portanto, não justificam a mudança no deslocamento dos perfis de velocidade.

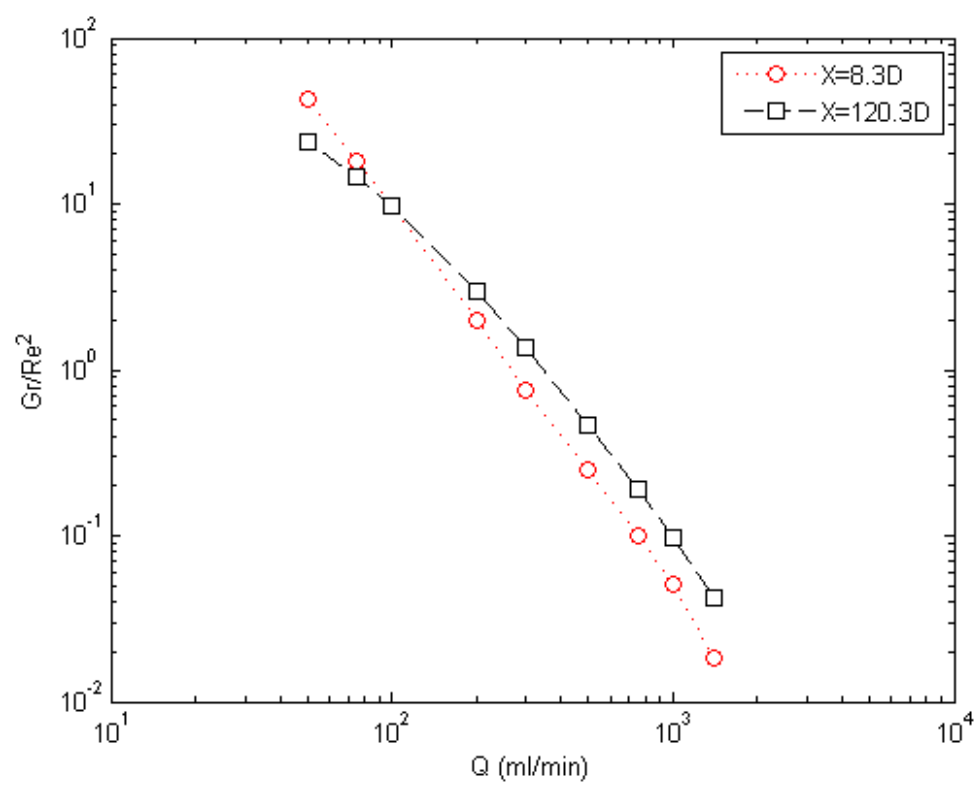

Figura 5.14 - Variação da razão $G r / \operatorname{Re}^{2}$ para diferentes vazões. Comparação entre as regiões de medição.

A análise apresentada sugere que o principal efeito da transferência de calor sobre a dinâmica do escoamento na seção de medição é devida a variação de viscosidades imposta pelas correntes convectivas presentes no escoamento.

Como verificação das medições realizadas, os perfis de velocidade medidos foram integrados na seção reta do tubo e a vazão obtida comparada 
com a vazão nominal de cada experimento. O resultado desta comparação foi muito bom, apresentando desvios abaixo de 10\%. A Tabela 5.3 exemplifica alguns dos resultados obtidos para as duas posições. Cabe ressaltar que para a integração do perfil, foi assumida simetria circunferencial, o que não é necessariamente verdade para todos os casos estudados. Seria interessante complementar o presente estudo com a medição de perfis de temperatura e velocidade em outros planos. Por restrições de tempo, estas medições não foram realizadas.

Tabela 5.3 - Exemplo de validação das medições dos perfis de velocidade com a vazão nominal do escoamento.

\begin{tabular}{cccc}
\hline$Q$ & Integral do Perfil & Integral do Perfil & Desvio Médio \\
$(\mathrm{ml} / \mathrm{min})$ & $x=8,3 D$ & $x=120,3 D$ & $(\%)$ \\
1414 & 1287 & 1309 & 8.2 \\
200 & 180 & 189 & 7.8 \\
50 & 49 & 50 & 1 \\
\hline
\end{tabular}

\section{5. \\ Comparação com Solução Numérica Tridimensional}

O escoamento do fluido com viscosidade variando com a temperatura ao longo do duto horizontal e trocando calor com um ambiente frio foi modelado por outros pesquisadores utilizando modelos com níveis de complexidade diferentes.

Um dos modelos desenvolvidos resolve as equações de conservação de massa, quantidade de movimento linear e energia em sua forma tridimensional. Simulações tridimensionais permitem uma análise mais detalhada dos campos de velocidade e temperatura e podem auxiliar no entendimento do problema abordado. Por isso buscou-se complementar a análise dos experimentos com simulações numéricas.

No modelo são utilizadas as equações de conservação na forma parabólica na direção principal do escoamento, onde os termos difusivos são desprezados. Esta aproximação permite que campos bidimensionais das variáveis de interesse em uma dada seção reta do tubo sejam obtidos com grande precisão e que as soluções para outros planos sejam obtidos por um processo de marcha na direção axial ao longo da coordenada axial. Isso confere ao modelo uma grande economia de tempo computacional e memória, quando comparado com uma solução onde a forma elíptica das equações de 
conservação é considerada em cada direção. O modelo também incorpora a aproximação de Boussinesq para o tratamento da modelagem dos efeitos de convecção natural. Uma descrição mais detalhada do modelo tridimensional parabólico pode ser encontrada em [15] e [17].

Para a realização das simulações buscou-se reproduzir as condições dos experimentos. Primeiramente foi necessário modelar as propriedades termofísicas da glicerina. Isso foi feito com auxílio da equação 3.1, utilizando-se os coeficientes $\left(\mu_{0}, A\right.$ e $B$ ) obtidos a partir da caracterização da glicerina, seguindo o procedimento descrito no Capítulo 3.

A geometria da bancada foi simplificada nas simulações devido a sua complexidade e a dificuldade de implementação da solução numérica para o escoamento nas seções interna, por onde escoa a solução de glicerina, e anular, por onde escoa o fluido refrigerante. No modelo tridimensional o coeficiente de transferência de calor entre o fluido externo e a parede do duto foi modelado através de correlações da literatura desenvolvidas para escoamento anular [14]. Outra simplificação relevante está relacionada a região de entrada. Nos experimentos existe um comprimento de tubulação anterior a seção de medição, conforme pode ser observado no desenho das Figura 3.3 e Figura 3.4. Isso faz com que o escoamento na entrada da região de medição possua distribuições de velocidade e temperatura não uniformes. Para tentar reproduzir tais condições foi adotado na simulação um comprimento de desenvolvimento de aproximadamente $13 \mathrm{D}$, distância física real utilizada no experimento. Além disso, foi implementado pelo grupo de simulação numérica, um procedimento iterativo para ajustar a temperatura inicial da solução de glicerina de modo a manter a temperatura no centro da entrada da seção de testes igual a $70^{\circ} \mathrm{C}$. Maiores detalhes das condições de contorno e iniciais do modelo podem ser encontradas em [15].

Os resultados de queda de pressão na tubulação obtidos com o modelo numérico para as vazões de $1000,100,50,30$ e $5 \mathrm{ml} / \mathrm{min}$, são comparados com os dados experimentais na Figura 5.15. No caso com vazão de $1000 \mathrm{ml} / \mathrm{min}$ a queda de pressão prevista pelo modelo ficou acima daquela medida experimentalmente. Já para as demais vazões a queda de pressão foi um pouco subestimada. Apesar disso, o comportamento da curva de perda de carga parece ser bem capturado pelo modelo, pois nota-se uma elevação da 
perda de carga nas vazões de 50 e $30 \mathrm{ml} / \mathrm{min}$, seguindo os dados da curva experimental.

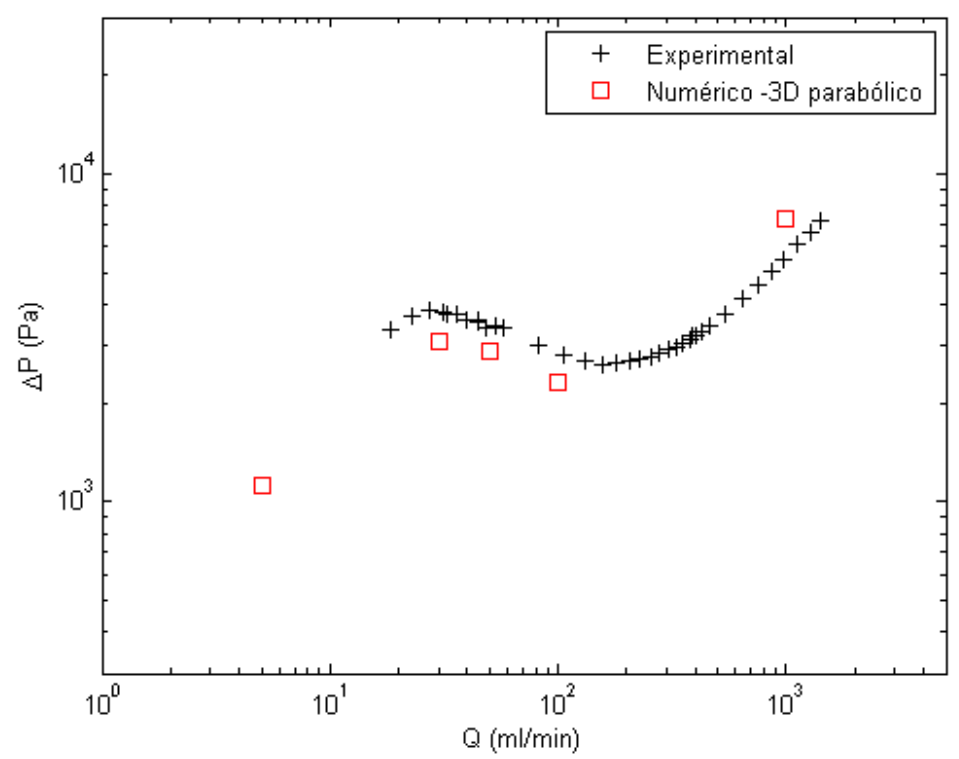

Figura 5.15 - Comparação entre os resultados numéricos $3 D$ e experimentais para a queda de pressão em função da vazão para o escoamento da solução de glicerina. Temperatura de entrada da glicerina: $70^{\circ} \mathrm{C}$. Temperatura do fluido de refrigeração: $5^{\circ} \mathrm{C} . L / D_{i}=241$.

Os perfis de velocidade medidos no plano diametral vertical do tubo são analisados nas posições axiais $x / D_{i}=8,3$ e 120,3. A Figura 5.16 apresenta os resultados obtidos para a vazão de $1000 \mathrm{ml} / \mathrm{min}$. Nota-se que na seção mais próxima à entrada, Figura 5.16(a), o perfil de velocidade da simulação possui uma forma bem próxima de uma parábola, assim como nos experimentos. Entretanto o maior valor de velocidade se encontra fora do centro, deslocado em direção à parte superior da tubulação, enquanto que nos experimentos o perfil é bastante simétrico. De acordo com a Figura 5.11 perfis assimétricos na região próxima à entrada só foram notados nos experimentos para vazões abaixo de $300 \mathrm{ml} / \mathrm{min}$. 


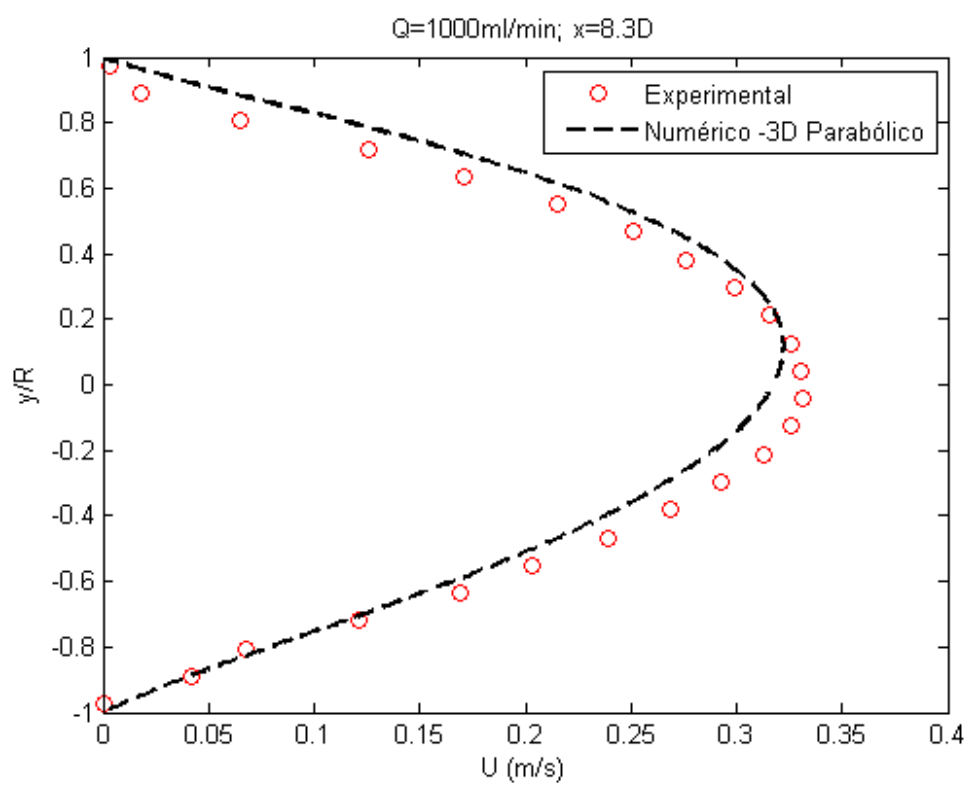

(a)

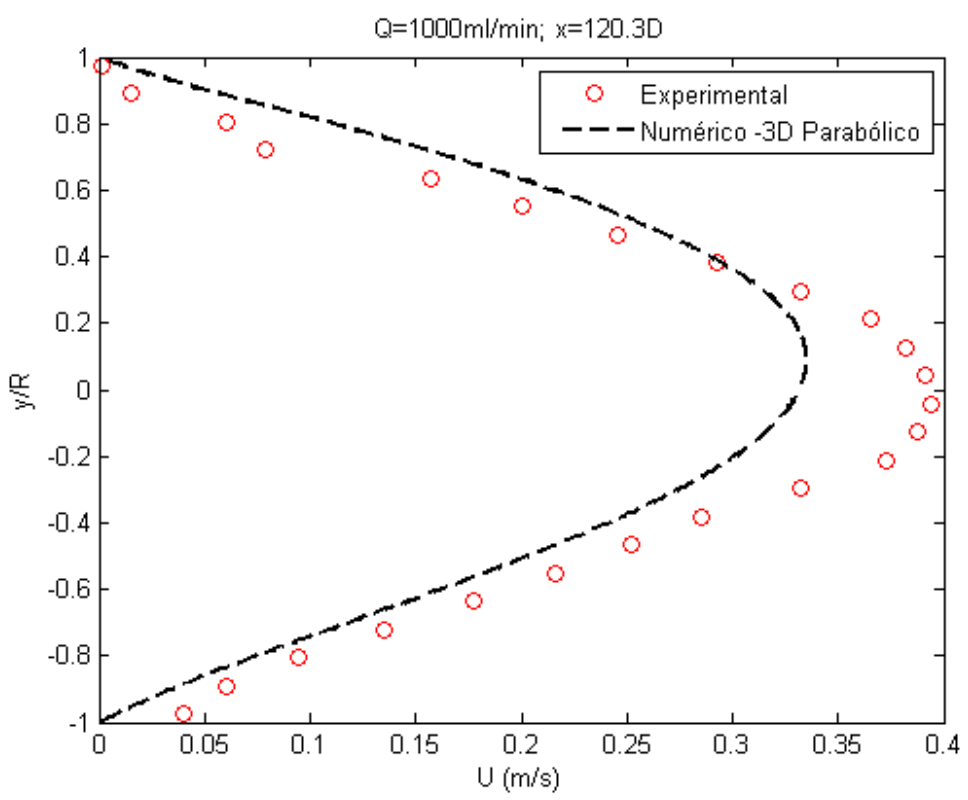

(b)

Figura 5.16 - Comparação entre os resultados numéricos $3 D$ e experimentais para os perfis radiais de velocidade da solução de glicerina em duas coordenadas axiais para vazão de $1000 \mathrm{ml} / \mathrm{min}$. (a) $x / D_{i}=8,3$ (b). Temperatura de entrada da glicerina: $70^{\circ} \mathrm{C}$. Temperatura da água de refrigeração: $5^{\circ} \mathrm{C}$.

Na região mais afastada da entrada há um maior desvio aparente entre os dados experimentais e numéricos, Figura 5.16(b). Nos experimentos, o fluido na parte central é mais acelerado. Julga-se que isso seja consequência de uma maior perda de quantidade de movimento próximo à parede, causada pelo 
aumento da viscosidade da glicerina nesta região. Como uma grande parcela da área da seção transversal do duto é de regiões próximas à parede, pequenas variações de quantidade de movimento nessas regiões podem causar grandes alterações na velocidade do escoamento na parte central. Por isso, os perfis numérico e experimental apesar de não apresentarem diferenças apreciáveis próximo as paredes, têm notável variação de velocidade próximo ao centro do tubo. Isso sugere que nos experimentos a influência da variação de viscosidade sobre o perfil de velocidade foi maior. No entanto, é importante notar que nas simulações também houve um aumento da velocidade na região central, ainda que tenha ocorrido em menor intensidade do que nos experimentos. Isso pode ser observado comparando as Figura 5.16(a) e (b). Cabe ressaltar também, que nas duas estações a localização dos máximos dos perfis se manteve inalterada, tanto nos experimentos como nas simulações.

Para a vazão de $100 \mathrm{ml} / \mathrm{min}$ o efeito de aumento da velocidade no centro do tubo ocorreu de forma mais acentuada, com a diferença de velocidade entre experimento e simulação se mantendo quase constante nas duas estações de referência, Figura 5.17(a) e (b). Esse comportamento reforça a ideia de que nos experimentos a variação de viscosidade teve maior influência. Comparando-se os perfis nas duas estações observa-se um deslocamento radial do pico de velocidades. Esse comportamento foi bem descrito pelo modelo, apesar da diferença nos valores de velocidade.

A análise dos perfis de velocidade sugere que apesar da dificuldade de se ajustar as condições iniciais da simulação às do experimento, o modelo parece ser capaz de capturar bem a dinâmica do escoamento. Entretanto, para avaliar o modelo ainda é necessário realizar uma validação mais detalhada e abrangente, o que foge do escopo do presente trabalho. 


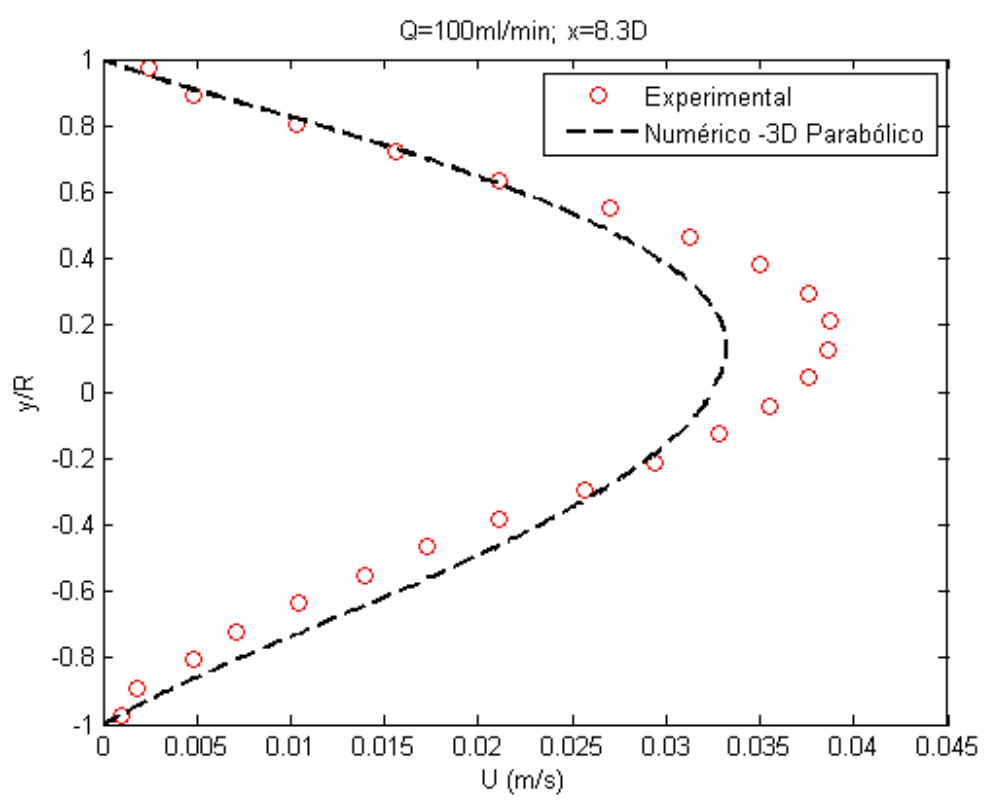

(a)

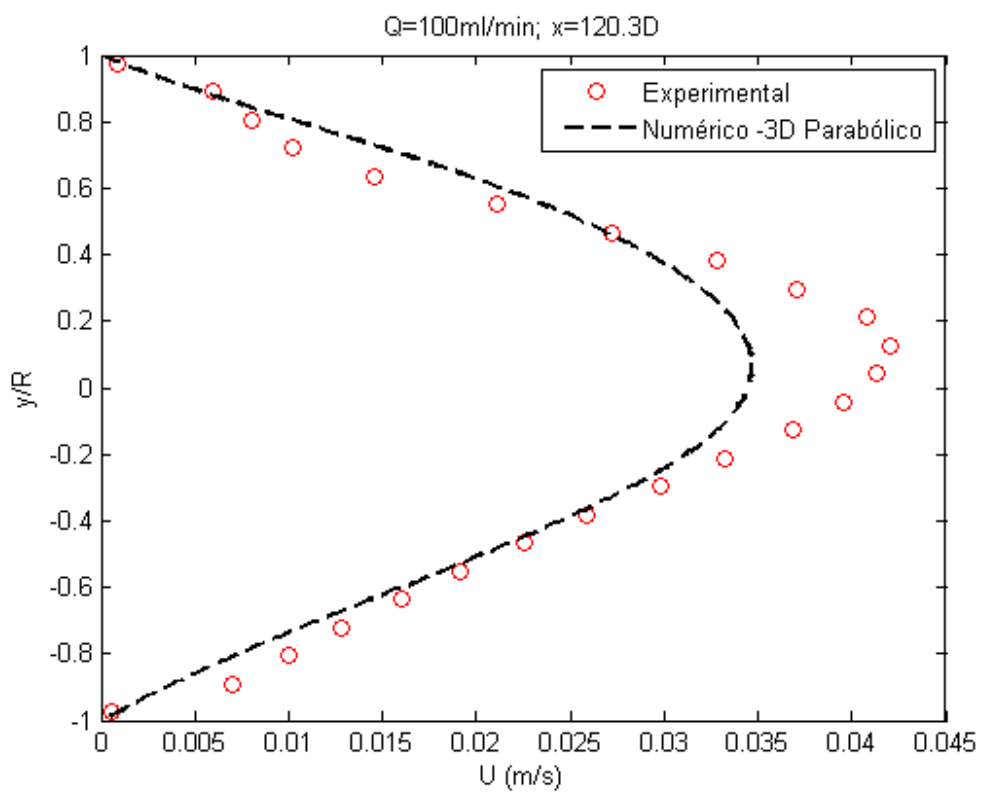

(b)

Figura 5.17 - Comparação entre os resultados numéricos $3 D$ e experimentais para os perfis radiais de velocidade da solução de glicerina em duas coordenadas axiais para vazão de $100 \mathrm{ml} / \mathrm{min}$. (a) $. x / D_{i}=8,3$. (b) Temperatura de entrada da glicerina: $70^{\circ} \mathrm{C}$. Temperatura da água de refrigeração: $5^{\circ} \mathrm{C}$.

Foram comparados também os perfis de temperatura medidos e previstos nas mesmas posições e vazões. Os resultados apresentados na Figura 5.18 , obtidos para a vazão de $1000 \mathrm{ml} / \mathrm{min}$, mostram algumas discrepâncias entre os dados do experimento e da simulação. Nos experimentos, o fluido na 
parte inferior da tubulação se mostrou mais frio do que o previsto pela simulação. Com isso, a variação entre a temperatura no centro do tubo e na parede inferior ficou aproximadamente o dobro da estimada pelo modelo. Esse comportamento corrobora, qualitativamente, as considerações feitas com base nos perfis de velocidade, onde se observou uma maior distorção dos perfis experimentais e que aparentemente foram causadas por variações de viscosidade. Como essas variações de viscosidade estão relacionadas com a temperatura, era de se esperar, portanto, que os perfis medidos também apresentassem as maiores diferenças de temperatura.

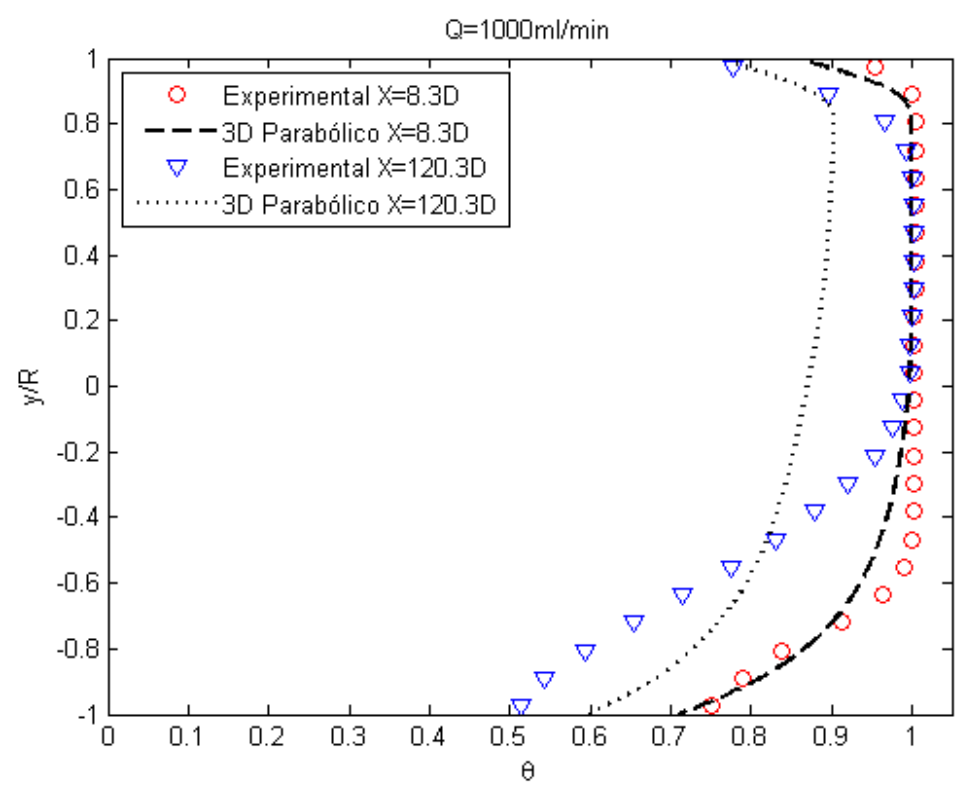

Figura 5.18 - Comparação entre os resultados numéricos $3 D$ e experimentais para os perfis radiais de temperatura da solução de glicerina nas coordenadas axiais $x / D_{i}=8,3$ e $x / D_{i}=120,3$, para vazão de $1000 \mathrm{ml} / \mathrm{min}$. Temperatura de entrada da glicerina: $70^{\circ} \mathrm{C}$. Temperatura da água de refrigeração: $5^{\circ} \mathrm{C}$.

Na vazão de $100 \mathrm{ml} / \mathrm{min}$, efeitos similares são observados, conforme mostra a Figura 5.19. A principal alteração e relação ao caso de $1000 \mathrm{ml} / \mathrm{min}$ se deve à distorção dos perfis de temperatura já na região próxima a entrada. Esse efeito não foi bem capturado com as simplificações assumidas para modelar o comprimento de tubulação a montante da entrada da seção de testes.

A jusante da entrada, as diferenças entre os perfis da Figura 5.19, aparentemente, se mantém. Isso sugere que apesar das correntes convectivas 
não terem sido capturadas fielmente pelo modelo, a perda de calor global do fluido para a tubulação foi razoavelmente prevista.

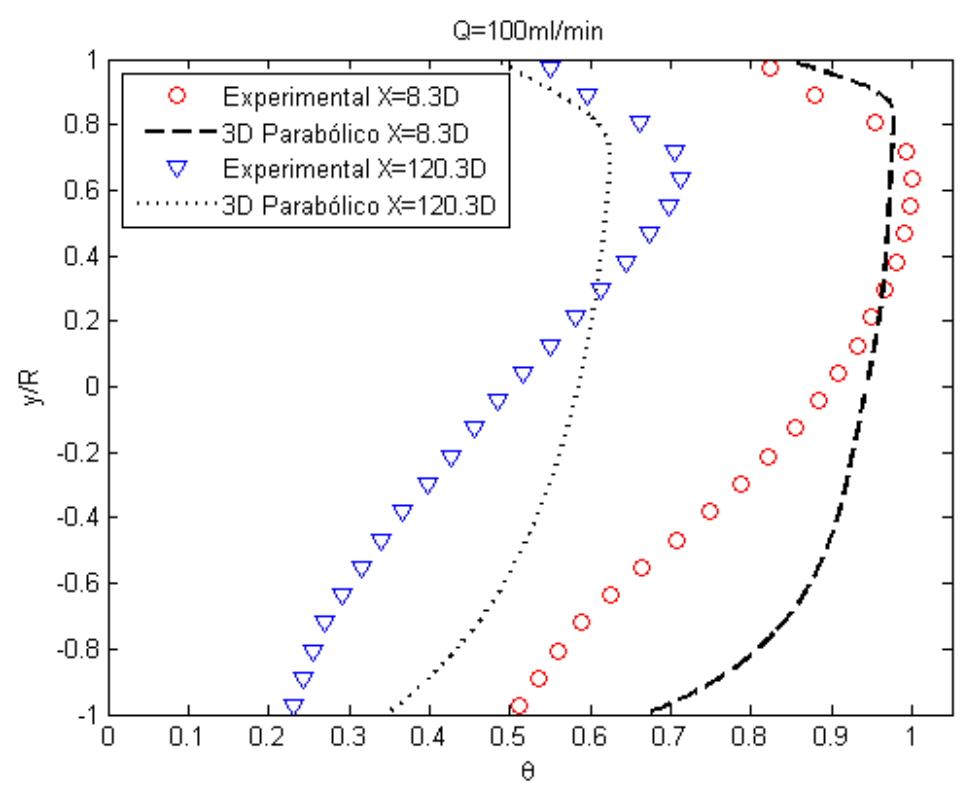

Figura 5.19 - Comparação entre os resultados numéricos $3 D$ e experimentais para os perfis radiais de temperatura da solução de glicerina nas coordenadas axiais $x / D_{i}=8,3$ e $x / D_{i}=120,3$, para vazão de $100 \mathrm{ml} / \mathrm{min}$. Temperatura de entrada da glicerina: $70^{\circ} \mathrm{C}$. Temperatura da água de refrigeração: $5^{\circ} \mathrm{C}$.

Os campos de velocidade e temperatura mostrados respectivamente nas Figura 5.20 e Figura 5.21 para a vazão de $50 \mathrm{ml} / \mathrm{min}$, permitem uma melhor avaliação dos efeitos tridimensionais presentes no escoamento. Os contornos da função corrente (Figura 5.20) indicam que nas posições iniciais do domínio computacional há uma forte circulação induzida por efeitos convectivos. Isso ocorre devido à elevada diferença de temperatura entre as paredes do duto e o fluido quente, pois assume-se, inicialmente, uma distribuição de temperaturas uniforme para a glicerina aquecida. À medida que o escoamento se desenvolve essas correntes convectivas se tornam mais fracas e a intensidade da circulação decai, atingindo em $x / D_{i}=120,3$ valores aproximadamente 20 vezes menores do que os da entrada. É importante notar que os valores da escala de cores da Figura 5.20(d) foram reduzidos para permitir a visualização da fraca circulação. 


$$
\begin{array}{ll}
D & D \\
D & D
\end{array}
$$


um deslocamento de apenas $0,5 \mathrm{~mm}$ na posição radial da sonda pode causar diferenças de até $10^{\circ} \mathrm{C}$ no perfil de temperaturas. Outra possível causa para as divergências entre experimento e simulação é o modelamento da região a montante da entrada, pois o forte transiente da entrada pode influenciar 0 escoamento ao longo de boa parte do comprimento do tubo.

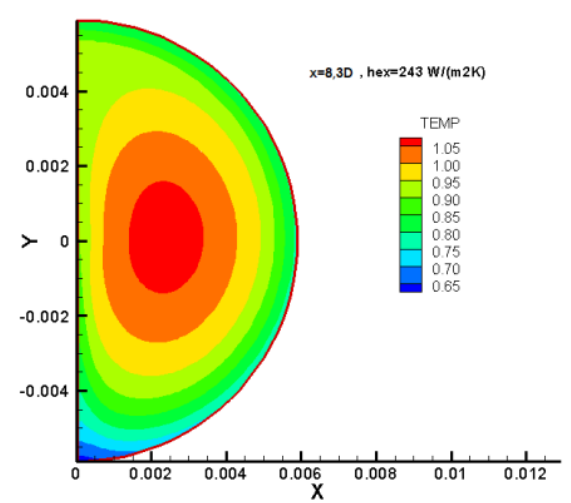

(a)

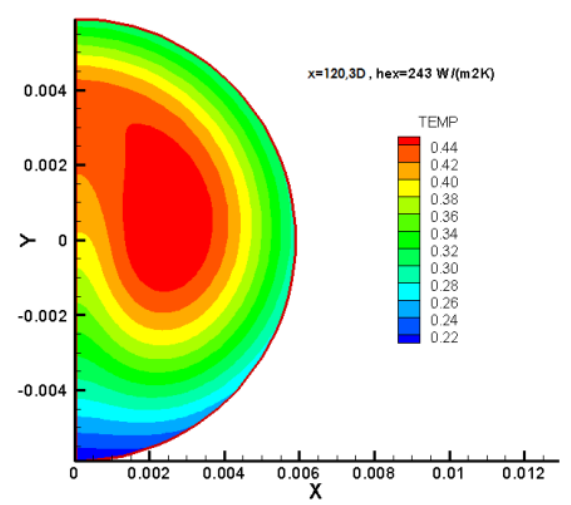

(c)

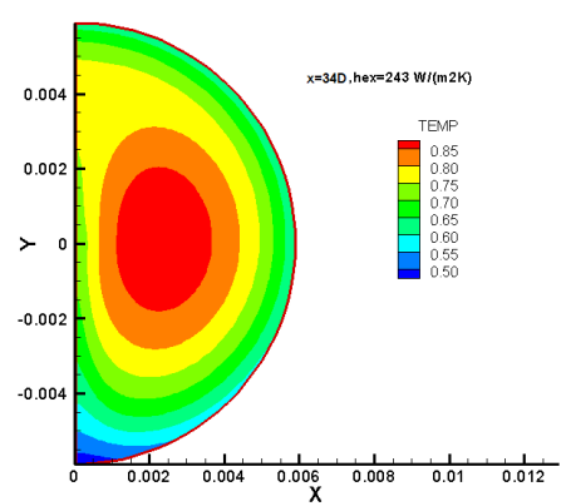

(b)

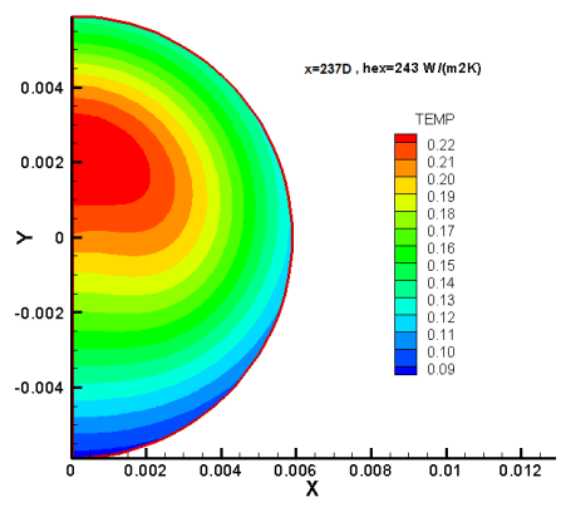

(d)

Figura 5.21 - Resultados das simulações numéricas $3 D$ para os campos de temperatura da solução de glicerina nas coordenadas axiais $x / D_{i}=8,3,34,120,3$ e 237 , para vazão de $50 \mathrm{ml} / \mathrm{min}$. Temperatura de entrada da glicerina: $70^{\circ} \mathrm{C}$. Temperatura da água de refrigeração: $5^{\circ} \mathrm{C}$.

\section{6.}

\section{Comparação com o Modelo Unidimensional}

O modelo unidimensional desenvolvido pelo grupo de pesquisa tem por objetivo fornecer soluções computacionalmente mais rápidas do problema, utilizando para isso uma formulação unidimensional das equações de 
conservação de quantidade de movimento e energia. Os termos de inércia da equação da quantidade de movimento são desprezados em face dos baixos valores esperados para o número de Reynolds. O conjunto de equações a ser resolvido consiste em uma equação integral para a quantidade de movimento linear e uma equação diferencial de segunda ordem para a temperatura. A troca de calor com o ambiente é considerada na forma de coeficientes convectivos de troca de calor interno e externo, obtidos de correlações da literatura. Detalhes do modelo unidimensional desenvolvido podem ser obtidos em Quinones \& Carvalho [7]. Uma comparação entre as medições e os resultados previstos por este modelo é apresentada na Figura 5.22.

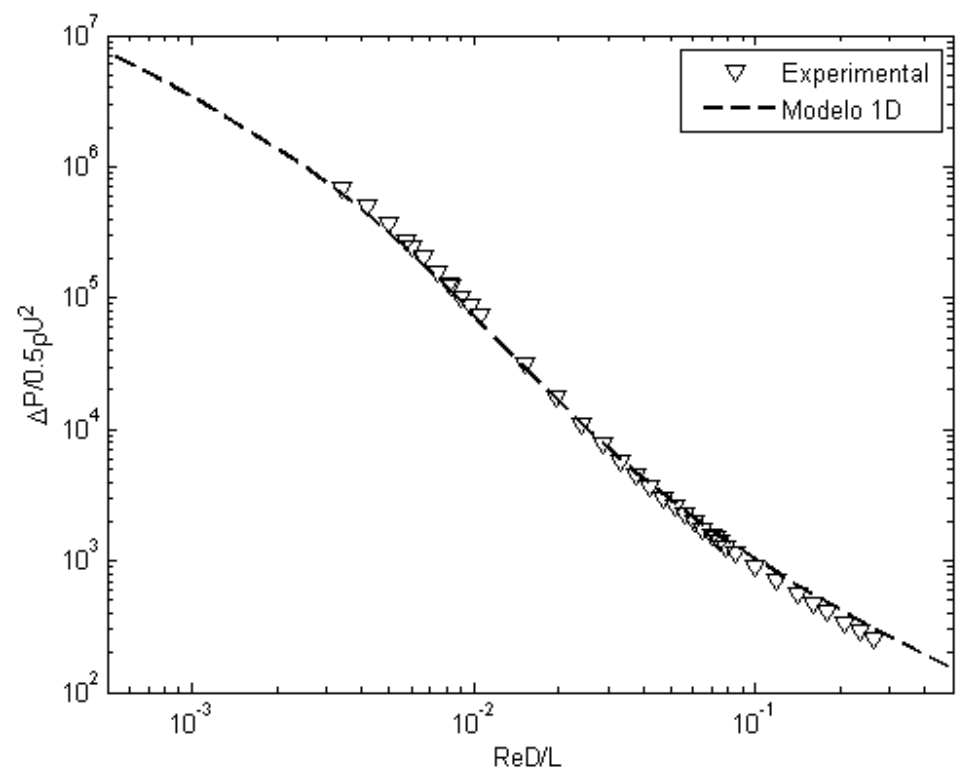

Figura 5.22 - Comparação entre os resultados adimensionais numéricos e experimentais de vazão versus queda de pressão para o escoamento de solução de glicerina. Temperatura de entrada da glicerina igual a $70^{\circ} \mathrm{C}$. Temperatura da água de refrigeração igual a $5^{\circ} \mathrm{C} . L / D_{i}=241$.

$\mathrm{Na}$ Figura 5.23, os valores dimensionais de perda de carga e vazão permitem que a região de transição possa ser mais facilmente observada. Notase um pequeno desvio entre o modelo e o experimento. Para vazões acima de $200 \mathrm{ml} / \mathrm{min}$ as pressões estimadas pelo modelo $1 D$ ficaram um pouco acima das observadas experimentalmente, o contrário ocorreu para vazões mais baixas. Esse comportamento também foi observado nas simulações tridimensionais. Contudo, esses desvios não chegam a ser significativos e, portanto, pode-se considerar como boa a concordância entre os resultados. 


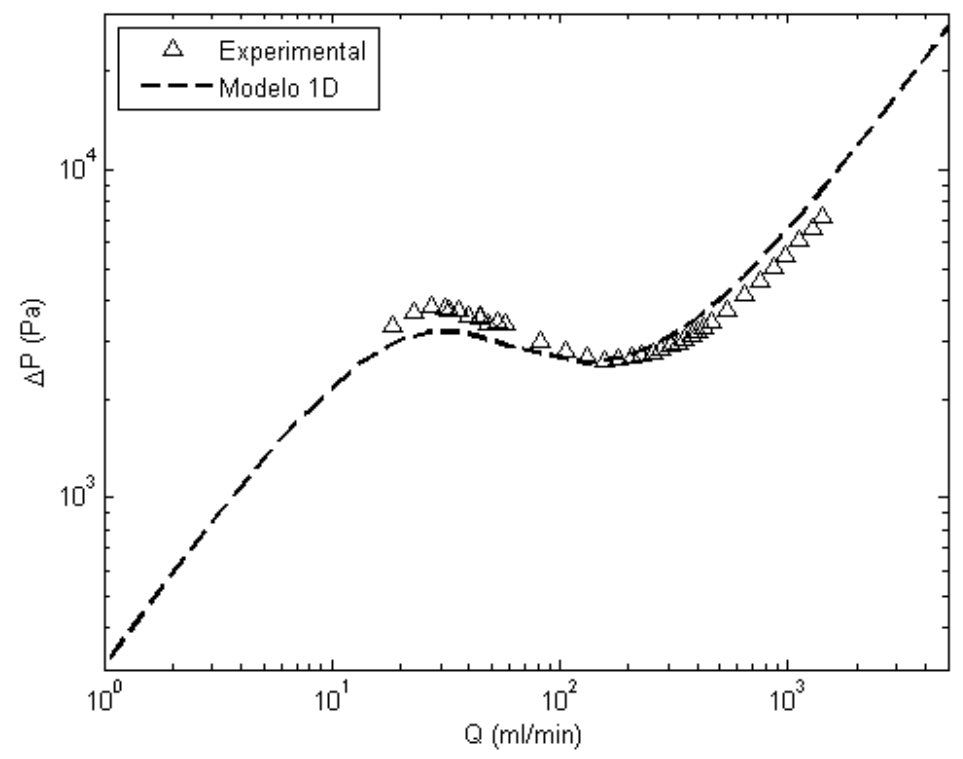

Figura 5.23 - Comparação entre os resultados numéricos e experimentais para a queda de pressão em função da vazão para o escoamento da solução de glicerina. Temperatura de entrada da glicerina: $70^{\circ} \mathrm{C}$. Temperatura do fluido de refrigeração: $5^{\circ} \mathrm{C} . L / D_{i}=241$.

A análise dos resultados apresentados na Figura 5.24 mostra que os valores da temperatura de saída são bem previstos pelo modelo simplificado apenas para as baixas vazões de glicerina. À medida que a vazão aumenta, nota-se uma crescente diferença entre os valores previstos e medidos. Acreditase que esta diferença crescente seja devida à maior contribuição do coeficiente externo de troca de calor no coeficiente global de troca de calor, como discutido a seguir. 


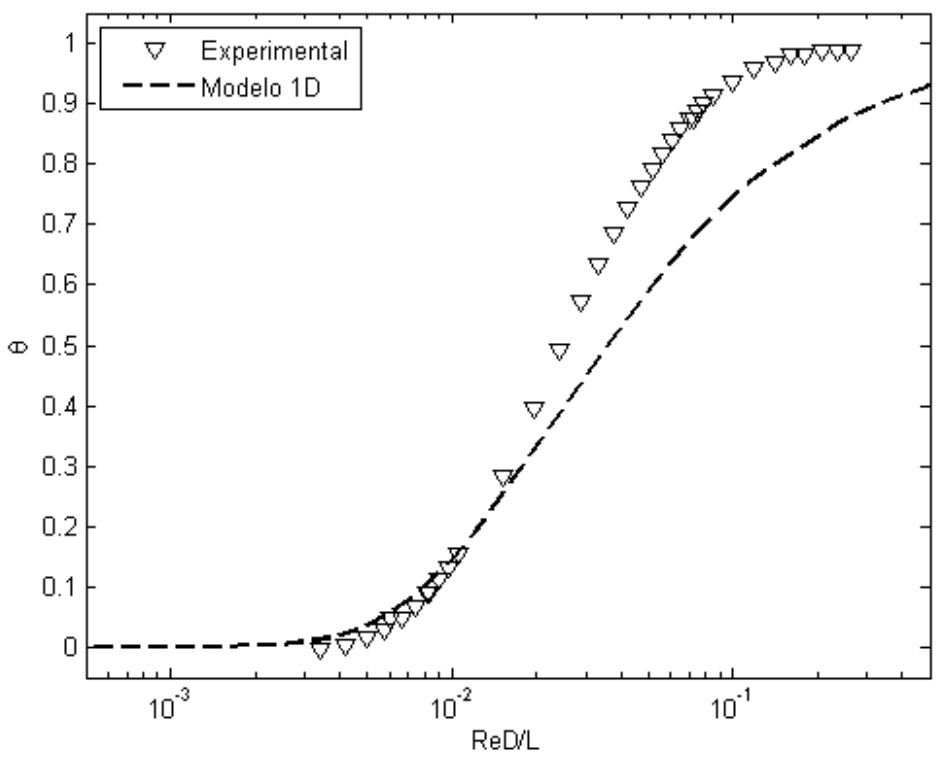

Figura 5.24 - Comparação entre os resultados numéricos e experimentais de temperatura de saída da solução de glicerina medida no centro do tubo em função da vazão. Temperatura de entrada da glicerina: $70^{\circ} \mathrm{C}$. Temperatura da água de refrigeração: $5^{\circ} \mathrm{C} . L / D_{i}=241$.

O valor da temperatura de saída da glicerina é influenciado pela troca de calor entre a glicerina escoando no interior do tubo e o ambiente externo frio. Esta troca de calor da glicerina quente para o fluido frio é controlada pelo valor do coeficiente global de troca de calor que prevalece em cada posição axial ao longo do tubo. O coeficiente global de troca de calor é formado pela combinação dos coeficientes de troca de calor convectivos interno e externo com a condutividade térmica da parede do tubo. Destas três parcelas, as contribuições da condutividade térmica da parede e do coeficiente convectivo externo permaneceram constantes nos experimentos realizados. Assim, a troca de calor entre a glicerina e o fluido de refrigeração variava com a vazão da glicerina apenas devido à variação do coeficiente convectivo interno. Para as baixas vazões o valor do coeficiente convectivo interno é relativamente mais baixo, sendo esta a resistência térmica dominante. À medida que a vazão de glicerina aumenta, o coeficiente convectivo interno aumenta e a resistência global à troca de calor passa a ser dominada pela resistência convectiva externa.

$O$ fato que o modelo simplificado desenvolvido produz boas estimativas para a temperatura de saída da glicerina apenas para as baixas vazões indica que a estimativa do coeficiente convectivo interno é boa, enquanto a estimativa do coeficiente convectivo externo deixa a desejar. Deve ser ressaltado que o 
modelo simplificado desenvolvido utiliza correlações disponíveis na literatura para estimar os coeficientes de troca de calor externo e interno. A configuração do escoamento interno laminar em um duto circular é bem definida, sendo as previsões das correlações consideradas confiáveis. No entanto, o escoamento externo se dá sob condições não tão bem definidas devido à presença de suportes com finalidade estrutural presentes na passagem anular por onde escoa o fluido de refrigeração. Desta forma, acredita-se que as correlações disponíveis na literatura produzidas para espaços anulares livres não estejam fornecendo bons resultados.

É importante ressaltar, no entanto, que mesmo com as diferenças verificadas na previsão da temperatura de saída da glicerina, as previsões da queda de pressão ao longo do escoamento apresentam boa concordância com os valores experimentais, como mostrado anteriormente nas Figura 5.22 e Figura 5.23. Sendo assim, julga-se que a formulação unidimensional pode ser usada para a previsão da queda de pressão do escoamento. Esta validação era um dos objetivos do projeto do qual o presente estudo foi parte. 


\section{6 \\ Conclusões}

Neste trabalho foram investigadas as características do escoamento de um fluido com viscosidade fortemente dependente da temperatura através de um duto onde há troca de calor com o meio externo. O trabalho teve como motivação o transporte de petróleo quente através de linhas submarinas longas, onde foram verificados em operações de campo desvios significativos da relação linear entre vazão e queda de pressão esperada para escoamentos hidrodinamicamente desenvolvidos.

O presente trabalho realizou um estudo experimental do escoamento de fluido com viscosidade dependente a temperatura, fazendo parte de um projeto de pesquisa onde o problema foi estudado também através de simulações computacionais com diferentes níveis de complexidade na modelagem numérica das equações que governam o escoamento.

Um estudo das equações de conservação que governam o problema revelou que os campos de temperatura, pressão e velocidade dependem de dez grupos adimensionais, a saber, números de Reynolds, Grashof, Prandtl, Eckert, o comprimento adimensional do duto $L / D_{i}$, o ângulo de inclinação do duto, o coeficiente adimensional de troca de calor e três parâmetros adimensionais que caracterizam a dependência da viscosidade com a temperatura. Ficou claro que um estudo paramétrico completo do problema seria uma tarefa inviável de ser concluída no prazo disponível. Assim, os experimentos limitaram-se ao estudo da influência do número de Reynolds do escoamento sobre a queda de pressão e os campos de temperatura e velocidade.

Para os estudos experimentais foi construída uma seção de testes em escala de laboratório, formada por um tubo horizontal principal de material isolante por onde escoava o fluido de testes, uma solução de glicerina e água. $\mathrm{O}$ tubo era resfriado externamente promovendo a variação de temperatura que induzia variação radial e axial da viscosidade. A solução de glicerina foi escolhida por apresentar variação de viscosidade com a temperatura semelhante aos petróleos de campo. Os estudos investigaram o regime laminar de escoamento. 
Medidas de queda pressão ao longo do tubo em função da vazão, ou do número de Reynolds, revelaram comportamento semelhante àquele verificado no campo. Para altas e baixas faixas de vazão, a relação da queda de pressão com a vazão era linear, comportamento característico de escoamento hidrodinamicamente desenvolvidos de fluidos com propriedades constantes. Para as baixas vazões, parte significativa do comprimento do duto se encontra em temperatura próxima à do fluido de refrigeração externo, provocando pequena variação em sua viscosidade e, portanto, permitindo que a condição de escoamento desenvolvido seja atingida. Para as altas vazões, a temperatura do fluido ao longo de grande parte do comprimento do tubo assume valor próximo à temperatura elevada de entrada e, novamente, não é verificada variação significativa da viscosidade, o que justifica o comportamento linear da queda de pressão com a vazão. Nas faixas intermediárias de vazão, no entanto, verificaram-se significativas variações radiais e axiais da temperatura do fluido, o que provoca fortes desvios da relação linear entre vazão e queda de pressão. 0 patamar verificado na curva de vazão versus queda de pressão implica em que o mesmo valor da queda de pressão pode ser obtido para valores da vazão diferindo de ordens de grandeza. Além da perda de linearidade, verificou-se que esta relação deixou de apresentar comportamento monotônico, o que significa que, para certas faixas de operação, um aumento na vazão pode estar associado a uma diminuição na queda de pressão.

A seção de testes foi preparada para permitir a medição de perfis radiais de temperatura e do componente axial da velocidade em diferentes posições axiais no tubo. Uma sonda utilizando termopar de pequenas dimensões foi usada para a medição dos perfis de temperatura. Os perfis de velocidade foram medidos com a técnica de velocimetria laser-Doppler. Para isso, foram projetadas e construídas sofisticadas janelas para acesso óptico ao escoamento no interior do tubo.

Para as faixas de vazão intermediárias onde o desvio da relação linear entre queda de pressão e vazão foi verificado, os perfis radiais de temperatura medidos apresentaram fortes assimetrias em relação ao eixo do tubo, com a parte superior significativamente mais quente que a parte inferior. Esta assimetria foi atribuída à presença de escoamentos secundários no plano da seção transversal do tubo induzidos por convecção natural. Os perfis radiais de velocidade axial também se apresentaram assimétricos, porém em menor grau do que os de temperatura. Os desvios em relação aos perfis parabólicos característicos do escoamento laminar desenvolvido não eram apreciáveis. No 
entanto, foi possível verificar o efeito de retardamento produzido nos perfis de velocidade pelo fluido mais frio e, portanto com maior viscosidade, junto à geratriz inferior do tubo. Este retardamento estava associado a uma aceleração do perfil na região central do tubo.

Para outras faixas de vazão que não a intermediária, a assimetria nos perfis de temperatura medidos não foi tão acentuada, o que, junto com a menor variação axial da temperatura do fluido, justifica a dependência linear verificada da queda de pressão com a vazão, tal como nos escoamentos desenvolvidos.

Os resultados das simulações tridimensionais parabólicas desenvolvidos por outros pesquisadores de nosso grupo de pesquisa foram analisados e comparados com as medições realizadas. Boa concordância foi obtida para a dependência da queda de pressão com a vazão, para toda a faixa de vazão investigada. Perfis radiais do componente axial da velocidade medidos em diferentes posições axiais ao longo do tubo também apresentaram boa concordância com as previsões numéricas. No entanto, os perfis de temperatura medidos apresentaram maiores assimetrias que aqueles previstos numericamente. Atribuí-se esta diferença, à falta de informações precisas sobre os campos de velocidade e temperatura na entrada do duto, que são necessários para serem utilizados como condições de contorno para as simulações. As simulações numéricas confirmaram a presença das correntes de convecção natural induzindo escoamentos secundários responsáveis pela assimetria nos perfis de temperatura e velocidade medidos.

Os resultados medidos para a queda de pressão como função da vazão foram também comparados com modelo simplificado unidimensional desenvolvido como parte do projeto de pesquisa do qual o presente trabalho fez parte. Boa concordância foi observada para toda a faixa de vazão investigada. $A$ boa concordância dos resultados para queda de pressão com um modelo unidimensional que considera apenas variações axiais da temperatura ao longo do escoamento é uma indicação que os efeitos globais na queda de pressão são controlados pela variação da viscosidade do fluido com a temperatura. Em outras palavras, a tensão cisalhante na parede responsável pela queda de pressão no escoamento, é mais afetada pela variação da viscosidade com a temperatura do que pela alteração no gradiente da velocidade junto à parede decorrente da distorção nos perfis de velocidade induzidos pelos escoamentos secundários decorrentes da convecção natural.

Como mencionado no início desta conclusão, o problema estudado depende de um grande número de parâmetros adimensionais, dentre as quais 
apenas a dependência com o número de Reynolds foi estudada. Para a continuação deste estudo sugere-se a investigação da influência de outros parâmetros, como número de Grashof. Em particular, seria interessante verificar o comportamento de outros fluidos que apresentem diferentes relações de dependência da viscosidade com a temperatura. Também, a medição de perfis de temperatura e velocidade em mais planos forneceria informações mais completas sobre a assimetria verificada nestes perfis. A estratégia de comparação com soluções numéricas tridimensionais deve ser mantida, pois fornece informações relevantes que auxiliam no entendimento dos fenômenos físicos envolvidos. Para isso, no entanto, é necessário que as condições de entrada usadas nas simulações sejam obtidas dos experimentos com melhor exatidão. Ainda como sugestão para trabalhos futuros, pode-se mencionar o estudo do comportamento transiente durante o início do escoamento, a partir de uma condição onde o fluido encontra-se parado e frio. 


\section{7 \\ Referências Bibliográficas}

[1] Ockendon, H., Ockendon, J. R., Vairiable-viscosity flows in heated and cooled channels, Journal Fluid Mechanics, 1977, vol. 83, part 1, pp 177 - 190.

[2] Richardson, S. M., Injection moulding of thermoplastics: Freezing of variableviscosity fluids. III. Fully-developed flows, 1986, Rheol. Acta 25, pp 372 - 379.

[3] Whitehead, J. A., Helfrich, K. R., Instability os flow with temperaturedependent viscosity: A model of magma dynamics, Journal of Geophysical Research, 1991, vol. 96, No. B3, pp 4145 - 4155.

[4] Helfrich, K. R., Thermo-viscous fingering of flow in a thin gap: A model of magma flow in dikes and fissures, Journal Fluid Mechanics, 1995, vol. 305, pp $219-238$.

[5] Wylie, J. J., Lister, J. R., The effects of temperature-dependent viscosity on flow in a cooled channel with application to basaltic fissure eruptions, Journal Fluid Mechanics, 1995, vol. 305, pp $239-261$.

[6] Giessler, C.; Lange, U. and Thess, A., Nonlinear laminar pipe flow of fluids with strongly temperature-dependent material properties, 2007, Physics of Fluids 19, 043601.

[7] Quinones, D. M., Carvalho, M. S., Pipeline flow of heavy oil with temperaturedependent viscosity, 13th Brazilian Congress of Thermal Sciences and Engineering, Uberlândia, MG, 2010.

[8] Incropera F.P., DeWitt D. P., Bergman T. L., Lavine A. S., Fundamentos da Transferência de Calor e de Massa. Sexta Edição Ed. LTC. 
[9] Glycerine Producers Association, Physical Properties of Glycerine and its solutions. Ed. Glycerine Producers Association, 1963.

[10] Tropea, C., Damaschke N., Borys, M.. Albrecht, H. E., Laser Doppler and Phase Doppler Measurement Techniques, Ed. Springer.

[11] International association of plastics distribution, www.iapd.org. , 2012.

[12] Refractive Index Database, http://refractiveindex.info/, 2013.

[13] Kline, S. J., McClintock, F. A., Mechanical Engineering, vol 75, 1953, pg 3.

[14] Rohsenow, W. M., Hartnett, J. P., Cho, Y. I., Handbook of Heat Transfer, Third Edition, Ed. McGraw-Hill.

[15] Nieckele, A. O., Azevedo L. F. A., Carvalho, M. S., Análise teórica e experimental do escoamento laminar em dutos de óleos pesados com viscosidade dependente da temperature, $3^{\circ}$ Relatório de Acompanhamento de Projeto, Departamento de Engenharia Mecânica, PUC-Rio, Fevereiro de 2012.

[16] Patankar, S. V., Spalding, D. B., A Calculation Procedure for Heat, Mass and Momentum Transfer in Three-Dimensional Parabolic Flows, Int. J. Heat Mass Transfer, 1972, vol 15, pp. 1787-1806.

[17] Almeida, V.F., "Programa Numérico para Solução das Equações de Transporte Tridimensionais Parabólicas", Tese de Mestrado, 1990, Dpto. De Engenharia Mecânica da Pontifícia Universidade Católica do Rio de Janeiro, RJ. 


\section{Apêndice}

\section{A \\ Estimativa das Incertezas nas Medições}

Esta presente seção do apêndice destina-se a apresentar a metodologia utilizada para estimativa dos níveis de incerteza associados às medições do presente trabalho. Nesta avaliação, foi adotada a metodologia comumente utilizada para o estudo de propagação de incertezas, referência [13], sendo brevemente descrita a seguir.

Considerando um resultado, $R$, de um experimento que dependa da medição de $N$ grandezas independentes, $x_{i}$, cada uma delas com incerteza experimental, $\delta x_{i}$, apresentando mesma distribuição de probabilidade, a incerteza no resultado, $\delta R$, pode ser avaliada como,

$$
\delta R=\left\{\left(\frac{\partial R}{\partial x_{1}} \cdot \delta x_{1}\right)^{2}+\left(\frac{\partial R}{\partial x_{2}} \cdot \delta x_{2}\right)^{2}+\ldots+\left(\frac{\partial R}{\partial x_{N}} \cdot \delta x_{N}\right)^{2}\right\}^{1 / 2}
$$

onde as derivadas parciais representam a sensibilidade do resultado a cada variável medida. A partir da equação básica acima, a seguir serão apresentados os cálculos relativos à incerteza dos valores medidos no experimento.

A primeira estimativa de incerteza será feita para vazão do fluido de trabalho, solução de glicerina.

A vazão da solução de glicerina em $\mathrm{cm}^{3} / s$, é definida segundo a equação abaixo.

$$
Q=\frac{\dot{m}}{\rho}
$$

onde, $\dot{m}$ é a vazão mássica em $\mathrm{g} / \mathrm{s}$, e $\rho$ é massa específica em $\mathrm{g} / \mathrm{cm}^{3}$ da solução de glicerina. 
Segundo a equação A.1, a incerteza na medição da vazão da solução em $\mathrm{ml} / \mathrm{s}$ pode ser estimada por,

$$
\delta Q^{2}=\left(\frac{\partial Q}{\partial \dot{m}} \cdot \delta \dot{m}\right)^{2}+\left(\frac{\partial Q}{\partial \rho} \cdot \delta \rho\right)^{2}
$$

As derivadas parciais podem ser obtidas derivando-se a equação A.2. Logo, a incerteza relativa na medição da vazão da solução de glicerina em $\mathrm{m} / \mathrm{s}$ pode ser estimada por,

$$
\left(\frac{\delta Q}{Q}\right)^{2}=\left(\frac{\delta \dot{m}}{\dot{m}}\right)^{2}+\left(\frac{\delta \rho}{\rho}\right)^{2}
$$

A vazão mássica da solução, $\dot{m}$, é dada pela equação abaixo:

$$
\dot{m}=\frac{\left(m_{f}-m_{0}\right)}{\Delta t}
$$

onde, $m_{f}$ é a massa em gramas do recipiente cheio, $m_{0}$ é a massa do recipiente vazio e $\Delta t$ é o intervalo de tempo de coleta.

Utilizando-se a equação A.1, a incerteza relativa na medição da vazão mássica em g/s pode então ser calculada como,

$$
\left(\frac{\delta \dot{m}}{\dot{m}}\right)^{2}=\left(\frac{\delta m_{f}}{m_{f}-m_{0}}\right)^{2}+\left(\frac{\delta m_{0}}{m_{f}-m_{0}}\right)^{2}+\left(\frac{\delta \Delta t}{\Delta t}\right)^{2}
$$

Finalmente, combinando as equações, a incerteza relativa na vazão volumétrica da solução de glicerina obtida pela técnica proposta pode ser estimada por:

$$
\left(\frac{\delta Q}{Q}\right)^{2}=\left(\frac{\delta m_{f}}{m_{f}-m_{0}}\right)^{2}+\left(\frac{\delta m_{0}}{m_{f}-m_{0}}\right)^{2}+\left(\frac{\delta \Delta t}{\Delta t}\right)^{2}+\left(\frac{\delta \rho}{\rho}\right)^{2}
$$


No Capítulo 5, a expressão mostrada abaixo, que relaciona a queda de pressão teórica com a vazão para o escoamento desenvolvido em um duto, foi utilizada como forma de validação dos experimentos.

$$
\Delta P_{\text {teórico }}=\frac{128 Q \mu L}{\pi D^{4}}
$$

A incerteza na queda de pressão obtida por esta expressão pode ser estimada como,

$$
\left(\frac{\delta \Delta P_{\text {teórico }}}{\Delta P_{\text {té́rico }}}\right)^{2}=\left(\frac{\delta \mu}{\mu}\right)^{2}+\left(\frac{\delta Q}{Q}\right)^{2}+\left(\frac{\delta L}{L}\right)^{2}+16\left(\frac{\delta D}{D}\right)^{2}
$$

A incerteza na queda de pressão adimensional e número de Reynolds utilizados na apresentação dos resultados pode ser obtida por,

$$
\begin{aligned}
& \left(\frac{\delta \Delta P^{*}}{\Delta P^{*}}\right)^{2}=\left(\frac{\delta \rho}{\rho}\right)^{2}+4\left(\frac{\delta Q}{Q}\right)^{2}+16\left(\frac{\delta D}{D}\right)^{2} \\
& \left(\frac{\delta \operatorname{Re}}{\operatorname{Re}}\right)^{2}=\left(\frac{\delta \rho}{\rho}\right)^{2}+\left(\frac{\delta Q}{Q}\right)^{2}+5\left(\frac{\delta D}{D}\right)^{2}+\left(\frac{\delta \mu}{\mu}\right)^{2}
\end{aligned}
$$

Os valores das incertezas em cada variável foram determinados baseados nas informações dos instrumentos utilizados. A Tabela A.1 apresenta os valores utilizados na estimativa na incerteza na medida da vazão da solução de glicerina.

Tabela A.1 - Valores das incertezas em cada variável medida utilizados na estimativa das incertezas nas medições do experimento.

\begin{tabular}{cc}
\hline Variável & Incerteza \\
$\delta m_{f}$ & $1 \mathrm{mg}$ \\
$\delta m_{0}$ & $1 \mathrm{mg}$ \\
$\delta t$ & $0,5 \mathrm{~s}$ \\
$\delta \rho$ & $0,01 \mathrm{~g} / \mathrm{cm}^{3}$ \\
$\delta \mu$ & $0,2 \mathrm{mPa} . \mathrm{s}$ \\
\hline
\end{tabular}


Apêndice A

Estimativa das Incertezas nas Medições

\begin{tabular}{cc}
\hline$\delta P$ & $25 P a$ \\
$\delta D$ & $5 e 10^{-5}$ \\
$\delta L$ & $5 e 10^{-4}$ \\
\hline
\end{tabular}

A Tabela A.2 apresenta os valores de incerteza (\%) calculados a partir das equações A.7, A.10 e A.11 em cada vazão medida no experimento.

Tabela A.2 - Valores de incerteza na vazão, pressão, número de Reynolds e pressão adimensional em cada vazão medida no experimento associados a um nível de probabilidade de abrangência de $95,4 \%$.

\begin{tabular}{|c|c|c|c|c|}
\hline \multirow{11}{*}{ 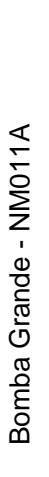 } & $\delta Q / Q$ & $\delta \Delta P_{\exp } / \Delta P_{\exp }$ & $\delta \mathrm{Re} / \mathrm{Re}$ & $\delta \Delta P^{*} / \Delta P^{*}$ \\
\hline & \pm 4.37 & \pm 0.35 & \pm 4.56 & \pm 8.95 \\
\hline & \pm 3.92 & \pm 0.38 & \pm 4.14 & \pm 8.08 \\
\hline & \pm 3.41 & \pm 0.42 & \pm 3.66 & \pm 7.09 \\
\hline & \pm 2.99 & \pm 0.46 & \pm 3.26 & \pm 6.27 \\
\hline & \pm 2.72 & \pm 0.50 & \pm 3.02 & \pm 5.76 \\
\hline & \pm 2.39 & \pm 0.55 & \pm 2.73 & \pm 5.15 \\
\hline & \pm 2.12 & \pm 0.61 & \pm 2.50 & \pm 4.65 \\
\hline & \pm 1.86 & \pm 0.68 & \pm 2.28 & \pm 4.18 \\
\hline & \pm 1.70 & \pm 0.74 & \pm 2.15 & \pm 3.90 \\
\hline & \pm 1.49 & \pm 0.79 & \pm 1.99 & \pm 3.54 \\
\hline \multirow{18}{*}{ 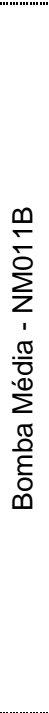 } & \pm 1.64 & \pm 0.76 & \pm 2.10 & \pm 3.79 \\
\hline & \pm 1.57 & \pm 0.78 & \pm 2.05 & \pm 3.68 \\
\hline & \pm 1.47 & \pm 0.81 & \pm 1.97 & \pm 3.50 \\
\hline & \pm 1.43 & \pm 0.83 & \pm 1.94 & \pm 3.44 \\
\hline & \pm 1.36 & \pm 0.85 & \pm 1.89 & \pm 3.32 \\
\hline & \pm 1.27 & \pm 0.87 & \pm 1.83 & \pm 3.18 \\
\hline & \pm 1.19 & \pm 0.89 & \pm 1.77 & \pm 3.05 \\
\hline & \pm 1.12 & \pm 0.91 & \pm 1.73 & \pm 2.95 \\
\hline & \pm 1.12 & \pm 0.93 & \pm 1.73 & \pm 2.95 \\
\hline & \pm 1.04 & \pm 0.94 & \pm 1.68 & \pm 2.83 \\
\hline & \pm 1.03 & \pm 0.96 & \pm 1.67 & \pm 2.81 \\
\hline & \pm 0.98 & \pm 0.96 & \pm 1.64 & \pm 2.74 \\
\hline & \pm 0.94 & \pm 0.94 & \pm 1.61 & \pm 2.68 \\
\hline & \pm 0.89 & \pm 0.91 & \pm 1.59 & \pm 2.61 \\
\hline & \pm 0.86 & \pm 0.84 & \pm 1.57 & \pm 2.58 \\
\hline & \pm 0.84 & \pm 0.75 & \pm 1.56 & \pm 2.55 \\
\hline & \pm 0.83 & \pm 0.70 & \pm 1.56 & \pm 2.54 \\
\hline & \pm 0.83 & \pm 0.68 & \pm 1.55 & \pm 2.53 \\
\hline \multirow{10}{*}{ 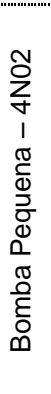 } & \pm 0.84 & \pm 0.75 & \pm 1.56 & \pm 2.55 \\
\hline & \pm 0.84 & \pm 0.74 & \pm 1.56 & \pm 2.55 \\
\hline & \pm 0.84 & \pm 0.75 & \pm 1.56 & \pm 2.54 \\
\hline & \pm 0.83 & \pm 0.72 & \pm 1.56 & \pm 2.54 \\
\hline & \pm 0.83 & \pm 0.70 & \pm 1.56 & \pm 2.54 \\
\hline & \pm 0.83 & \pm 0.68 & \pm 1.55 & \pm 2.53 \\
\hline & \pm 0.83 & \pm 0.67 & \pm 1.55 & \pm 2.53 \\
\hline & \pm 0.83 & \pm 0.66 & \pm 1.55 & \pm 2.53 \\
\hline & \pm 0.82 & \pm 0.69 & \pm 1.55 & \pm 2.52 \\
\hline & \pm 0.82 & \pm 0.75 & \pm 1.55 & \pm 2.52 \\
\hline
\end{tabular}

Para validação da seção de testes, considerando os parâmetros apresentados na seção 5.1, a incerteza na queda de pressão teórica calculada a 
Apêndice A

Estimativa das Incertezas nas Medições

partir da equação $A .9$ foi de $\pm 4,2 \%$. A incerteza na queda de pressão experimental foi aproximadamente $\pm 0,4 \%$. 
B

\section{Desenhos e Dimensões da Seção Experimental}

Esta presente seção do apêndice destina-se a apresentar os desenhos com as principais dimensões em $\mathrm{mm}$ da seção experimental.

B.1.

Vista Geral da Seção

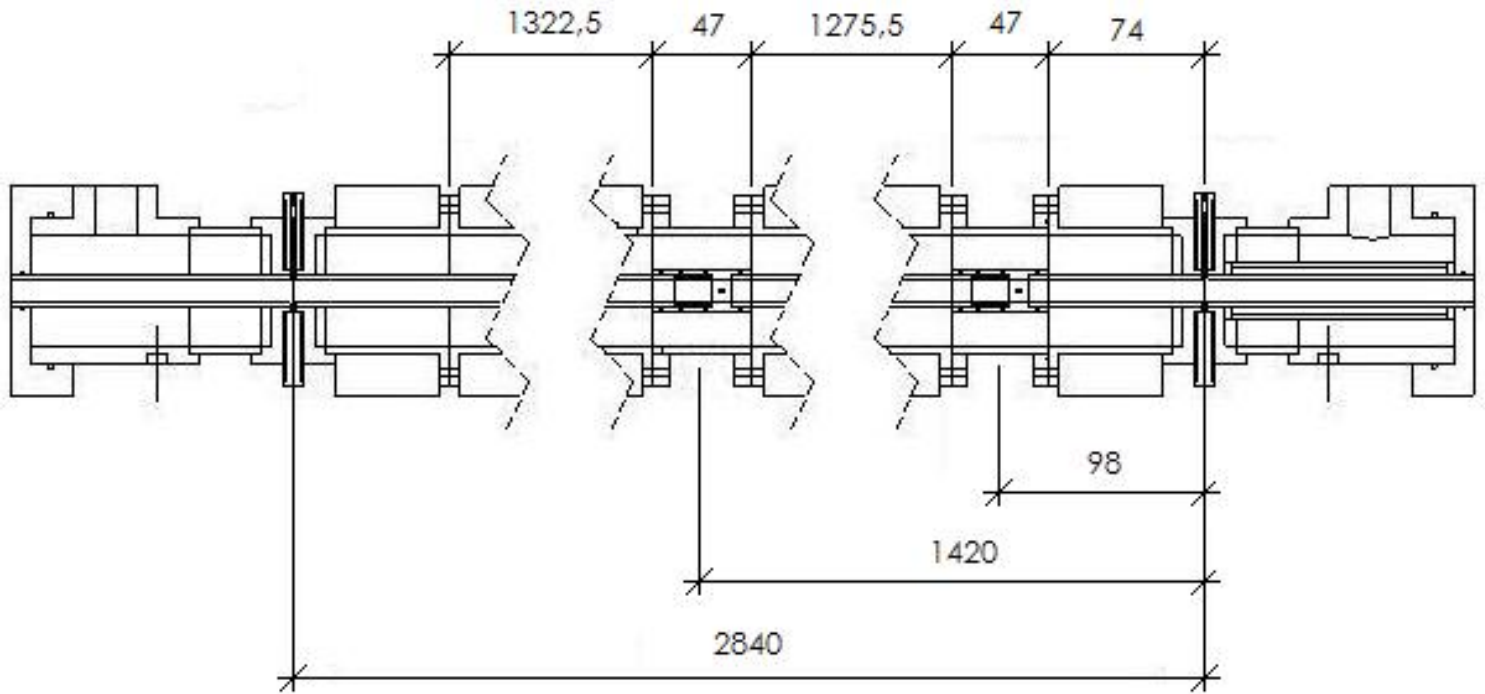

Figura B.1 - Vista geral em corte da seção experimental com as principais dimensões longitudinais. 


\section{B.2.}

\section{Janela de Visualização}

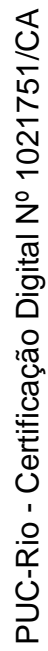
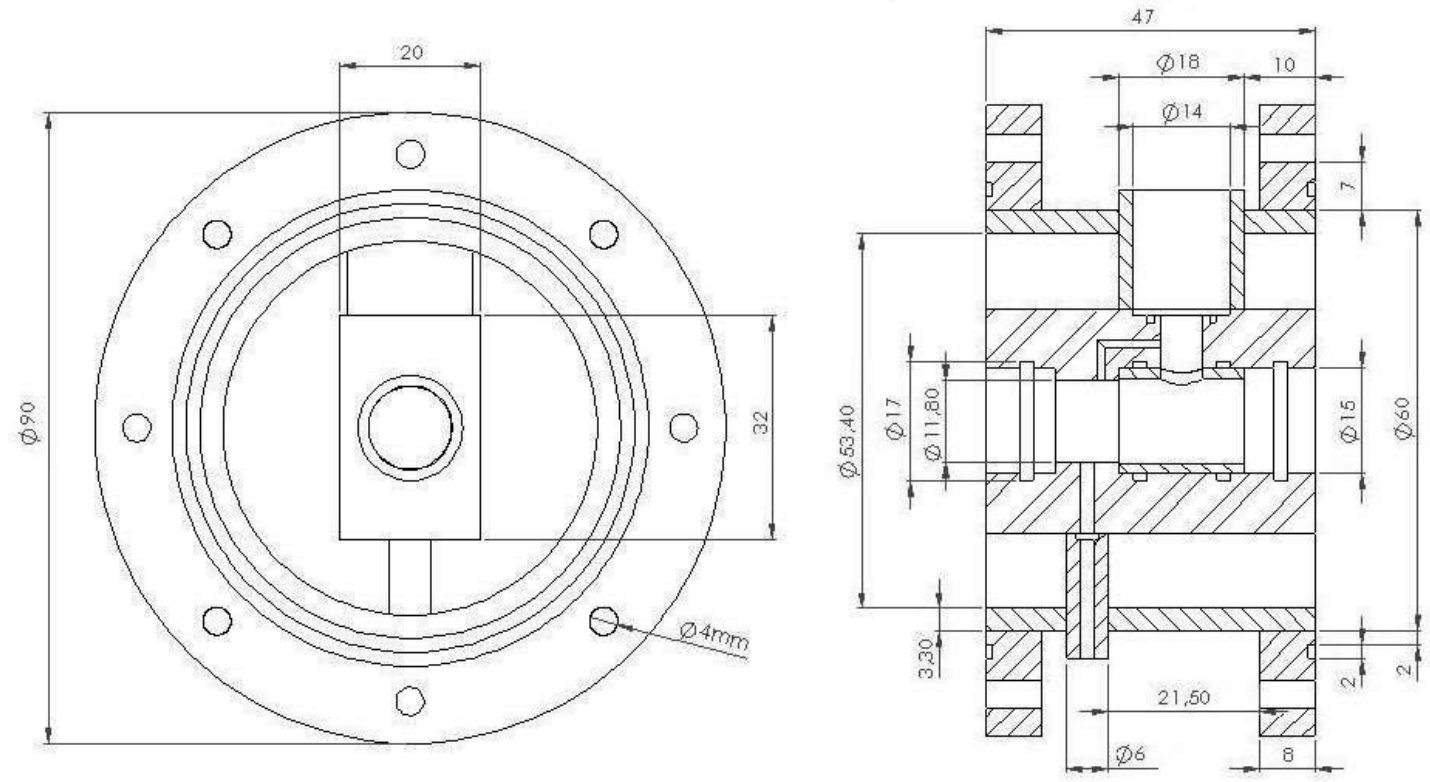

(a)
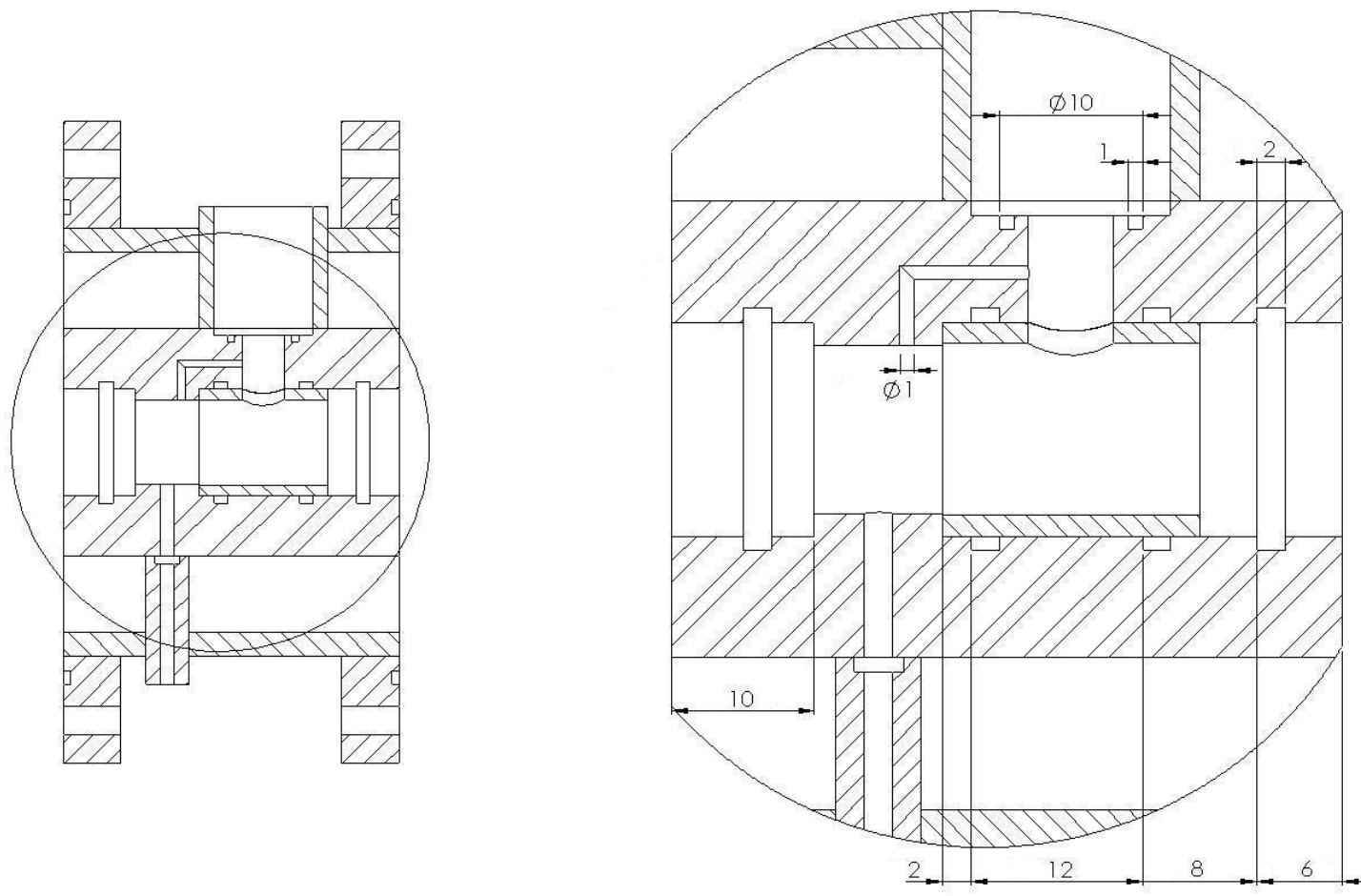

(b)

Figura B.2 - (a) Vistas lateral e em corte frontal da Janela de Visualização. (b) Vista detalhada do interior da Janela de Visualização. 
Apêndice $B$

\section{B.3.}

\section{Entrada da Seção Experimental}

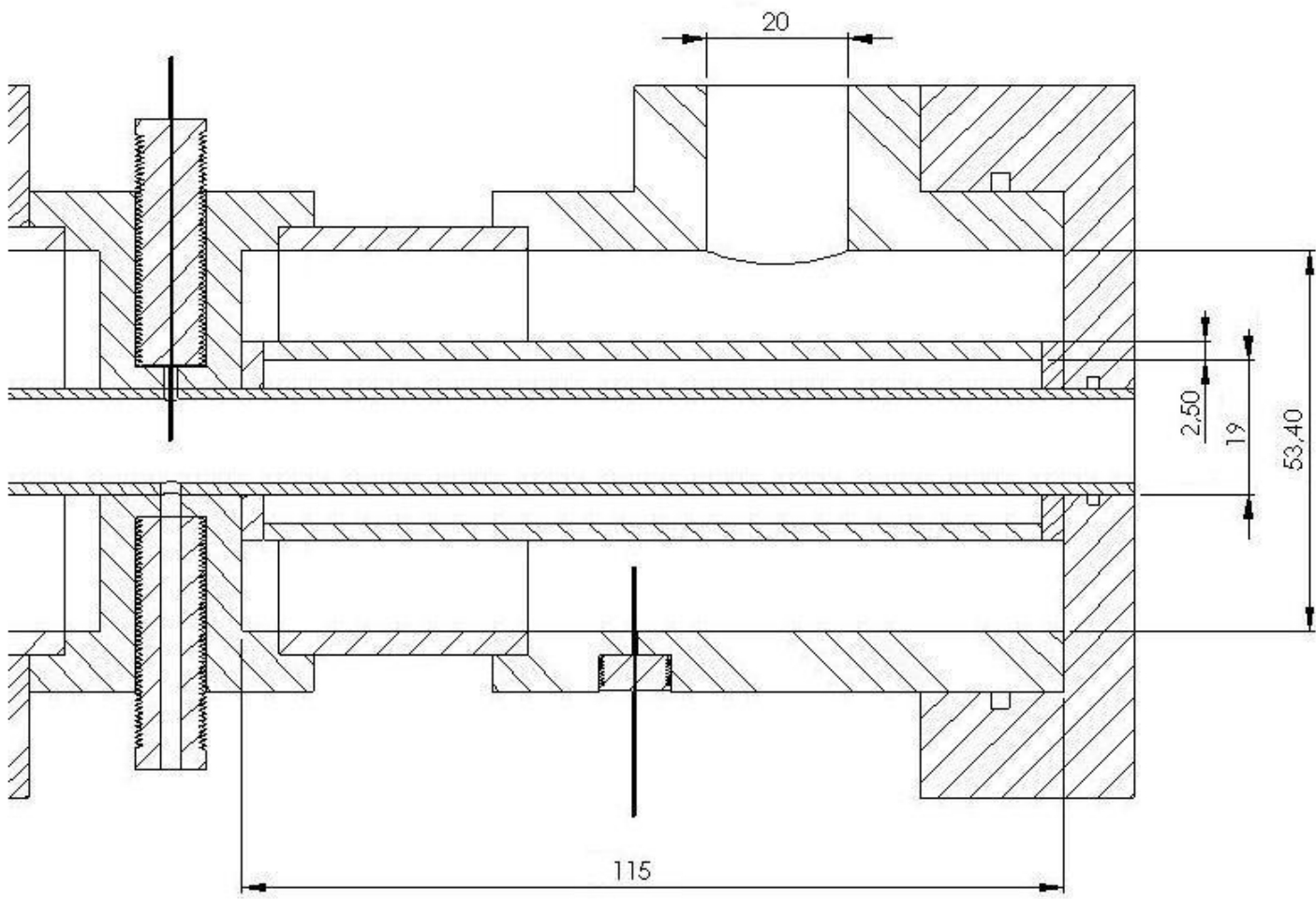

Figura B.3 - Vista em corte da região de entrada da Seção. 
Apêndice B

Desenhos e Dimensões da Seção Experimental

B.4.

Flange com Tomadas de Pressão e Temperatura
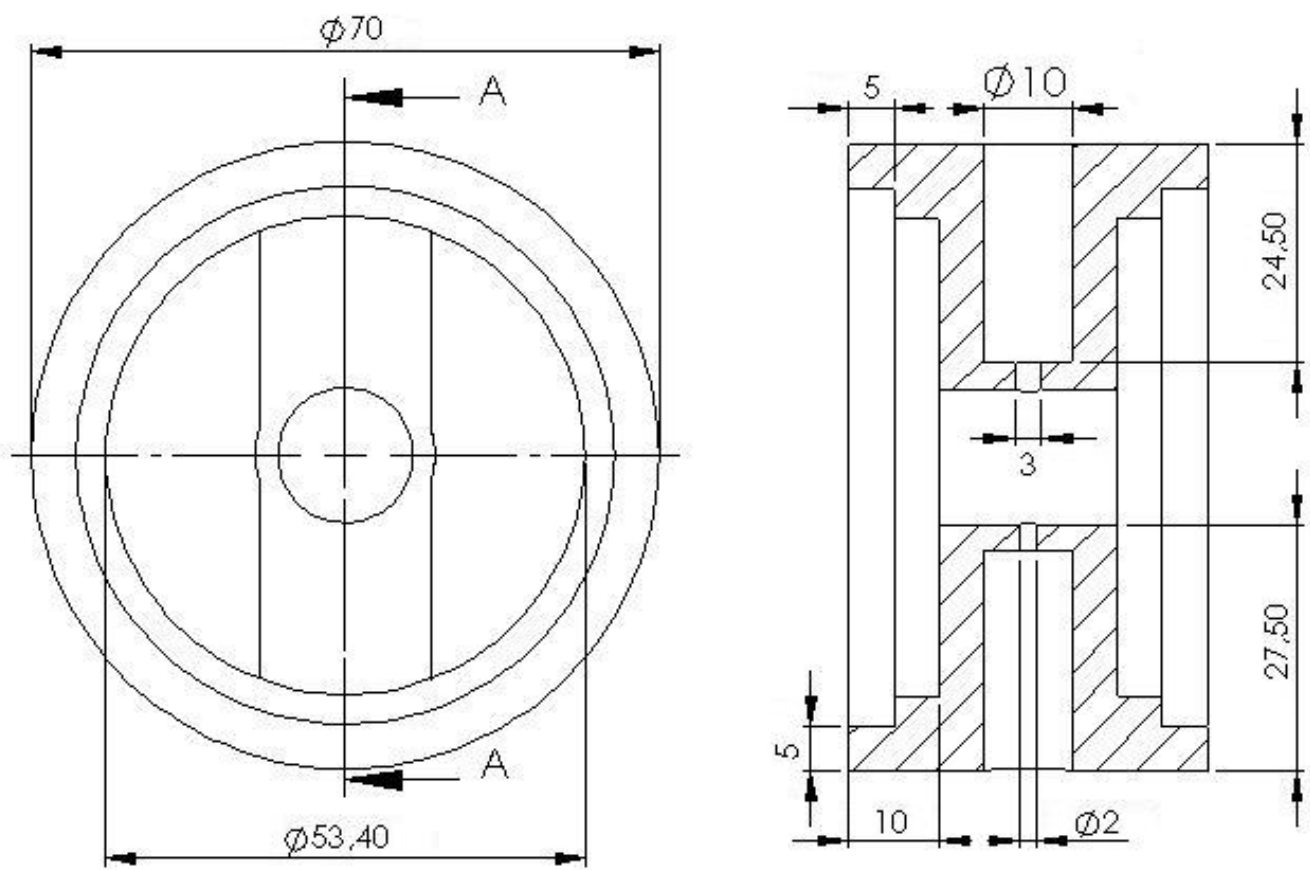

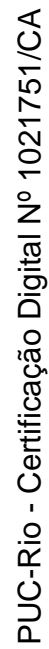

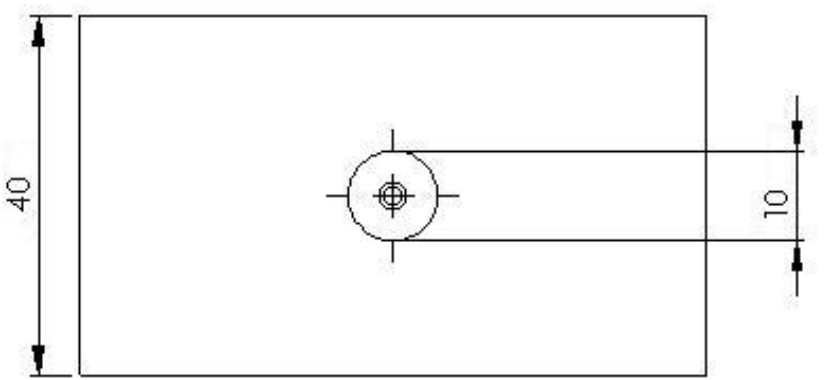

Figura B.4 - Flange sedes para as tomadas de pressão e temperatura. Duas unidades semelhantes foram instaladas na entrada e na saída da seção de testes. 